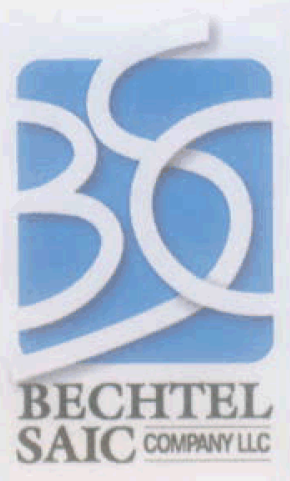

\section{Impacts of Solubility and Other Geochemical Processes on Radionuclide Retardation in the Natural System}


Preparation:

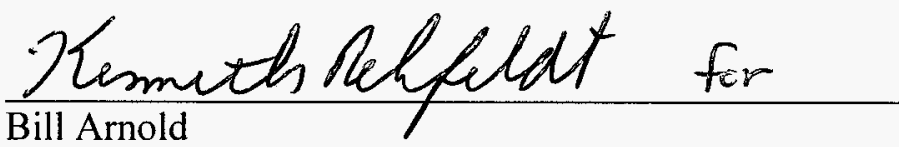

Lead, Saturated Zone Flow \& Transport Team

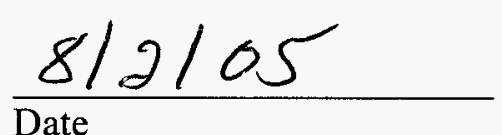

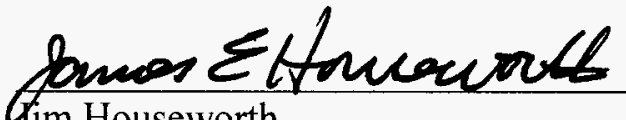

Gim Houseworth

Lead, Unsaturated Zone Transport

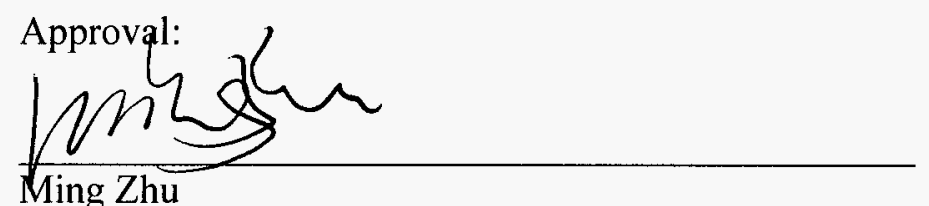

Manager, Natural Systems

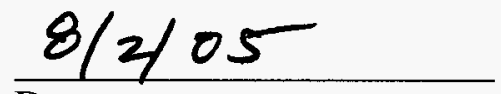

Date

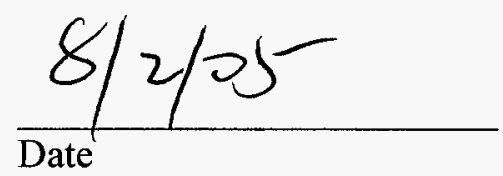




\section{ACKNOWLEDGEMENTS}

This report was produced as a collaborative effort with contributions by several authors. Arend Meijer is the source for Sections 2.1 and 2.3. Bill Arnold contributed to Sections 1, 2.1, 2.4, 2.5, and 2.6. Elena Kalinina is the source for Section 2.2. Stephanie Kuzio is the source for Section 3. Bruce Robinson is the primary source for Section 2.5. Sharad Kelkar is the primary source for Section 2.6. Terry Miller contributed to Sections 2.5 and 2.6. Carlos Jove-Colon contributed to Section 2.2. Jim Houseworth contributed to Section 1. Scott James performed checking of the report. 
INTENTIONALLY LEFT BLANK 


\section{CONTENTS}

\section{Page}

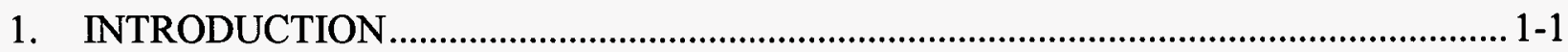

2. RADIONUCLIDE RETARDATION IN THE SATURATED ZONE ................................ 2-1

$2.1 \quad$ REDOX CONDITIONS IN THE SATURATED ZONE ......................................... 2-1

2.1.1 Oxidizing Groundwaters ........................................................................ 2-2

2.1.2 Reducing Groundwaters .......................................................................... 2-3

2.1.3 Summary of Eh Distribution ....................................................................... 2-6

2.1.4 Conceptualization of Eh Distribution and Groundwater Flow...................... 2-7

2.2 SOLUBILITY AS A FUNCTION OF REDOX CONDITIONS ........................... 2-8

2.2.1 Data from Yucca Mountain .................................................................. 2-8

2.2.2 Chemical Equilibrium Analyses.................................................................. 2-9

2.2.4 Summary of Expected Technetium Solubility under Reducing

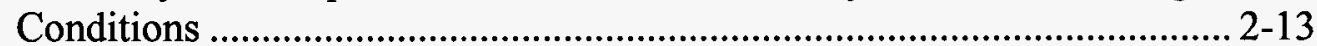

2.3 SORPTION AS A FUNCTION OF REDOX CONDITIONS ............................ 2-13

2.3.1 Sorption Coefficients for Neptunium and Technetium under Oxidizing Conditions ................................................................................... 2-13

2.3.2 Sorption Coefficients under Reducing Conditions.................................... 2-13

2.4 CONCEPTUAL MODEL OF REDOX CONDITIONS, SOLUBILITY, AND SORPTION ........................................................................................ 2-16

2.5 ANALYSIS OF SENSITIVITY TO SOLUBILITY LIMITS …........................... 2-17

2.5.1 General Sensitivity to Solubility Limits in the Saturated Zone.................. 2-17

2.5.2 Reactive Transport Model Setup .......................................................... 2-20

2.5.3 Transport Simulation Results with Solubility Limits.................................. 2-22

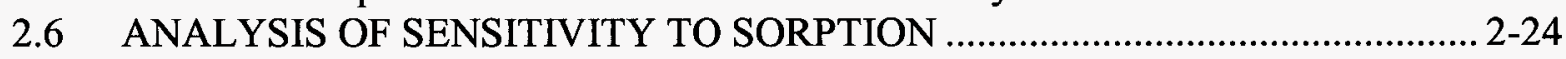

2.6.1 Effective Sorption Coefficient.................................................................... 2-25

2.6.2 Saturated Zone Site-Scale Transport Model Setup ................................... 2-27

2.6.3 Transport Simulation Results with Sorption ............................................. 2-28

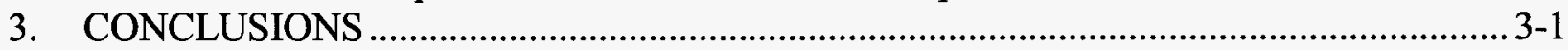

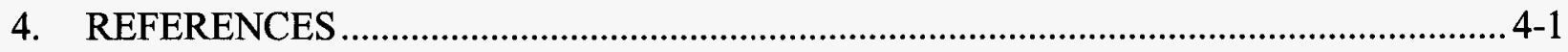

4.1 DOCUMENTS CITED .......................................................................................

4.3 CODES, STANDARDS, REGULATIONS, AND PROCEDURES......................... 4-5

4.4 DATA, LISTED BY DATA TRACKING NUMBER …………............................. 4-5 


\section{INTENTIONALLY LEFT BLANK}




\section{FIGURES}

2.1-1. Eh Versus $\mathrm{pH}$ for Oxidizing (i.e., DO>1.0 mg/L) Groundwaters from the Yucca Mountain Area

2.1-2. Map Showing Locations of Wells with Oxidizing and Reducing Groundwaters............F-2

2.1-3. Measured Dissolved Oxygen Versus Measured Total Iron in Oxidizing (DO $>1.0$ $\mathrm{mg} / \mathrm{L})$ and Reducing (DO $<1.0 \mathrm{mg} / \mathrm{L})$ Groundwaters.

2.1-4. Measured pH Values Versus Measured and Calculated Eh Values

2.1-5. Measured Eh Values (Platinum Electrode) Versus Eh Values Calculated From Total Iron Concentrations

2.2-1. Technetium Solubility in J-13 and p\#1 Water from EQ3 and EQ6 Calculations...........F-4

2.2-2. Major Aqueous Technetium Species and Total Dissolved Technetium as a Function of Eh.

2.3-1. Neptunium Sorption Coefficients versus Eh on Sediments and Groundwaters from the Gorleben Site in Germany.

2.3-2. Surface Complexation Modeling Results for Neptunium Sorption on Quartz in Dilute Groundwater as a Function of Eh

2.3-3. Technetium Sorption Coefficients versus Eh on Sediments and Groundwaters from the Gorleben Site in Germany....

2.5-1. ${ }^{99} \mathrm{Tc}$ Release Rate Required to Exceed the Solubility Limit as a Function of Volumetric Groundwater Flow Rate for a Range of Solubility Limits

2.5-2. ${ }^{99} \mathrm{Tc}$ Breakthrough Curves at the Compliance Boundary and at the Entrance of the Reducing Zone for the One-Dimensional Streamtube Model

2.5-3. ${ }^{99} \mathrm{Tc}$ Breakthrough Curves at the Compliance Boundary for the One-Dimensional Streamtube Model for Different Durations of the Input Concentration

2.5-4. ${ }^{99}$ Tc Concentrations at the Entrance to the Reducing Zone for the OneDimensional Streamtube Model for Different Durations of the Input Concentration.

2.5-5. ${ }^{99} \mathrm{Tc}$ Breakthrough Curves at the Compliance Boundary and at the Entrance of the Reducing Zone for the One-Dimensional Streamtube Model for Different Values of the Sorption Coefficient $\left(K_{d}\right)$ in the Reducing Zone

2.5-6. ${ }^{99}$ Tc Breakthrough Curves at the Compliance Boundary and at the Entrance of the Reducing Zone for the One-Dimensional Streamtube Model for Different Values Lengths of the Pathway Within the Reducing Zone....

2.6-1. Schematic Diagram of One-Dimensional Flow Path with Two Zones of Contrasting Values in Sorption Coefficient.

2.6-2. Effective Sorption Coefficient as a Function of Fraction of the Flow Path with Reducing Conditions for Technetium

2.6-3. Effective Sorption Coefficient as a Function of Fraction of the Flow Path with Reducing Conditions for Neptunium in Volcanic Units

2.6-4. Effective Sorption Coefficient as a Function of Fraction of the Flow Path with Reducing Conditions for Neptunium in Alluvium.

2.6-5. Footprint of the Redox Curtain and Footprint of the Repository at Yucca Mountain. 


\section{FIGURES (Continued)}

2.6-6. Breakthrough Curves for Technetium with Wide Redox Curtain for $K_{d}=0$ (base case), $K_{d}=50 \mathrm{~mL} / \mathrm{g}$, and $K_{d}=1000 \mathrm{~mL} / \mathrm{g}$.

2.6-7. Comparison of Breakthrough Curves for Different Matrix Diffusion Coefficients for Technetium with Wide Redox Curtain and $K_{d}=1000 \mathrm{~mL} / \mathrm{g}$

2.6-8. Breakthrough Curves for Technetium with Narrow Redox Curtain and $K_{d}=0$ (base case), $K_{d}=50$, and $K_{d}=1000 \mathrm{~mL} / \mathrm{g}$.

2.6-9. Breakthrough Curves for Neptunium with Wide Redox Curtain and $K_{d}=1.3$ (base case), $K_{d}=200$, and $K_{d}=1000 \mathrm{~mL} / \mathrm{g}$.

2.6-10. Breakthrough Curves for Neptunium with Narrow Redox Curtain and $K_{d}=1.3$ (base case), $K_{d}=200$, and $K_{d}=1000 \mathrm{~mL} / \mathrm{g}$. 


\section{TABLES}

\section{Page}

2.2-1. Ground Water Composition in Wells $\mathrm{J}-13$ and $\mathrm{p} \# 1$.........................................................T-1

2.2-2. Summary of Technetium Solubility Calculations.............................................................T-3

2.5-1. Peak Simulated Releases from the UZ ...........................................................................T-3

2.6-1. Coordinates of the Footprint of the Redox Curtain ............................................................T-4

2.6-2. Simulations for Sensitivity Analysis and 50\% Breakthrough Times for technetium and neptunium 
INTENTIONALLY LEFT BLANK 


\section{INTRODUCTION}

This report documents results and findings of a study of solubility/co-precipitation effects and enhanced sorption due to variations in redox conditions on radionuclide transport in the natural system (BSC 2005 [DIRS 173951]; BSC 2005 [DIRS 173859]) conducted in response to DOE Contracting Officer Authorization Letter 05-001, Item d (Mitchell 2005 [DIRS 173265]). The purpose of this study is to assess the potential impacts of precipitation and enhanced sorption due to variations in redox conditions on radionuclide transport in the saturated zone (SZ) at Yucca Mountain. The information presented in this report is intended to aid in assessing the conservatism in the SZ transport model for supporting the total system performance assessment (TSPA) calculations. A similar study was performed for the impact of solubility/precipitation on radionuclide transport in the unsaturated zone (UZ). However, because the unsaturated zone is under predominately oxidizing conditions and that the radionuclides released from the engineered barrier system are not excepted to precipitate in the UZ for the reasons described below, it was concluded that the effect on unsaturated zone transport is not significant to warrant a detailed study. Solubility limiting conditions for neptunium in the UZ are expected to be similar to the conditions for neptunium solubility in the waste emplacement drift invert, where $\mathrm{Np}_{2} \mathrm{O}_{5}$ is recommended as the controlling solid phase (BSC 2005 [DIRS 174566], Section 6.6.1). Solubility limits for neptunium inside the waste package, however, are expected to be controlled by $\mathrm{NpO}_{2}$ (BSC 2005 [DIRS 174566], Section 6.6.1). The solubility limits for $\mathrm{Np}_{2} \mathrm{O}_{5}$ are generally much higher than for $\mathrm{NpO}_{2}$ (BSC 2005 [DIRS 174566], Tables 6.6-4 and 6.6-7). Therefore, the low concentrations of neptunium releases from waste packages are unlikely to be affected by solubility limits in the unsaturated zone.

The $\mathrm{SZ}$ is part of the Lower Natural Barrier to the migration of radionuclides and to the exposure of the potential receptor population in two ways. First, delay in the release of radionuclides to the accessible environment during transport in the SZ allows radioactive decay to diminish the mass of radionuclides that is ultimately released. In addition, dilution of radionuclide concentrations in groundwater used by the potential receptor population occurs during transport in the saturated zone and in the process of producing groundwater from wells.

Delay in the release of radionuclides is affected by factors such as the rates of groundwater flow, the flow pathways, matrix diffusion in fractured volcanic rocks, sorption, and colloid cotransport and filtration. While current saturated zone transport simulations incorporate these processes (BSC 2004 [DIRS 170036]; BSC 2005 [DIRS 174012]), they do not consider limits to the solubility of radionuclides or the potential impacts of variability in certain geochemical conditions on solubility and sorption. If solubility limits were exceeded at locations along the flow path from the repository in the SZ, some radionuclide mass would be precipitated from the groundwater and immobilized as a solid phase. This process would delay the overall rate of release of radionuclides to the accessible environment. Similarly, geochemical conditions that enhance the sorption of radionuclides along the flow path in the saturated zone would lead to greater overall retardation of radionuclides and further delay their release.

Concentrations of radionuclides would also decrease during migration through the $\mathrm{SZ}$ because of dispersion and diffusion. This leads to the general conclusion that precipitation of radionuclides would not be expected to occur downstream in the SZ if solubility limits remain constant in the 
system. However, variations in water geochemistry could lead to decreased solubility of radionuclides along the SZ flow path. Solubility can be influenced by major ion chemistry of groundwater, but dramatic variations in major ion chemistry along the inferred flow path from Yucca Mountain to the boundary of the accessible environment do not exist (BSC 2004 [DIRS 170037]). Solubility limits of some radionuclides, however, can be strongly affected by variations in redox (shorthand for "reduction/oxidation") conditions in groundwater (Langmuir 1997 [DIRS 100051]), and significant variations in redox conditions have been observed in the saturated zone near Yucca Mountain (BSC 2004 [DIRS 170036]). Sorption coefficients for some radionuclides also exhibit sensitivity to redox conditions of groundwater, with significantly greater sorption under more reducing conditions (Langmuir 1997 [DIRS 100051]). Redox conditions and the impacts on radioelement speciation and solubility are important considerations for other geological disposal programs (e.g., Amme 2002 [DIRS 172848]). Consequently, this report focuses on variability in redox conditions in the saturated zone and the sensitivity of solubility and sorption to these conditions.

Two previous studies are directly relevant to these potential effects in the Yucca Mountain SZ. An assessment of the potential impacts of reducing conditions in the saturated zone at Yucca Mountain on ${ }^{99} \mathrm{Tc}$ transport and overall repository performance has been conducted by Pabalan et al. (2000 [DIRS 172603]). Their study considered the impacts of lower solubility and enhanced sorption assuming reducing conditions in the tuff and alluvial aquifers. Pabalan et al. (2000 [DIRS 172603]) concluded that simulated peak dose from ${ }^{99} \mathrm{Tc}$ at 50,000 years is reduced by three orders of magnitude when solubility limits are considered, and that enhanced sorption in the alluvium has an even greater impact on reducing simulated dose. Hu and Smith (2004 [DIRS 172847]) synthesized data on the distribution of ${ }^{99} \mathrm{Tc}$ and ${ }^{129} \mathrm{I}$ in groundwater from the Nevada Test Site to assess their migration from underground nuclear testing and concluded that ${ }^{99} \mathrm{Tc}$ did not necessarily migrate as a conservative species and that retardation of ${ }^{99} \mathrm{Tc}$ migration could be attributed to locally reducing conditions.

This report presents an overview of the conditions and processes stated above and preliminary sensitivity analyses of their impacts on SZ radionuclide transport. The assessments presented in this report were not performed under quality assurance procedures. Inputs to the analyses are taken from both qualified and unqualified sources, with the reliability of sources evaluated through professional judgment of the authors. 


\section{RADIONUCLIDE RETARDATION IN THE SATURATED ZONE}

This study consists of examining the distribution of redox conditions in the SZ, the relationship between solubility and redox conditions, the relationship between sorption and redox conditions, and the conceptualization of these processes, sensitivity analyses, and conclusions. These assessments are conducted for neptunium and technetium, which are representative of redox-sensitive elements in the repository and are potential key contributors to simulated dose in the individual protection analyses with the TSPA model. Both site-specific and analogue data are used to assess redox conditions in the SZ and to infer relationships between solubility and sorption. The sensitivity analyses of radionuclide transport in the SZ are conducted with a one-dimensional model that incorporates the processes of solubility limits and enhanced sorption and with a three-dimensional site-scale SZ transport model, which incorporates enhanced sorption. Uncertainties in conceptual models and in parameter values are addressed in the evaluations of data and in the sensitivity analyses. Finally, the potential impacts to performance assessment calculations and further recommendations are discussed.

\subsection{REDOX CONDITIONS IN THE SATURATED ZONE}

In this document, the term "redox conditions" refers to the reduction/oxidation potentials measured in SZ waters using an inert platinum electrode, the presence of reductants and oxidants in the saturated zone, the concentrations of these reductants and oxidants, and the reactions that control these concentrations.

Under equilibrium conditions, the ratio of the concentrations of reduced and oxidized species in a redox couple (e.g., $\mathrm{Fe}^{2+} / \mathrm{Fe}^{3+}$ ) can be derived from the measured redox potential and visa-versa. Under nonequilibrium conditions, this is not the case. Based on measurements in numerous groundwater systems, nonequilibrium redox conditions appear to be the rule rather than the exception in aquifers (Lindberg and Runnells 1984 [DIRS 106685]). The existence of nonequilibrium conditions makes it difficult to accurately predict the transport behavior of redox-sensitive species. Fortunately, by analyzing redox data in toto, bounds can be placed on the behavior of redox-sensitive species during transport in the saturated zone. These bounds are usually sufficient for performance assessment purposes.

Given inherent uncertainties in determining redox conditions in groundwater samples, an approach based on a preponderance of evidence is used to identify oxidizing and reducing locations in the SZ. Uncertainties are related to factors such as the potential for contamination of water samples (in wells and during sampling), instrumentation errors, and apparent inconsistencies in redox estimates due to chemical disequilibrium. Groundwater samples that contain more than $1.0 \mathrm{mg} / \mathrm{L}$ of dissolved oxygen (DO) are probably representative of oxidizing conditions and these locations are designated as oxidizing based on DO analyses alone. Groundwater samples with less than $1.0 \mathrm{mg} / \mathrm{L}$ or lacking DO measurements are viewed as potentially reducing and other geochemical data are used to assess the most likely redox state at those locations in the SZ. 


\subsubsection{Oxidizing Groundwaters}

Groundwaters that contain more than $1.0 \mathrm{mg} / \mathrm{L} \mathrm{DO}$ are defined here as oxidizing. Theoretically, even groundwaters with only $0.01 \mathrm{mg} / \mathrm{L}$ DO are significantly oxidizing (Langmuir 1997 [DIRS 100051], p. 409); however, activities associated with the drilling and completion of boreholes may introduce atmospheric oxygen "contamination." Pumping a borehole prior to sampling may also introduce some atmospheric contamination. For these and other reasons discussed below, the lower limit defining an oxidizing groundwater is conservatively $1.0 \mathrm{mg} / \mathrm{L}$.

As noted previously, the concentrations of major redox-sensitive species (e.g., DO, $\mathrm{Fe}^{2+} / \mathrm{Fe}^{3+}$, $\mathrm{Mn}^{2+} / \mathrm{Mn}^{4+}$, $\mathrm{NO}^{2-} / \mathrm{NO}^{3-}$, etc.) in groundwaters can be used to calculate redox potentials (Eh values) under the assumption of equilibrium conditions. An Eh value is the redox potential normalized to the Standard Hydrogen Electrode (SHE). Eh values calculated using data on redox-sensitive species in oxidizing groundwaters from the Yucca Mountain area are plotted against measured $\mathrm{pH}$ values in Figure 2.1-1. Measured Eh values (relative to SHE) obtained with a platinum electrode are also plotted in this figure. As shown in the figure, the Eh values calculated for the different redox-sensitive species span a wide range of values. Those Eh values calculated from dissolved iron concentrations lie at the low end of the range in Eh values measured with a platinum electrode. Conversely, the Eh values calculated from the dissolved manganese and nitrogen species concentrations lie at the high end of the range in measured Eh values. Note that all of these Eh values are less than the values calculated on the basis of DO concentrations in the groundwaters.

The wide data scatter in Figure 2.1-1 implies an absence of equilibrium conditions among the redox-sensitive species in the oxidizing groundwaters. This lack of equilibrium is likely caused by more than one process. First, dissolved oxygen is the redox-sensitive species present in the highest concentrations in oxidizing groundwaters. Thus, the measured Eh values would reasonably be expected to reflect the $\mathrm{DO} / \mathrm{H}_{2} \mathrm{O}$ couple, but this is not observed in Figure 2.1-1. The reason is because the reaction of dissolved oxygen with a platinum electrode produces much smaller exchange currents relative to the currents produced by other redox couples (including impurities in the platinum), even those present at much lower concentrations (Stumm and Morgan 1981 [DIRS 100829], p. 492). As a result, platinum electrode measurements tend to underestimate the Eh values of groundwaters containing dissolved oxygen.

Second, it is likely that activities associated with borehole construction and completion introduced reduced species into oxidizing groundwaters. For example, $\mathrm{Fe}^{2+}$ is found at concentrations near the detection limit $(0.01 \mathrm{mg} / \mathrm{L})$ in many of the groundwaters that contain $\mathrm{DO}>1.0 \mathrm{mg} / \mathrm{L}$. The $\mathrm{Fe}^{2+}$ concentrations in such groundwater should theoretically be $<10^{-15} \mathrm{M}$ $\left(5.6 \times 10^{-11} \mathrm{mg} / \mathrm{L}\right)$ (Langmuir 1997 [DIRS 100051], p. 438). The presence of $\mathrm{Fe}^{2+}$ in these groundwaters at concentrations $\geq 0.01 \mathrm{mg} / \mathrm{L}$ could reflect activities associated with borehole construction. For example, a steel drill and steel drill pipe are used to drill most boreholes. In addition, steel casing and screens are present in some boreholes. Thus, small chips and flakes of steel may be introduced into the aquifers as a result of borehole construction activities and could be a source of the $\mathrm{Fe}^{2+}$ in oxidizing groundwaters. The elevated manganese concentrations found in these groundwaters may have a similar origin. 
The presence of reduced species (e.g., $\mathrm{Fe}^{2+}, \mathrm{Mn}^{2+}$ ) together with dissolved oxygen results in groundwaters with mixed redox potentials (Stumm and Morgan 1981 [DIRS 100829], p. 492). In such groundwaters, the Eh value measured with a platinum electrode is likely dominated by those redox-sensitive species (i.e., redox couples) that produce the highest exchange currents, which are not necessarily those with the highest concentrations in the groundwaters. For example, the kinetics of $\mathrm{Fe}^{2+}$ oxidation is relatively fast in these groundwaters (Stumm and Morgan 1981 [DIRS 100829], p. 465). Thus, $\mathrm{Fe}^{2+}$ may contribute a higher exchange current than other species present at much higher concentrations (e.g., DO). For this reason, $\mathrm{Fe}^{2+}$ could significantly contribute to a mixed potential measured with a platinum electrode in oxidizing groundwaters. Nitrogen species (e.g., nitrate, nitrite, ammonium, etc.) in groundwaters are not electroactive on platinum electrodes and do not contribute to mixed potential measurements (Stumm and Morgan 1981 [DIRS 100829], p. 493).

In view of the uncertainties associated with the interpretation of redox conditions in groundwaters with $\mathrm{DO}>1.0 \mathrm{mg} / \mathrm{L}$, these groundwaters will be considered as fully oxidizing waters with in-situ Eh values that lie in the region between the $\mathrm{H}_{2} \mathrm{O} / \mathrm{DO}$ and the $\mathrm{Mn}^{2+} / \mathrm{MnO}_{2}$ couples in Figure 2.1-1.

As shown in Figure 2.1-2, oxidizing groundwaters are quite common in the Yucca Mountain area. These groundwaters occur in volcanic units near northern Yucca Mountain, in alluvium along Fortymile Wash, and in volcanic units at various locations on and around Yucca Mountain. Note that the groundwater from a well that penetrated the Paleozoic aquifer beneath Yucca Mountain (p\#1) is also oxidizing.

\subsubsection{Reducing Groundwaters}

Reducing groundwaters $(\mathrm{DO}<1.0 \mathrm{mg} / \mathrm{L})$ are also found in the Yucca Mountain region (Figure 2.1-2). As noted above, even groundwaters with $\mathrm{DO}<1.0 \mathrm{mg} / \mathrm{L}$ can, theoretically, be quite oxidizing. To more fully evaluate whether these groundwaters are oxidizing or reducing, other redox parameters (e.g., Eh, total iron, total manganese, nitrogen species, etc.) must be evaluated in addition to DO concentrations.

\subsubsection{Reducing Groundwaters in Volcanic Units}

In addition to DO concentrations of less than $1.0 \mathrm{mg} / \mathrm{L}$, reducing waters generally have iron concentrations greater than $0.1 \mathrm{mg} / \mathrm{L}$ and measured Eh values less than $200 \mathrm{mV} / \mathrm{SHE}$. A plot of iron concentrations against DO concentrations is shown in Figure 2.1-3. Note that total iron concentrations in groundwaters with little or no dissolved oxygen range from $0 \mathrm{mg} / \mathrm{L}$ to around $5 \mathrm{mg} / \mathrm{L}$. The three iron concentrations in excess of $0.5 \mathrm{mg} / \mathrm{L}$ in oxidizing groundwaters probably represent borehole construction artifacts.

The Eh values measured in reducing groundwaters $(\mathrm{DO}<1.0 \mathrm{mg} / \mathrm{L})$ are plotted against measured $\mathrm{pH}$ in Figure 2.1-4. Most of the measurements on reducing groundwaters show Eh values less than $200 \mathrm{mV} / \mathrm{SHE}$ with a trend of decreasing Eh with increasing $\mathrm{pH}$. This trend is typical of groundwaters with Eh values that are controlled by the solubility of a solid phase involving the dominant redox couple (e.g., $\left.\mathrm{Fe}^{2+} / \mathrm{Fe}^{3+}\right)$. Three measurements lie well above the main trend. These three measurements were obtained soon after the boreholes were constructed. Resampling 
of one of these boreholes at a later date resulted in a substantially lower measured Eh value that is consistent with the main trend.

Consistency between the measured Eh value and the Eh value calculated from the measured iron concentrations is a key criterion in identifying reducing groundwaters. The identification of reducing waters on the basis of water chemistry parameters (DO, Eh, iron) is further strengthened if solid reductants are discovered in the aquifer matrix. For example, pyrite has been identified as a primary component of the lower Tram Tuff (Castor et al. 1994 [DIRS 102495]). Apparently, pyrite was entrained in the ash-flow eruption(s) that produced the Tram Tuff and this mineral is widely dispersed in the lower portion of this formation. According to Carr et al. (1984 [DIRS 101522], Figure 11), the Tram Tuff was deposited over an area that spanned Bare Mountain on the west, Jackass Flats on the east, and to approximately 5 miles north of Highway 95 on the south. Assuming pyrite is still present in the lower Tram Tuff in the $\mathrm{SZ}$, reducing conditions would be expected in groundwaters that have come into contact with this unit.

The presence of pyrite in the lower Tram Tuff helps to explain the reducing conditions found in borehole H-3 as waters were pumped from the Tram (Ogard and Kerrisk 1984 [DIRS 100783]). In borehole $\mathrm{H}-4$, reducing waters were pumped from the Bullfrog Tuff, which directly overlies the Tram Tuff (Ogard and Kerrisk 1984 [DIRS 100783]). Because pyrite has not been identified in the Bullfrog Tuff in this borehole, the origin of the reducing characteristics of these groundwaters is less clear. One possibility is that the waters pumped from this borehole were once in contact with the pyrite-bearing matrix of the lower Tram Tuff. Another possibility is that pyrite is present in the Bullfrog Tuff at a location upgradient from borehole H-4. In fact, pyrite was identified in the Bullfrog Tuff in borehole G-2 (Caporuscio et al. 1982 [DIRS 101322], p. 38). The reducing waters found in the Bullfrog Tuff in borehole H-1 (Ogard and Kerrisk 1984 [DIRS 100783]) may have a similar origin. Alternatively, groundwaters from these boreholes may have been reduced by some other, as yet unidentified, reductant. It is important to note that once DO is removed from groundwater by reaction with a reductant such as pyrite, the water generally remains free of DO as it moves downgradient.

In borehole WT-17, reducing waters have been pumped from the Prow Pass Tuff. This tuffaceous unit overlies the Bullfrog Tuff. The reducing conditions in groundwaters from borehole WT-17 are evident in the low DO concentrations $(0.01-0.5 \mathrm{mg} / \mathrm{L})$, high ferrous iron concentrations (1.0-6.0 mg/L), and low Eh values $(-100$ to $-200 \mathrm{mV})$ measured in these waters (DTN: LAAM831311AQ98.010 [DIRS 149522]). The origins of reducing conditions in groundwaters from this borehole are less obvious than they are for boreholes H-3, H-4, and H-1. Available descriptions of rock chips recovered during drilling of WT-17 do not indicate the presence of reductants such as pyrite (DTN: GS940308314211.010 [DIRS 152561]). It is possible that rocks containing reductants such as pyrite are present in the Prow Pass Tuff at this location but were not recovered during drilling because a minimal amount of rock was recovered from below the water table. Alternatively, the groundwaters pumped from WT-17 are reducing because they came into contact with reductants upgradient from the WT-17 location. Caporuscio et al. (1982 [DIRS 101322], p. 35) report the presence of "a pyrite-bearing bedded tuff' in core samples from the Prow Pass Tuff in borehole G-2. 
The idea that reducing conditions in borehole WT-17 are an artifact of well construction is difficult to support. First, reducing conditions were evident in groundwater samples even after $19 \mathrm{~m}^{3}$ (5,000 gal) were pumped from the borehole (Meijer 1998 [DIRS 101051]). If in-situ groundwaters in this borehole were oxidizing rather than reducing, evidence for mixing of oxidizing groundwater (DO $>1.0 \mathrm{mg} / \mathrm{L}$ ) with reducing waters associated with drilling activities would be expected. The DO data obtained during pumping of this borehole are not consistent with such a mixing process. Further, borehole WT-17 was drilled using procedures similar to those used in the construction of borehole WT-3, yet groundwaters in borehole WT-3 are quite oxidizing $(\mathrm{DO}=6.0 \mathrm{mg} / \mathrm{L})$.

The reaction of oxygenated groundwater with pyrite in the volcanic units at some locations near Yucca Mountain would effectively remove DO and result in an increase in the sulfate content of the groundwater. Examination of sulfate concentrations in groundwater samples can thus serve as a test of this hypothesis. The likely reaction between pyrite and DO in groundwater is:

$$
\mathrm{FeS}_{2}+\frac{15}{4} \mathrm{O}_{2}+\frac{1}{2} \mathrm{H}_{2} \mathrm{O} \rightarrow \mathrm{Fe}^{3+}+2 \mathrm{SO}_{4}^{2-}+\mathrm{H}^{+}
$$

The average DO concentration in five wells in the volcanic aquifer near Yucca Mountain with oxidizing conditions (H-1, H-5, H-6, WT-3, and J-13) is about $5 \mathrm{mg} / \mathrm{L}$. According to the chemical reaction given above, reaction of $5 \mathrm{mg} / \mathrm{L}$ of DO with pyrite would result in an increase in sulfate concentration in the groundwater of about $7 \mathrm{mg} / \mathrm{L}$. The average sulfate concentration in the five oxidizing wells in the volcanic units is about $20 \mathrm{mg} / \mathrm{L}$ (BSC 2004 [DIRS 170037]). The average sulfate concentration in seven wells in the volcanic aquifer with reducing conditions (b\#1, H-4, H-3, WT-10, WT-17, WT-12, and WT-14) is about $26 \mathrm{mg} / \mathrm{L}$ (BSC 2004 [DIRS 170037]). Comparison of the average sulfate concentrations in the oxidizing wells and the reducing wells indicates that the average sulfate concentration in the reducing wells is higher by approximately the amount expected from reaction of DO with pyrite in the system. This observation supports the hypothesis that reducing conditions in these wells are caused by pyrite in parts of the volcanic aquifer.

To further delineate the extent of reducing conditions in the saturated zone in and around Yucca Mountain, it would be useful to have redox data on as many boreholes as possible. Unfortunately, most WT boreholes (WT-1, 2, 4, 5, 6, 7, 10, 11, 12, 13, 14, 15, 16, and 18) have not been sampled for dissolved oxygen or redox potential. Of these boreholes, only WT-10, WT-12 and WT-14, have been sampled for general water chemistry parameters by the USGS. In these three boreholes, the measured parameter that provides the best indication of in-situ redox conditions is total iron. As noted above, iron concentrations greater than $0.5 \mathrm{mg} / \mathrm{L}$ in filtered waters are usually associated with reducing conditions. Thus, iron concentrations reported for groundwaters from these boreholes can be used to calculate Eh values.

In Figure 2.1-5, the available data on Eh values measured in reducing groundwaters $(\mathrm{DO}<1.0 \mathrm{mg} / \mathrm{L}$ ) have been plotted against Eh values calculated for each groundwater on the basis of iron concentrations. Although the correlation is not perfect, there is a clear trend in the data when outliers are removed. The outliers are from boreholes NC-EWDP-19D (measured Eh of $400 \mathrm{mV}$ ) and NC-EWDP-1D (two triangles below the upward sloping line). The boreholes in the Alluvial Testing Complex (including NC-EWDP-19D) have been extensively pumped, and water was re-injected in some of these boreholes. Further, groundwaters from NC-EWDP-19D 
were highly turbid and were, therefore, not good candidates for water chemistry analyses. Thus, data on redox conditions in groundwaters from boreholes in this complex are of questionable reliability. Data on redox conditions in NC-EWDP-1D are also questionable because they were obtained very soon after completion of the borehole. Further, it is likely that this borehole was not adequately developed after construction. However, because pyrite was identified in cuttings from this borehole, groundwaters in this borehole are most likely reducing.

The Eh values calculated for groundwaters from boreholes WT-10, WT-12, and WT-14 are noted on the abscissa in Figure 2.1-5. These Eh values suggest groundwater in these boreholes is reducing. When combined with data from other boreholes, the iron and Eh data from boreholes WT-10, WT-12, and WT-14 suggests the existence of a trend of reducing groundwaters in the shallow saturated zone in volcanic units immediately east of the repository footprint (Figure 2.1-2). Whether the reducing conditions identified in the shallow saturated zone as sampled by WT (i.e., water table) boreholes extend downward to reducing conditions thought present in the lower Tram Tuff east of the repository footprint is uncertain. The fact that reducing conditions are evident in groundwaters in the Bullfrog Tuff at boreholes H-1 and H-4 and in the Prow Pass Tuff at borehole WT-17 argues for the idea that reducing conditions along this trend extend from the shallow saturated zone to the lower Tram Tuff.

\subsubsection{Reducing Groundwaters in Alluvium}

As shown in Figure 2.1-2, there are several locations where groundwaters in alluvium were found to be reducing. These include NC-EWDP boreholes 1D, 3S, 5SB, 7SC, 12PA, and 12PB. Descriptions of drill cuttings from borehole NC-EWDP-1D suggest pyrite is present in this borehole. The origin of the reducing conditions in the other boreholes is undetermined. However, because these boreholes are outside the area of potential flow paths from the repository, the reducing conditions found in these boreholes would be unlikely to impact radionuclide transport to the accessible environment.

Interestingly, groundwaters in the upper most zone in borehole NC-EWDP 19D also appear to have reducing characteristics (i.e., $\mathrm{DO}=0.1 \mathrm{mg} / \mathrm{L}, \mathrm{Eh}=100 \mathrm{mV} / \mathrm{SHE}, \mathrm{Fe}_{\text {total }}=1.0 \mathrm{mg} / \mathrm{L}$ ). This borehole does lie along potential flow paths of radionuclides from the repository. Although the analytical data appear reliable, the fact that this borehole contains 5 deeper zones that contain oxidizing groundwaters casts some suspicion on the identification of reducing groundwaters in the uppermost zone. The reducing conditions in this borehole may reflect artifacts of well construction or tracer testing activities. Overall, there is no clear evidence that redox conditions along potential transport pathways in alluvium would include reducing conditions. However, it is possible that reducing conditions could occur on a localized basis (e.g., dead-end pores containing reductants).

\subsubsection{Summary of Eh Distribution}

Measurements of redox parameters in groundwaters in volcanic units in and around Yucca Mountain suggest the existence of two zones of reducing groundwaters. The first zone is within the part of the Tram Tuff that contains primary pyrite. The amount of pyrite in this tuff unit is sufficient to cause reducing conditions in groundwater within the unit. Second, measurements of redox parameters in groundwaters pumped from boreholes located directly east of Yucca 
Impacts of Solubility and Other Geochemical Processes on Radionuclide Retardation in the Natural System

Mountain suggest the existence of a north-south zone of reducing groundwaters in volcanic units. This zone transects the transport pathways from the repository predicted by the flow model.

Measurements of redox conditions in alluvium along potential flow paths from the repository indicate primarily oxidizing conditions.

The redox barrier in the lower Tram Tuff may retard the transport of redox-sensitive radionuclides to the deeper saturated zone. The redox barrier east of the repository footprint may retard the transport of redox-sensitive radionuclides eastward and possibly southward from the repository footprint.

\subsubsection{Conceptualization of Eh Distribution and Groundwater Flow}

These observations and inferences about redox conditions in the SZ are discussed in a generalized conceptualization of Eh distribution and the groundwater flow system in this section. Atmospheric oxygen is the primary oxidant in groundwater systems and is added to the SZ flow system via recharge from the vadose zone. There are many potential aqueous species and mineral phases that can serve as reductants in the groundwater system, but organic matter and sulfides are the major reductants in most systems (Langmuir 1997 [DIRS 100051]). The distribution of redox conditions in the SZ flow system and the evolution of these conditions along flow paths are a function of the rate at which DO is transported into the system, balanced by the rate at which it is consumed by reaction with reductants. Consequently, in natural groundwater systems redox conditions generally evolve along regional flow paths from more oxidizing near zones of recharge to more reducing at downgradient locations. Redox conditions can vary in response to local occurrences of reductants in the system. For example, depletion of DO can be quite rapid in cases where recharge occurs through sediments with high organic content or through landfill wastes.

Spatial variability in redox conditions in groundwater flow systems can occur over a wide range of scales, from centimeters to kilometers. Transient, but long-lived, redox reaction fronts can result in strong contrasts in Eh over relatively small scales, such as those associated with some uranium ore deposits (Guilbert and Park 1986 [DIRS 158074]). Where permeability is low, reaction of DO with solid-phase reductants may be limited by the slow rate of molecular diffusion, leading to variability in Eh over small to intermediate scales. In regional-scale groundwater flow systems, systematic variations in redox conditions have been observed at the scale of tens of kilometers, such as the downgradient transition of oxidizing conditions to reducing conditions in a chalk aquifer in Great Britain, as it becomes confined (Edmunds et al. 1987 [DIRS 172740]; Schurch et al. 2004 [DIRS 172731]).

In arid environments, oxygenated groundwater can persist over relatively long flow distances in regional flow systems. Oxidizing groundwater has been observed in the Continental Intercalaire aquifer of Algeria and Tunisia up to $300 \mathrm{~km}$ from the outcrop and apparent recharge area of the aquifer (Edmunds et al. 2003 [DIRS 172728]). Groundwater chemistry indicates oxidizing conditions in the regional carbonate aquifer of a closed basin in northern Mexico tens of kilometers from recharge areas (Ortega-Guerrero 2003 [DIRS 172732]). These observations are consistent with the oxidizing groundwater samples in the deep regional carbonate aquifer from well p\#1 near Yucca Mountain. Low organic contents in desert soils, the thick vadose zone 
containing atmospheric oxygen, and rapid, highly episodic limited infiltration probably facilitate highly oxidizing recharge to the SZ in arid environments. Persistence of oxidizing groundwaters over long flow distances obviously requires low concentrations of reductants in the aquifer.

Reducing conditions do occur in regional groundwater flow systems in arid locations in some aquitards and in playa sediments. Ortega-Guerrero (2003 [DIRS 172732]) observed groundwater geochemical characteristics indicating reducing conditions in the clay-rich aquitard overlying the regional carbonate aquifer in northern Mexico. Reducing conditions have been observed in shallow groundwater samples from Owens Dry Lake bed in California (Ryu et al. 2004 [DIRS 172744]). Playas are important discharge locations in arid regional flow systems that comprise highly evolved (long subsurface residence time) groundwater at the regional flow outlet. Such groundwater would be depleted of DO by any reductants present along the entire flow path of the system. In addition, fine-grained sediments in aquitards and playa deposits can contain residual organic material, which serves as a strong reductant. Reducing groundwaters at wells NC-EWDP-1D and NC-EWDP-7SC are consistent with these observations given that these wells have clay-rich sediments similar to playa deposits. The reducing conditions found at well NC-EWDP-5SB may be related to the clay-rich sediments in the alluvium at this location and their potential behavior as an aquitard in the SZ flow system.

Sulfide minerals such as pyrite are also strong reductants and their presence in aquifers can lead to reducing conditions in the groundwater flow system. Redox potentials of about $-300 \mathrm{mV}$ have been observed in fractured granite with disseminated pyrite near a uranium mine in Japan (Iwatsuki and Yoshida 1999 [DIRS 172727]). Similarly reducing conditions and associated mobilization of iron in groundwater have been observed in the groundwater flow system in fractured metasedimentary bedrock with disseminated pyrite in fractures and veins in Australia (Jankowski 2001 [DIRS 172771]). Water chemistry in several wells to the south and east of Yucca Mountain, as described in Section 2.1.2.1, is consistent with reducing conditions associated with pyrite in the fractured tuff aquifer of the SZ.

\subsection{SOLUBILITY AS A FUNCTION OF REDOX CONDITIONS}

The purpose of the analysis presented in this section is to define the functional relationship between the redox potential of the groundwater and the solubility of technetium under the hydrogeologic and geochemical conditions typical of the SZ at the Yucca Mountain site. Technetium is known to be redox-sensitive and has extremely different solubilities under oxidizing versus reducing conditions. There are other redox-sensitive radioelements that could be considered in this analysis (e.g., neptunium, uranium, and plutonium). The following analysis of solubility is limited to technetium because ${ }^{99} \mathrm{Tc}$ is likely to demonstrate the maximum impact of redox-related solubility constraints in the saturated zone.

\subsubsection{Data from Yucca Mountain}

The solubility of technetium was calculated using two different ambient water composition types observed at the Yucca Mountain site that bracket the geochemical conditions in the saturated zone along the potential flow path from the repository to the accessible environment (BSC 2005 [DIRS 174012]). The first water composition considered is from well UE-25 J-13 (referred to as $\mathrm{J}-13$ further in the text). The second water composition considered is from well UE-25 p\#1 
(referred to as p\#1 further in the text). Well J-13 is located on the east side of the Fortymile Wash and well p\#1 is located to the southeast of the repository as shown in Figure 2.1-2. Well $\mathrm{p} \# 1$ has two sampling intervals, one in volcanics and one in carbonate aquifer. The water composition from the carbonate aquifer interval was used in the analysis, since it has more pronounced differences from the J-13 water. The water compositions used in the analysis are provided in Table 2.2-1. A number of interpretations of water composition from these 2 wells are available. The average groundwater compositions in Table 2.2-1 represent the most recent interpretation (BSC 2004 [DIRS 170036], Table A-2a).

\subsubsection{Chemical Equilibrium Analyses}

Changes in solubility as a function of redox conditions were calculated using two different approaches. In the first approach, the chemical equilibrium and speciation code EQ3 V 8.0 (BSC 2003 [DIRS 162228]) calculated solubility under specified conditions. The aqueous concentration of an element of interest in equilibrium with a solid phase known to be controlling under the highly oxidizing conditions was simulated to derive the corresponding high-Eh solubility. Similarly, the aqueous concentration in equilibrium with a solid phase known to be controlling under the reducing conditions was simulated to derive the corresponding low-Eh solubility.

Simulations for J-13 and p\#1 groundwater compositions estimated the possible impact of the different compositions on the solubilities. Models were also run subject to different temperatures $\left(25^{\circ} \mathrm{C}\right.$ and $\left.35^{\circ} \mathrm{C}\right)$ to estimate the effects due to temperature fluctuations in the $\mathrm{SZ}$.

The runs were also done for different $\mathrm{Eh}$ and $\mathrm{pH}$ values. In the second approach, the chemical reaction path code EQ6 (BSC 2003 [DIRS 162228]) was used to evaluate transitions in solubility of the chemical reactions involving technetium in solid and aqueous phases within the Eh interval of interest $(-0.800$ to $+800 \mathrm{mV})$. The EQ3 and EQ6 calculations were performed using the updated version of the thermodynamic database data0.ymp.R2 (DTN: MO0302SPATHDYN.000 [DIRS 161756]). Ultimately, the two approaches were compared. It should be noted that EQ6 calculations are quite complex and it is important to compare EQ3 results to EQ6 results to assure that the EQ6 calculations are in agreement with the chemical equilibrium results from EQ3. The details of these calculations are provided below. The assumptions used in constructing the models rely heavily on experiments and calculations from studies available in the literature. The results and the conclusions of this analysis are compared to the data available for the Yucca Mountain site and elsewhere.

\subsubsection{Technetium Solubility under Oxidizing Conditions}

Technetium is highly soluble under oxidizing conditions, up to $10 \mathrm{M}$ (Langmuir 1997 [DIRS 100051], Table 13.9). Based on this, no solubility limits (e.g., infinite solubility) are assumed for technetium in the Yucca Mountain performance assessment calculations (BSC 2004 [DIRS 169425]). The dissolution of crystalline technetium oxide $\left(\mathrm{TcO}_{2}\right)$ and hydrated technetium oxide $\left(\mathrm{TcO}_{2} \cdot x \mathrm{H}_{2} \mathrm{O}\right)$ was studied in experiments conducted by Lieser et al. (1987 [DIRS 172723]) under varying Eh conditions with a minimum Eh of $300 \mathrm{mV}$. The dissolution proceeded continuously, the concentration of technetium in solution did not reach the saturation value for either $\mathrm{TcO}_{2}$ or $\mathrm{TcO}_{2} \cdot x \mathrm{H}_{2} \mathrm{O}$, and the equilibrium was not established (Lieser et al. 1987 
[DIRS 172723]). Dissolved technetium was always identified as $\mathrm{TcO}_{4}^{-}$. There are other technetium solids that may control technetium solubility under the oxidizing conditions in the case of concentrated solutions. For example, $\mathrm{KTcO}_{4}$ may affect technetium solubility in the solutions with high potassium concentration greater than $1.45 \mathrm{M}$ for J-13 water.

\subsubsection{Technetium Solubility Under Reducing Conditions}

Technetium solubility under reducing conditions is limited either by $\mathrm{TcO}_{2}$ or $\mathrm{TcO}_{2} \cdot x \mathrm{H}_{2} \mathrm{O}$ (Langmuir 1997 [DIRS 100051], Table 13.9). In the experimental studies conducted by Meyer et al. (1991 [DIRS 172733]), the dissolution of technetium under reducing conditions was limited by $\mathrm{TcO}_{2} \cdot 1.6 \mathrm{H}_{2} \mathrm{O}$. Pabalan et al. (2000 [DIRS 172603]) refer to these experiments when selecting hydrated technetium oxide as a solubility-controlling solid in their calculations. However, few experimental data are available to completely discard crystalline $\mathrm{TcO}_{2}$ as a solubility-controlling solid. It is not clear whether the short duration of the experiments or some other conditions favored the formation of hydrated technetium oxide over the crystalline one. Based on this, both $\mathrm{TcO}_{2}$ and $\mathrm{TcO}_{2} \cdot 1.6 \mathrm{H}_{2} \mathrm{O}$ were considered in solubility calculations in the analyses presented in this report.

EQ3 calculations were carried out using J-13 and p\#1 water composition with the measured pH of $6.9(\mathrm{~J}-13)$ and $6.7(\mathrm{p \# 1)}$ and $\mathrm{pH}$ of 8.5 and assuming crystalline and hydrated technetium oxide as a controlling solid. Multiple calculations were performed to obtain technetium solubility under different Eh values. The calculations continued until the critical Eh under which the equilibrium is possible was identified. Attempts to run EQ3 with the Eh value above the critical resulted in non-convergence.

Results from these calculations are shown in Figure 2.2-1, which shows that the controlling solid has the greatest effect on the solubilities. The solubility of technetium in equilibrium with $\mathrm{TcO}_{2} \cdot 1.6 \mathrm{H}_{2} \mathrm{O}\left(4 \times 10^{-9} \mathrm{~mol} / \mathrm{kg}\right)$ is four orders of magnitude higher than when in equilibrium with $\mathrm{TcO}_{2}\left(4 \times 10^{-13} \mathrm{~mol} / \mathrm{kg}\right)$. Water composition has a minor effect on the solubility and solubility under reducing conditions remains constant until a transitional $\mathrm{Eh}, \mathrm{Eh}^{\mathrm{tr}}$, is reached. Above $\mathrm{Eh}^{\mathrm{tr}}$, the solubility rapidly increases until the critical $\mathrm{Eh}, \mathrm{Eh}^{\mathrm{cr}}$, is reached. Above $\mathrm{Eh}^{\mathrm{cr}}$, the solubility is large.

The $\mathrm{pH}$ does not affect solubility when $\mathrm{Eh}$ is below $\mathrm{Eh}^{\mathrm{tr}}$. This is related to the fact that under this Eh condition, the major technetium species is $\mathrm{TcO}(\mathrm{OH})_{2}$ (Figure 2.2-2). The $\mathrm{pH}$ also does not affect the rate at which the solubility increases within the Eh interval from $\mathrm{Eh}^{\text {tr }}$ to $\mathrm{Eh}^{\mathrm{cr}}$. However, it does affect the values of $\mathrm{Eh}^{\mathrm{tr}}$ and $\mathrm{Eh}^{\mathrm{cr}}$.

At a lower $\mathrm{pH}$, solubility transition occurs at $\mathrm{Eh}=0.0 \mathrm{mV}$ and at a higher $\mathrm{pH}$, solubility transition occurs at $\mathrm{Eh}=-100 \mathrm{mV}$. The $\mathrm{Eh}^{\mathrm{cr}}$ values are 150 to $200 \mathrm{mV}(\mathrm{pH}=8.5)$ and 250 to $260 \mathrm{mV}(\mathrm{pH}=6.7-6.9)$. As shown in Figure 2.2-2, above $\mathrm{Eh}=50$ to $150 \mathrm{mV}$, the major technetium species is $\mathrm{TcO}_{4}^{-} . \mathrm{TcO}(\mathrm{OH})_{2}$ is present in significantly smaller amounts and its concentration does not change with Eh. The technetium carbonate complex, $\mathrm{TcCO}_{3}(\mathrm{OH})_{2}$, is present in only small concentrations at Eh values below $-200 \mathrm{mV}$. It is present in concentrations slightly smaller than concentrations of $\mathrm{TcO}(\mathrm{OH})_{2}$ within an $\mathrm{Eh}$ interval of -200 to $200 \mathrm{mV}$. It starts to increase at Eh values above $200 \mathrm{mV}$, but with negligible effect on the total dissolved concentration of technetium. 
It should be noted that $\mathrm{pH}$ and Eh are artificially fixed in the EQ3 calculations and the water composition remains constant. In a real system, the water composition would change to reflect changes in $\mathrm{pH}$ and Eh. Also, EQ3 does not allow for precipitation of oversaturated species, so such species remain in the solution. For example, in all the EQ3 runs, technetium was in oversaturation with regard to the solid technetium phase.

The EQ6 runs were done to more accurately represent the system. The initial equilibrium solution composition was obtained from EQ3 calculations using J-13 water with a measured $\mathrm{pH}$ of 6.7 and Eh fixed at $-400 \mathrm{mV}$. The calculations with the p\#1 water were not performed because the EQ3 calculations showed no sensitivity with regard to the water composition. The formation of solid technetium was suppressed because none of the technetium dissolution experiments yielded this mineral. The controlling solids in the first and second runs were $\mathrm{TcO}_{2}$ and $\mathrm{TcO}_{2} \cdot 1.6 \mathrm{H}_{2} \mathrm{O}$, respectively. Oxygen was continuously added to system to increase Eh. It was noted that while Eh was changing from -400 to $400 \mathrm{mV}$, the system $\mathrm{pH}$ was adjusted to about 9 at the beginning of the reaction, was continuously dropping as the reactions in the system progressed, and reached a low value $(\mathrm{pH} \sim 2)$ at the end of the simulations. Calcite was added to the system to buffer $\mathrm{pH}$. As a result, the $\mathrm{pH}$ at the end of simulation was about 6 and the range of $\mathrm{pH}$ fluctuation was narrowed to 3 units. When the same calculations were repeated with $\mathrm{TcO}_{2} \cdot 1.6 \mathrm{H}_{2} \mathrm{O}$ as a controlling solid, the resulting technetium concentrations were identical to the run with the $\mathrm{TcO}_{2}$ as a controlling solid. The analysis of these results showed that the precipitation of $\mathrm{TcO}_{2}$ began shortly after the beginning of the reaction and that this process overshadowed the precipitation of $\mathrm{TcO}_{2} \cdot 1.6 \mathrm{H}_{2} \mathrm{O}$, even though only $\mathrm{TcO}_{2} \cdot 1.6 \mathrm{H}_{2} \mathrm{O}$ was specified as a reacting mineral. Only after the precipitation of the $\mathrm{TcO}_{2}$ was suppressed did the results of EQ6 and EQ3 agree.

Both runs are shown in Figure 2.2-1 and EQ3 and EQ6 results are in good agreement in the low Eh field. The EQ6 results are between the two EQ3 runs (one with the original $\mathrm{pH}=6.7$ and another with $\mathrm{pH}=8.5$ ) due to the fact that the $\mathrm{pH}$ was changing in the EQ6 runs with the increasing Eh. The speciation shown in Figure 2.2-1 and discussed above was obtained from these two runs.

\subsubsection{Summary of Technetium Solubility Results and Comparison with the Literature Data}

The results of technetium solubility calculations are summarized in Table 2.2-2. Comparison of these results with literature data with regard to the range of estimated technetium solubility and $\mathrm{Eh}^{\mathrm{cr}}$ indicates that these results are consistent with other studies. This study examined two controlling solids $\left(\mathrm{TcO}_{2} \cdot 1.6 \mathrm{H}_{2} \mathrm{O}\right.$ and $\left.\mathrm{TcO}_{2}\right)$ to determine technetium solubility. A technetium solubility of $4 \times 10^{-9} \mathrm{M}$ was calculated assuming $\mathrm{TcO}_{2} \cdot 1.6 \mathrm{H}_{2}$ as a controlling solid. This value was shown to be independent of temperature, $\mathrm{pH}$, and water composition within the parameter ranges considered. A technetium solubility of $4 \times 10^{-13} \mathrm{M}$ was calculated assuming $\mathrm{TcO}_{2}$ as a controlling solid. However, based on various solubility experiments in the literature, the most likely controlling solid is $\mathrm{TcO}_{2} \cdot 1.6 \mathrm{H}_{2} \mathrm{O}$. Therefore, the one-dimensional streamtube sensitivity analyses, which explicitly simulate solubility limits and enhanced sorption in this study, will use the technetium solubility value of $4 \times 10^{-9} \mathrm{M}$. 
The Eh-pH diagram for the system $\mathrm{Tc}-\mathrm{O}_{2}-\mathrm{CO}_{2}-\mathrm{H}_{2} \mathrm{O}$ at $25^{\circ} \mathrm{C}$ and 1 bar pressure for total technetium concentration of $10^{-8} \mathrm{M}$ is provided elsewhere (Langmuir 1997 [DIRS 100051], Figure 13.21). Based on this diagram either $\mathrm{TcO}_{4}{ }^{-}$or $\mathrm{TcO}_{2} \cdot 2 \mathrm{H}_{2} \mathrm{O}$ are in the system within the $\mathrm{pH}$ interval of interest, 6.5 to 8.5 . $\mathrm{Eh}^{\mathrm{tr}}$ is a function of $\mathrm{pH}$ : when $\mathrm{pH}=8.5, \mathrm{Eh}^{\mathrm{tr}}=-0.1$, which is consistent with the value shown in Table 2.2-2; when $\mathrm{pH}=7$, the $\mathrm{Eh}^{\mathrm{tr}}=0.1$, which is slightly higher than the value shown in Table 2.2-2. The solubility of technetium in equilibrium with $\mathrm{TcO}_{2} \cdot 2 \mathrm{H}_{2} \mathrm{O}$ (see Langmuir (1997 [DIRS 100051], Figure 13.21) is $10^{-8} \mathrm{M}$, which is a little higher than shown in Table 2.2-2. In the work of Langmuir (1997 [DIRS 100051], Table 13.9), both $\mathrm{TcO}_{2}$ and $\mathrm{TcO}_{2} \cdot 2 \mathrm{H}_{2} \mathrm{O}$ are shown as the solubility controlling solids. The technetium solubility range selected in most of the repository programs shown in this table is from $10^{-12} \mathrm{M}$ to $10^{-7} \mathrm{M}$. This is in relatively good agreement with the range in Table 2.2-2 taking into account that the repository programs tend to bias toward conservatism. This seems to be the case of technetium solubility of $5 \times 10^{-8} \mathrm{M}$ published for the disposal program in Finland by Vieno and Nordman (1999 [DIRS 172783]). The range of the solubility of technetium under oxidizing conditions from the work of Langmuir (1997 [DIRS 100051], Table 13.9) is from $3.6 \times 10^{-7} \mathrm{M}$ to $10.0 \mathrm{M}$. This agrees with the results of the calculations shown in Figure 2.2-1. The solubility of technetium in the groundwater from well SKI-90 located in Sweden and calculated by Langmuir (1997 [DIRS 100051]) is $3.3 \times 10^{-8} \mathrm{M}$.

The Eh-pH diagram provided by Pabalan et al. (2000 [DIRS 172603], Figure 1) shows that for $\mathrm{TcO}_{2} \cdot 1.6 \mathrm{H}_{2} \mathrm{O}, \mathrm{Eh}^{\mathrm{tr}}=-0.03 \mathrm{~V}(\mathrm{pH}=8.5)$ and $\mathrm{Eh}^{\mathrm{tr}}=0.08 \mathrm{~V}(\mathrm{pH}=7)$, which is in good agreement with the values shown in Table 2.2-2. Eh corresponding to transitional conditions in this table changes from $-0.1 \mathrm{~V}\left(\mathrm{TcO}_{2} \cdot 1.6 \mathrm{H}_{2} \mathrm{O}\right.$ is a controlling solid) to $0.36 \mathrm{~V}$ ( $\mathrm{TcO}_{2}$ is a controlling solid). The solubility of technetium in equilibrium with $\mathrm{TcO}_{2} \cdot 2 \mathrm{H}_{2} \mathrm{O}$ in well UE-25 WT\#17 water calculated by Pabalan et al. (2000 [DIRS 172603]) is $4 \times 10^{-9} \mathrm{~mol} / \mathrm{L}$, which coincides with the solubility value when $\mathrm{TcO}_{2} \cdot 1.6 \mathrm{H}_{2} \mathrm{O}$ is the controlling solid. Pabalan et al. (2000 [DIRS 172603]) also calculated technetium solubility in equilibrium with $\mathrm{TcO}_{2}$. Their value of $4 \times 10^{-13} \mathrm{~mol} / \mathrm{L}$ coincides with the corresponding value in Table $2.2-2$ as well.

A number of experimental data on technetium solubilities in reducing conditions is available in the work of Meyer et al. (1991 [DIRS 172733]). Meyer et al. (1991 [DIRS 172733]) used the different molality solutions of $\mathrm{NaCl}$ and synthetic groundwater (simulating water composition in well GR-4) in their experiments conducted with $\mathrm{pH}$ ranging from 0 to 10 . They used two different methods (chemical reducing with hydrazine and electrodeposition) to measure solubility. Based on these experiments, they determined the composition of the precipitate to be $\mathrm{TcO}_{2} \cdot 1.6 \mathrm{H}_{2} \mathrm{O}$. They concluded that technetium solubility increases with increasing $\mathrm{pH}$ and that it is not a function of $\mathrm{NaCl}$ concentrations when $\mathrm{NaCl}$ concentration is below $0.5 \mathrm{M}$. The following results were obtained for GR-4 technetium solubility based on different experiments and $\mathrm{pH}$ values: $9.43 \times 10^{-9}, 2.94 \times 10^{-9}$, and $1.47 \times 10^{-8} \mathrm{M}$. The average of these measurements is $9 \times 10^{-9} \mathrm{M}$, which is in good agreement with the calculations in this report. GR-4 water composition differs from $\mathrm{J}-13$ and $\mathrm{p} \# 1$ water composition primarily with regard to $\mathrm{Na}^{+}$and $\mathrm{Cl}^{-}$, which are present in higher concentrations in GR-4. The following results were obtained for diluted $\mathrm{NaCl}$ solutions based on different experiments and $\mathrm{pH}$ values: $3.14 \times 10^{-9} ; 3.20 \times 10^{-9}$; and $1.01 \times 10^{-8} \mathrm{M}$. The average of these measurements is $5.5 \times 10^{-9} \mathrm{M}$, which is in good agreement with the solubility value of $4 \times 10^{-9} \mathrm{M}$ reported here. 
Finally, the technetium solubilities of Salter and Jacobs (1982 [DIRS 172604]) are in the range of $4 \times 10^{-14}$ to $4 \times 10^{-12} \mathrm{M}$. The technetium solubility in equilibrium with $\mathrm{TcO}_{2}$ from the analyses in this report falls close to the mid point of this interval.

\subsubsection{Summary of Expected Technetium Solubility under Reducing Conditions}

Based on the analyses of solubility as a function of redox conditions in the SZ, the recommended solubility limit for technetium is $4 \times 10^{-9} \mathrm{M}$. This solubility may be expected when groundwater Eh value is below -100 to $0.0 \mathrm{mV}$. These results are used as input to the sensitivity analyses conducted to examine the impact of redox conditions on radionuclide transport in the SZ by explicitly simulating solubility limits and enhanced sorption due to reducing conditions using a one-dimensional streamtube model as discussed in Section 2.5.2 and 2.5.3.

\subsection{SORPTION AS A FUNCTION OF REDOX CONDITIONS}

Sorption coefficients for the elements neptunium and technetium are sensitive to redox potential (Eh). In general, sorption coefficients are smaller under oxidizing conditions than they are under reducing conditions. In Saturated Zone Flow and Transport Model Abstraction (BSC 2005 [DIRS 174012]), sorption coefficient distributions were derived under the assumption that redox conditions were oxidizing along all potential flow paths to the accessible environment. However, field data discussed in Section 2.1 indicate that reducing conditions exist in some parts of the groundwater flow field. To assess the impact of these zones on the transport of redox-sensitive radionuclides, transport calculations must be carried out using separate sorption coefficients for the oxidizing and reducing portions of the flow paths. In this section, the sorption coefficients for neptunium and technetium under oxidizing and reducing conditions are derived.

\subsubsection{Sorption Coefficients for Neptunium and Technetium under Oxidizing Conditions}

A discussion of the methods used to derive sorption coefficient distributions for neptunium and technetium on Yucca Mountain volcanic rocks and alluvium under oxidizing conditions is provided by (BSC (2004 [DIRS 170036], Appendices A and E).

\subsubsection{Sorption Coefficients under Reducing Conditions}

Sorption coefficients for neptunium and technetium under reducing conditions have not been obtained using Yucca Mountain geologic samples. However, there are several sources of sorption coefficient data obtained under reducing conditions available in the literature. Lieser and Muhlenweg (1988 [DIRS 106684]) and Hakanen and Lindberg (1991 [DIRS 105905]) have reported on neptunium sorption experiments under reducing conditions and Lieser and Bauscher (1987 [DIRS 172722]) have reported on technetium sorption experiments under reducing conditions.

The experiments reported by Lieser and Muhlenweg (1988 [DIRS 106684]) and Lieser and Bauscher (1987 [DIRS 172722]) involved quartz-rich sediments containing 5-25 weight percent of feldspar, muscovite, chlorite, and kaolinite and less than 5 percent of calcite, chlorite, montmorillonite, anhydrite, and dolomite. These mineral compositions are not unlike the mineral compositions of Yucca Mountain tuffs. The experiments also involved water 
compositions similar to the composition of saturated zone waters at Yucca Mountain. Thus, the results of these experiments can be used to estimate sorption coefficients for neptunium and technetium under reducing conditions on Yucca Mountain tuffs.

\subsubsection{Sorption Coefficient for Neptunium under Reducing Conditions}

A graph showing neptunium sorption coefficients as a function of Eh as reported by Lieser and Muhlenweg (1988 [DIRS 106684]) is shown in Figure 2.3-1. Under oxidizing conditions $(\mathrm{Eh}>250 \mathrm{mV})$, the neptunium sorption coefficients shown in Figure 2.3-1 are similar to the range of neptunium sorption coefficients obtained using Yucca Mountain rock and water samples (BSC 2004 [DIRS 170036], Appendix A). Under reducing conditions, the neptunium sorption coefficients reported by Lieser and Muhlenweg (1988 [DIRS 106684]) increase to approximately $1,000 \mathrm{~mL} / \mathrm{g}$. Lieser and Muhlenweg (1988 [DIRS 106684]) refer to the sorption coefficients they obtained under reducing conditions as "apparent $K_{d}$ " because they were unsure whether neptunium was sorbed or precipitated in their experiments under reducing conditions.

The question of whether neptunium was sorbed or precipitated in the experiments is an important question. Several lines of evidence suggest that the neptunium was sorbed in these experiments. First, Hakanen and Lindberg (1991 [DIRS 105905]) performed neptunium sorption experiments under oxidizing and reducing conditions with neptunium solution concentrations of $10^{-14} \mathrm{M}$. This solution concentration is well below the solubility limit of $\mathrm{NpO}_{2}$ (Kazuba and Runde 1999 [DIRS 122379]). Thus, precipitation was not a concern in these experiments. Yet, the sorption of neptunium "was higher under anoxic than under aerobic conditions." Reducing conditions also yielded greater neptunium sorption than aerobic (oxidizing) conditions.

Second, a modeling study was performed to test neptunium sorption behavior as a function of Eh. The modeling study used a nonelectrostatic surface complexation model with a quartz substrate. Quartz $\left(\mathrm{SiO}_{2}\right)$ is a good surrogate for the mineral surfaces in the devitrified tuffs of Yucca Mountain because it is a common mineral in these tuffs and the tuffs contain 75-80 weight percent $\mathrm{SiO}_{2}$. Sorption site density information for quartz is reported by Turner et al. (1998 [DIRS 162989]). A surface area was chosen $\left(0.02 \mathrm{~m}^{2} / \mathrm{g}\right)$ that was representative of the Gorleben sediments used in the experiments reported by Lieser and Muhlenweg (1988 [DIRS 106684]). A dilute water composition reported by Lieser and Muhlenweg (1988 [DIRS 106684]) was used for the solution composition. This water composition is similar to water compositions found in the SZ at Yucca Mountain.

For oxidizing conditions, the neptunium binding constant reported by Turner et al. (1998 [DIRS 162989]) was used for neptunium sorption on quartz. For reducing conditions, a binding constant was derived for $\mathrm{Np}^{4+}$ sorption by using $\mathrm{Th}^{4+}$ as an analogue to $\mathrm{Np}^{4+}$. Allard et al. (1983 [DIRS 162982]) reported sorption coefficients for thorium on quartz in a dilute water. Thorium solution concentrations used by Allard et al. (1983 [DIRS 162982]) were $2.5 \times 10^{-9} \mathrm{M}$. This is close to the solubility of hydrous $\mathrm{ThO}_{2}$ as reported by Hummel et al. (2002 [DIRS 161904], Figure 5.21.1). Thus, precipitation of (hydrous) $\mathrm{ThO}_{2}$ was unlikely to have been an issue in these experiments. By using the thorium sorption coefficient data, water composition, and surface area reported by Allard et al. (1983 [DIRS 162982]), and the sorption site density reported by Turner et al. (1998 [DIRS 162989]), a binding constant for $\mathrm{Th}^{4+}$ on quartz was 
derived using the surface complexation model available in the PHREEQC code (BSC 2001 [DIRS 155323]).

The derived $\mathrm{Th}^{4+}$ binding constant on quartz was combined with the $\mathrm{Np}^{5+}$ binding constant on quartz reported by Turner et al. (1998 [DIRS 162989]), the water chemistry reported by Lieser and Muhlenweg (1988 [DIRS 106684]), a quartz surface with an area of $0.02 \mathrm{~m}^{2} / \mathrm{g}$, the sorption site density on quartz reported by Turner et al. (1998 [DIRS 162989]), and the EQ3 thermodynamic database for neptunium solution species, to produce the neptunium sorption coefficient curve shown in Figure 2.3-2. It is evident from a comparison of Figures 2.3-1 and 2.3-2 that the surface complexation models reproduces the experimental curve reasonably well. This lends additional support to the idea that $\mathrm{Np}^{4+}$ is strongly sorbed under reducing conditions. Note that the position of the "step" in the model curve is a function only of water chemistry and thermodynamic data for neptunium species.

Lieser and Hill (1992 [DIRS 147532]) measured $\mathrm{Th}^{4+}$ sorption coefficients on Gorleben sediments and groundwaters similar to those described above. Their results indicate that: (1) in laboratory experiments using natural samples, the presence of fine-grained particulates and colloids can obscure the magnitude of the "true" sorption coefficient; (2) the presence of particulates generally cause the measured $\mathrm{Th}^{4+}$ sorption coefficient to be a function of the volume to mass ratio used in a given experiment; and, (3) when corrections are made for these particulate "interferences," it is found that $\mathrm{Th}^{4+}$ sorbs very strongly to silicate surfaces with a "true" (i.e., particulate-corrected) sorption coefficient of greater than $1,000 \mathrm{~mL} / \mathrm{g}$. Assuming $\mathrm{Th}^{4+}$ is a reasonable analogue for $\mathrm{Np}^{4+}$ (Choppin 1999 [DIRS 172748]), these results imply that $\mathrm{Np}^{4+}$ will also sorb strongly to silicate surfaces.

Thus, the inference by Langmuir (1997 [DIRS 100051], Figure 13.35) that the large neptunium sorption coefficient values reported by Lieser and Muhlenweg (1988 [DIRS 106684]) under reducing conditions "reflect precipitation of $\mathrm{Np}$ (IV) solids rather than adsorption" is not borne out by the analysis presented here.

On the basis of this analysis, a value of $1,000 \mathrm{~mL} / \mathrm{g}$ is recommended for the sorption coefficient of neptunium on Yucca Mountain tuffs under reducing conditions. A range extending to much larger values could be derived with additional analysis.

\subsubsection{Sorption Coefficient for Technetium under Reducing Conditions}

Technetium sorption coefficients as a function of Eh as reported by Lieser and Bauscher (1987 [DIRS 172722]) are shown in Figure 2.3-2. This graph has a shape similar to that for neptunium in Figure 2.3-1. The main differences are that the average sorption coefficient under oxidizing conditions is lower for technetium $(0.1 \mathrm{~mL} / \mathrm{g})$ when compared to neptunium $(1-4 \mathrm{~mL} / \mathrm{g})$ and the Eh value at which there is a step in the sorption coefficient distribution is lower for technetium (approximately $150 \mathrm{mV}$ ) when compared to neptunium (approximately $200 \mathrm{mV}$ ) at neutral $\mathrm{pH}$. However, the average values of the technetium and neptunium sorption coefficients under reducing conditions are similar $(1,000$ to $2,000 \mathrm{~mL} / \mathrm{g})$.

On the basis of the sorption coefficient data presented by Lieser and Bauscher (1987 [DIRS 172722]) and the general similarity in rock and water compositions used in their 
experiments to Yucca Mountain rock and water compositions, it is recommended that a sorption coefficient of $1,000 \mathrm{~mL} / \mathrm{g}$ be used to model technetium sorption under reducing $(<150 \mathrm{mV}$ at $\mathrm{pH}=7.0$ ) conditions.

\subsection{CONCEPTUAL MODEL OF REDOX CONDITIONS, SOLUBILITY, AND SORPTION}

The analyses and assessments presented in Sections 2.1-2.3 are used to develop a general conceptual model of the features and processes in the SZ that could affect the transport of redox-sensitive radioelements. The conceptual model presented in this section forms the basis for the sensitivity analyses performed in Sections 2.5 and 2.6.

Assessment of redox measurements in groundwater samples indicates that there are reducing conditions in the fractured volcanic aquifer to the east and south of Yucca Mountain. The most likely reductant responsible for these conditions is pyrite in the volcanic units (particularly the Tram Tuff). Although groundwater samples come from fractures in the volcanic units of the SZ, reducing conditions probably also exist in the rock matrix, given the inferred role of pyrite in controlling the redox conditions. The conceptual model of redox conditions in the SZ includes a "curtain" of reducing conditions to the east and south of Yucca Mountain extending from the water table into the older volcanic units. This curtain is located such that all or most of the flow pathways from beneath the repository in the SZ would encounter it. There is also a (strata-bound) reducing zone in the lower Tram Tuff that results from the presence of primary pyrite. Oxidizing conditions are presumed to occur elsewhere in the SZ flow system, including the shallow volcanic units elsewhere, the regional carbonate aquifer, and the alluvium along the flow paths to the accessible environment. Although, reducing conditions in alluvium have been inferred in several Nye County wells, they have not been observed in wells completed in the alluvium along the predicted SZ flow paths from beneath the repository, with the possible exception of one zone in well NC-EWDP-19D.

Where reducing conditions exist in the SZ, the transport of redox-sensitive species would be subject to potential precipitation due to lower solubility and enhanced sorption due to higher sorption coefficients under reducing conditions. It is assumed that chemical equilibrium would exist in reducing zones with regard to aqueous speciation of radionuclides, precipitation and dissolution, and sorption. Precipitation of radionuclides in fractured volcanic units could occur in the fractures and in the rock matrix. However, it is anticipated that precipitation would occur primarily in the fractures because redox-sensitive radionuclides would be transported into zones of reducing conditions via fracture flow. It is assumed that radionuclides precipitating from the aqueous phase due to lower solubility limits in the reducing zones would be immobilized (at least temporarily) by direct precipitation or co-precipitation as mineral coatings on fracture surfaces or within matrix pores. Enhanced sorption would occur in the rock matrix of volcanic units in the SZ. As with sorption under oxidizing conditions, in radionuclide transport modeling, sorption is assumed to occur only in the matrix and not on fracture surfaces. As a result, this conceptual model requires diffusion of radionuclides into the rock matrix for access to the enhanced sorption therein.

There are some potentially significant uncertainties in this conceptual model that are not implemented in the sensitivity analyses in this report. A general spatial distribution of reducing 
conditions in the volcanic aquifer near Yucca Mountain has been defined, but there could be greater spatial heterogeneity in redox conditions than is represented in the sensitivity analyses. Due to uncertainties in the interpretations of chemical data and to limited data resolution, the spatial structure of redox conditions could be more complex. In particular, there could be areas of local oxidizing conditions within the reducing curtain and there could be isolated zones of reducing conditions within the generally oxidizing zones of the aquifer. Another conceptual uncertainty is the nature of the precipitation process for radionuclides in reducing zones. It is assumed that the precipitate would be immobile, but precipitation as or onto colloids is a possible process that potentially could allow further migration of radionuclides. These conceptual uncertainties could be addressed through additional analyses of existing data and more complex modeling.

\subsection{ANALYSIS OF SENSITIVITY TO SOLUBILITY LIMITS}

This section examines the sensitivity of radionuclide transport simulations to solubility limits in the SZ at Yucca Mountain. A simplified approach is presented to assess the relation between radionuclide mass input, the volumetric groundwater flow rate in the $\mathrm{SZ}$, and solubility limits. A one-dimensional reactive transport model for the $\mathrm{SZ}$ is also developed to explicitly simulate the coupled processes of radionuclide precipitation, matrix diffusion, and sorption. These analytical approaches are applied to the SZ using predicted radionuclide release rates from the repository and unsaturated zone (UZ) systems. Results are discussed with regard to the potential significance of solubility limits to radionuclide transport in the SZ.

\subsubsection{General Sensitivity to Solubility Limits in the Saturated Zone}

This section presents a general analysis of the sensitivity to solubility limits in the SZ, specifically the potential for technetium solubility to be limited under reducing conditions along a flow path. This simplified analysis is based on a groundwater flow tube and calculates the average concentration of the radionuclide from the mass input rate and the volume flow rate of groundwater. The calculated average radionuclide concentration is greater for larger radionuclide mass input or for smaller flow tube cross-sectional area (and correspondingly lower volumetric groundwater flow rate).

\subsubsection{Analytical Approach}

This simplified analytical approach is limited in several ways. The average radionuclide concentration is calculated at the scale of each groundwater flow tube. Due to the natural heterogeneity in the system, any variations in concentration within the flow tube that are not taken into account could result in concentrations exceeding the solubility limit at a local scale, thereby resulting in some precipitation. This effect would not be captured in the analysis, but would yield lower radionuclide concentrations downstream. Also, this analysis does not consider variations in radionuclide concentration between fractures and matrix during transport through fractured media. For example, radionuclide concentrations could be significantly higher in the flowing fractures than in the surrounding rock matrix. In addition, this simplified analysis does not account for the process of sorption, which would result in lower concentrations in groundwater due to the removal of radionuclide mass from the aqueous phase by sorption onto mineral grains. At equilibrium, sorption is a competitive process with precipitation. 
Consequently, the simplified analytical approach described here overestimates the potential for precipitation of radionuclides that also experience sorption.

The release rate of a radionuclide into the $\mathrm{SZ}$ required to exceed a particular value of the solubility limit can be calculated as a function of the volumetric groundwater flow rate into which the radionuclide mass is released. These relationships are shown for ${ }^{99} \mathrm{Tc}$ in Figure $2.5-1$ for a range of values of the solubility limit. As an example, Figure 2.5-1 indicates that for a flow tube having a groundwater flow rate of 10 acre- $\mathrm{ft} / \mathrm{yr}\left(12,335 \mathrm{~m}^{3} / \mathrm{yr}\right)$ and if the solubility limit of technetium is $1 \times 10^{-8} \mathrm{M}$ at some location in the flow tube, then the input of ${ }^{99} \mathrm{Tc}$ would have to exceed about $2 \times 10^{-1} \mathrm{Ci} / \mathrm{yr}$ for precipitation to occur at that location within the flow tube. Note that these relationships are calculated using the value of specific activity of $1.68 \mathrm{Ci} / \mathrm{mol} \mathrm{for}{ }^{99} \mathrm{Tc}$ (Wilson et al. 1994 [DIRS 100191]).

\subsubsection{Volumetric Groundwater Flow Rate}

The volumetric groundwater flow rate that is appropriate for the analysis depends on the scale under consideration. The representative volumetric flow rate of $3,000 \mathrm{acre}-\mathrm{ft} / \mathrm{yr}\left(4 \times 10^{5} \mathrm{~m}^{3} / \mathrm{yr}\right)$ given in the regulations (10 CFR 63.332 [DIRS 156605]) is an upper bound to the volumetric flow rate. However, this annualized volumetric flow rate for discharge to the biosphere exceeds both the entire volume of contaminated groundwater in the $\mathrm{SZ}$ and the volume flow rate through the all model cells on the $18-\mathrm{km}$ compliance boundary that convey contaminated groundwater. A more appropriate volumetric flow rate would be related to the amount of groundwater carrying contaminants into the SZ from the UZ.

The approximate volumetric flow rate of groundwater recharging the SZ under the general outline of the repository is 28 acre- $\mathrm{ft} / \mathrm{yr}$ under present-day climatic conditions, as simulated by the 2003 UZ site-scale flow model (DTN: SN0407T0504404.002 [DIRS 170929]). The outline of the repository is taken from the bounds of the SZ source regions used in the SZ transport abstraction model (BSC 2005 [DIRS 174012]). Under glacial-transition climatic conditions, the volume of groundwater simulated to recharge the SZ beneath the repository would be about 3.9 times greater (110 acre-ft/yr). During transport in the SZ, the volume of contaminated groundwater relative to the volumetric flow rate recharging beneath the repository would increase with transport distance due to transverse dispersion. However, the small values of transverse dispersivity used in radionuclide transport modeling (BSC 2005 [DIRS 174012]) suggest that transverse spreading and dilution would not be significant.

The appropriate value of volumetric groundwater flow could be significantly smaller than the estimated recharge for the footprint of the repository early in the postclosure history, when radionuclides would be leaking from only few waste packages. It is difficult to estimate the appropriate volumetric flow rate for a flow tube in the SZ from a single leaking waste package, but it could be smaller than 1 acre-ft/yr.

Taken together, this information on volumetric groundwater flow rates in flow tubes from the repository suggests that a range of 1 to $100 \mathrm{acre}-\mathrm{ft} / \mathrm{yr}$ would be appropriate to consider in this simplified analytical approach. The lower limit is appropriate when radionuclide mass would be coming from a few leaking waste packages, most likely in the first few thousand to 10,000 years. 
The upper bound is reasonable when radionuclide mass would be coming from numerous leaking waste packages and during wetter climatic conditions, such as the glacial-transition climate.

\subsubsection{Radionuclide Mass Release Rate}

The release rates for radionuclide mass have been estimated in TSPA-LA simulations for 20,000 years following repository closure (BSC 2005 [DIRS 174227]). Estimates of release rates have been made out to 100,000 years in the TSPA-SR (CRWMS M\&O 2000 [DIRS 153246]). The simulated peak release rate of ${ }^{99} \mathrm{Tc}$ from the UZ to the SZ from these performance assessment analyses is shown in Table 2.5-1.

This information on predicted ${ }^{99} \mathrm{Tc}$ release rate provides an indication of the range of values that may be relevant to TSPA calculations with regard to radionuclide precipitation in reducing zones in the SZ. It should be noted that the TSPA calculations are probabilistic, with the range of results from Monte Carlo realizations incorporating uncertainty in input parameters. Consequently, solubility limits could be significant in some realizations, but not in others. The results presented in Table 2.5-1 are generally for the mean peak simulated releases from the UZ for the specified scenarios. The results for the $95^{\text {th }}$ percentile for the nominal early failure modeling case are documented for the TSPA-LA, giving some indication of how the upper tail of the results may vary among the realizations.

Note that for TSPA-LA, the predicted mean peak release rates from the UZ are higher for the igneous intrusion modeling case and the seismic mechanical damage modeling case than for the nominal early failure modeling case, for ${ }^{99} \mathrm{Tc}$. The mean release rates for the nominal scenario in TSPS-SR at 100,000 years are the highest among all the cases shown in Table 2.5-1.

\subsubsection{Implications for Radionuclide Precipitation in the SZ}

The estimates of peak simulated radionuclide releases to the SZ in Table 2.5-1 can be used with the relationships shown in Figure 2.5-1 for the expected value of solubility, to determine the maximum volumetric groundwater flow rate at which radionuclide precipitation might occur. This provides a first-order assessment of the potential relevance of solubility limits to radionuclide transport in the $\mathrm{SZ}$.

The estimated values of the maximum volumetric groundwater flow rate at which ${ }^{99} \mathrm{Tc}$ precipitation could occur are determined from Figure 2.5-1 by plotting the estimated release rates from Table 2.5-1 on the $y$-axis and finding the corresponding values of volumetric flow rate given the estimated solubility limit of $4 \times 10^{-9} \mathrm{M}$ from Section 2.2. The mean peak simulated release rate for the TSPA-LA nominal early failure modeling case corresponds to volumetric groundwater flow rates of less than $1 \mathrm{acre}-\mathrm{ft} / \mathrm{yr}$. The mean peak UZ release rates for ${ }^{99} \mathrm{Tc}$ from the TSPA-LA igneous intrusion modeling case and seismic mechanical damage modeling case, and the TSPA-SR nominal scenario correspond to volumetric flow rates of about 7 acre-ft/year, $50 \mathrm{acre}-\mathrm{ft} /$ year, and $120 \mathrm{acre}-\mathrm{ft} /$ year, respectively. These results suggest that precipitation of ${ }^{99} \mathrm{Tc}$ in reducing zones in the $\mathrm{SZ}$ could be a significant process in the disruptive scenarios in TSPA-LA or at longer times as represented in the TSPA-SR nominal scenario.

It should be noted that in the TSPA realizations with releases above the $95^{\text {th }}$ percentile, the release rates could be more than an order of magnitude greater. Taking this into consideration, 
the release rate of ${ }^{99} \mathrm{Tc}$ for the TSPA-LA nominal early failure modeling case and seismic mechanical damage modeling case, respectively, could correspond to volumetric flow rates of greater than 1 acre- $\mathrm{ft} / \mathrm{yr}$ at the solubility limit and thus potentially be subject to precipitation in the SZ. It should also be noted, in a contrary fashion, the competing effects of enhanced sorption of ${ }^{99} \mathrm{Tc}$ could lower concentrations to the point at which precipitation would not occur.

Overall, this analysis indicates that the impacts of solubility limits in reducing zones in the SZ could have an impact on the simulations of ${ }^{99} \mathrm{Tc}$ transport in TSPA calculations.

\subsubsection{Reactive Transport Model Setup}

Radionuclide transport subject to the combined effects of solubility-limited transport behavior and sorption has not been examined to date. The following sections examine the sensitivity of radionuclide transport in the $\mathrm{SZ}$ to redox conditions by explicitly simulating solubility limits and enhanced sorption using a one-dimensional streamtube model extracted from the site-scale SZ transport model. These reactive transport processes are modeled in combination with the process of matrix diffusion for the fractured tuff units. These sensitivity analyses use representative flow and transport parameter values under oxidizing and reducing conditions and possible values for input concentrations of radionuclides from the UZ based on the assessments presented above.

Performing reactive transport simulations at the complexity required for this analysis on the full three-dimensional SZ flow and transport model is impractical due to computational burden and time constraints. Therefore, a one-dimensional streamtube model approach is used in these analyses. In this method, a representative pathway from the full model is extracted, "straightened" into a one-dimensional path, and reactive transport simulations are conducted. This simplified approach is often advocated in the literature as a practical alternative to large-scale simulation in full three-dimensional models (e.g., Simmons et al. 1995 [DIRS 172719]; Ginn 2001 [DIRS 172726]). The strengths of the method are the simplification of the computational problem and the minimization of numerical dispersion artifacts that plague reactive transport problems in large-scale numerical models. However, the streamtube approximation yields a simplification that neglects transverse mixing and mixing of fluids with different transport times and aqueous concentrations. For a more complete analysis, full three-dimensional approaches or simplified micromixing models (e.g., Robinson and Viswanathan 2003 [DIRS 172724]; Viswanathan and Valocchi 2004 [DIRS 172725]) are possible. These approaches should be considered in a follow-on to this study. Nevertheless, calculations presented herein are useful for examining, to first order, the behavior of ${ }^{99} \mathrm{Tc}$ should it encounter a reducing zone.

The approximation for the one-dimensional pathway used for this reactive transport streamtube model is based on the SZ one-dimensional transport model formulation (BSC 2005 [DIRS 174012]). In that report, a set of one-dimensional models was developed to simulate decay-chain transport of multiple radionuclides, because these species could not be treated using the convolution method used for other radionuclides. The pathway called "Source Region 1" is used as the basis for the pathway. In this path, distinct zones were established along the pathway from the source $(x=0)$ to $5,000 \mathrm{~m}$, from $5,000 \mathrm{~m}$ to $18,500 \mathrm{~m}$, and from $18,500 \mathrm{~m}$ to the compliance boundary at $22,500 \mathrm{~m}$. Note that this pathway is somewhat longer than the nominal $18-\mathrm{km}$ distance from the repository to the compliance boundary to account for the curved 
Impacts of Solubility and Other Geochemical Processes on Radionuclide Retardation in the Natural System

pathline predicted by the SZ transport model. The first two zones are fractured volcanic tuff zones, and the third zone represents flow and transport through the alluvium.

To represent the presence of a reducing zone where solubility and sorption reactions are present under reducing conditions, a $1,000-\mathrm{m}$ zone from $5,100 \mathrm{~m}$ to $6,100 \mathrm{~m}$ is established. This zone roughly corresponds to the thickness of the "curtain" where reducing conditions are present.

In all fractured volcanic rock zones, the Generalized Dual Porosity Model option in FEHM, Version 2.20 [DIRS 161725] is used. This conceptual model assumes that flow occurs through a primary porosity, in this case the fracture network in these rocks. Radionuclides advect along the fractures and diffuse into the surrounding rock matrix, which is conceptualized as a zone in which one-dimensional transport occurs perpendicular to the flow direction from the fracture to the half-distance to the adjacent fracture. A local one-dimensional grid of computational cells is assumed in the matrix, starting at a $0.001 \mathrm{~m}$ spacing next to the primary porosity zone and increasing to $5 \mathrm{~m}$ at the centerline between fractures. With this matrix grid discretization, the code can simulate sharp concentration gradients into the rock matrix. In these simulations, the alluvium is a single continuum and the fractured volcanics are dual-porosity.

In the three-dimensional flow and transport model, converging flow at downstream locations along the flow path result in a higher specific discharge near the end of the path. This effect must be taken into account for to obtain accurate relative transport times in the different zones. To accomplish this, specific discharge and inlet water flow rate are set to achieve the correct specific discharge at the inlet $(0.685 \mathrm{~m} / \mathrm{yr})$, for an assumed cross-sectional area of $1 \mathrm{~m}^{2}$. Then, the cross-sectional areas of the path are reduced in the other two zones of the model to achieve the specific discharge values of $2.52 \mathrm{~m} / \mathrm{yr}$ for zone 2 and $2.71 \mathrm{~m} / \mathrm{y}$ in zone 3 . In this way, the streamtube can be modeled as a closed system, yet it approximates the spatially varying velocities in the full three-dimensional model.

A steady state flow path in the model is established in a preliminary run where the permeabilities are set to values typical of the primary porosity for the media, and to a low value for the matrix. This approach maintains the assumption that flow in the matrix is negligible compared to fracture flow (this assumption is present in all SZ transport modeling to date). Transport is simulated by injecting radionuclide at the top of the SZ beneath the UZ, and recording concentration versus time at the compliance boundary. The reactive transport module of FEHM [DIRS 161725] is used to simulate sorption and solubility-limited precipitation-dissolution reactions. For sorption, the linear kinetic sorption model (FEHM Reaction type 1) is used, and large kinetic constants are selected to simulate equilibrium sorption. Therefore, sorption in the matrix is modeled assuming an effective $K_{d}$. Sorption is assumed negligible on fracture surfaces and sorption in the reducing zone has $K_{d}=50 \mathrm{~mL} / \mathrm{g}$. For ${ }^{99} \mathrm{Tc}$, sorption in the matrix is neglected for regions outside the reducing zone, including the alluvium. Solubility-limited behavior is modeled using a dissolution-precipitation reaction (FEHM reaction type 7) applied only within the reducing zone. Fast kinetics are also assumed for this reaction. The reaction is $R n(a q) \Leftrightarrow R n(s)$, where $R n(a q)$ is ${ }^{99} \mathrm{Tc}$ or ${ }^{237} \mathrm{~Np}$ in the aqueous phase, and $R n(s)$ is the precipitated solid. The complex chemistry associated with this reaction is modeled simply as a reaction that proceeds rapidly to equilibrium with a solubility product equal to the concentration of the radionuclide in the reducing zone. The aqueous concentration is the same concentration used in the sorption reaction mentioned above, whereas separate solid species are assumed for 
the sorption and precipitation-dissolution reactions. When fluid enters the reducing zone at a concentration greater than the solubility, precipitation will occur. Conversely, if at any point in the model run the concentration of the precipitated solid is present is lower than the solubility limit, dissolution occurs. In other words, the reaction is assumed to be reversible and controlled by the aqueous concentration and the presence or absence of the solid species. Finally, although radioactive decay could have been included in these runs, it was neglected because for these radionuclides, the half-lives are much longer than the characteristic transport times through the streamtube.

\subsubsection{Transport Simulation Results with Solubility Limits}

Breakthrough curves for ${ }^{99} \mathrm{Tc}$ are presented in Figure 2.5-2 representing concentration versus time at the entrance to the redox zone (solid curves) and at the compliance boundary (dashed curves). A simulation with sorption $\left(K_{d}=50 \mathrm{~mL} / \mathrm{g}\right)$ and solubility-limited reaction (solubility of $4 \times 10^{-9} \mathrm{M}$ ) in the reducing zone (black curves), and a simulation with sorption in the reducing zone, but no solubility-limited reaction (red and green curves) are shown. The left $y$-axis applies to the case with solubility-limited reaction and sorption, and the right axis applies to the cases with no solubility-limited reaction. The most important difference in the simulations is the much lower concentration at the compliance boundary (outlet concentration) for the solubility-limited case (dashed black curve). Radionuclides, upon reaching the reducing zone, precipitate onto the rock so that the aqueous concentration decreases to the solubility limit of $4 \times 10^{-9} \mathrm{M}$. Technetium concentration from this point to the compliance boundary must be lower that this limit even though the injection concentration is $5 \times 10^{-7} \mathrm{M}$, two orders of magnitude greater. Sorption also reduces the travel velocities compared to that of a nonsorbing radionuclide (green curves). A comparison of the dashed green and dashed red breakthrough curves shows that the effect of sorption is rather small in this simulation. This is a result of the short reducing zone length to total path length ratio, and there is no sorption in the rest of the path. Thus, sorption acts to retard radionuclide transport only during a small portion of the total travel time. Sorption occurs in the matrix of the fractured volcanics and not in the porous continuum, so increased sorption in the reducing zone plays a secondary role only after radionuclides have diffused from the fractures into the matrix. Breakthrough at the compliance boundary still occurs well before 10,000 years, even for a $K_{d}$ value of $50 \mathrm{~mL} / \mathrm{g}$.

It is perhaps unexpected that the normalized breakthrough with no solubility limit (red dashed) appears to have a somewhat longer transport time than for the case with solubility-limited precipitation (black dashed). That is, although the scales for the axes on which these curves are plotted differ, it remains clear that the time for 50 percent breakthrough for transport with no solubility limit is longer than that for the case with solubility limited precipitation. The reason for this behavior is related to the concentration versus time behavior at the entrance to the reducing zone, illustrated with the solid red and solid black curves on Figure 2.5-2. With solubility-limited reaction, the time required for this concentration to reach the solubility limit (and thus the maximum input concentration) is short and the curve is attenuated by more than two orders of magnitude shortly after first arriving at the reducing zone. In contrast, breakthrough at this location (time to reach maximum input concentration) for the case of no solubility limit occurs over the entire 10,000-year simulation period, due to the impact of matrix diffusion and dispersion. Therefore, the differences of the normalized curves are due to different 
normalized breakthrough curves at the entrance of the reducing zone, rather than to any differences in the transport behavior through the rest of the streamtube.

Radionuclide releases are not necessarily constant over the model time period, so this effect must also be examined. To study the influence of transient concentration inputs, a series of simulations were carried out where the radionuclide is input only for a specified duration, rather than for the entire simulation. Once the radionuclide has been input for a specified duration, the inlet concentration thereafter is assumed to be zero. Figures 2.5-3 and 2.5-4 show the influence of input duration on the breakthrough curve at the outlet (Figure 2.5-3) and at the entrance to the reducing zone (Figure 2.5-4) for ${ }^{99} \mathrm{Tc}$ (all other reactive transport parameters are the same as those in Figure 2.5-2). For a duration of 1 year for the inlet injection of ${ }^{99} \mathrm{Tc}$, the concentration at the reducing zone never reaches $4 \times 19^{-9} \mathrm{M}$, the value at which precipitation occurs. Under these conditions, ${ }^{99} \mathrm{Tc}$ transports without precipitation, and sorption is the only retardation mechanism in the reducing zone. In contrast, the 10-year input function results in precipitation at the reducing zone. However, once the source is exhausted, dissolution of the previously precipitated ${ }^{99} \mathrm{Tc}$ occurs until this new source, located at the entrance to the reducing zone, is depleted. After this time, concentrations decline in the breakthrough at the compliance boundary. The duration over which dissolution occurs is a linear function of the ratio of the injection concentration to the solubility limit. This ratio, $R$, can be used to define the mass fraction that accumulates as a solid in the reducing zone via the equation $1-R^{-1}$. If the source concentration is less than the solubility, no accumulation occurs and the equation does not apply. For longer source durations, the precipitated ${ }^{99} \mathrm{Tc}$ is not depleted by dissolution even after 10,000 years, so the breakthrough curves at the compliance boundary are identical to those of the constant duration case.

These results indicate that that precipitation does not behave as an irreversible retardation mechanism, in that the radionuclide can re-dissolve when the source of radionuclides upstream of the reducing zone is exhausted. The principle impact of solubility-limited reaction is to attenuate the maximum downstream concentration at the solubility limit, but radionuclide mass is not removed from the system. The mass that precipitates is delayed until it can become remobilized by dissolution. Remaining mass present at the solubility limit during periods of precipitation is subject to sorption in the reducing zone. Despite the fact that precipitation could be reversible under certain circumstances, solubility-limited behavior is potentially important to performance because the dose contribution of a radionuclide is directly proportional to the concentration at the compliance boundary.

The influence of the sorption coefficient in the reducing zone on the breakthrough curve at the compliance boundary is examined in Figure 2.5-5. As expected, increasing $K_{d}$ in the reducing zone leads to longer breakthrough times. As discussed earlier, the effect is somewhat diminished because of the short length of the pathway under reducing conditions $(1,000 \mathrm{~m})$ compared to the total length of the streamtube. Nevertheless, for the largest $K_{d}$ values, a significant fraction of the ${ }^{99} \mathrm{Tc}$ is delayed to times greater than 10,000 years. This effect is examined more thoroughly in the three-dimensional modeling presented in Section 2.6.3. Finally, to allow for the possibility of longer path lengths under reducing conditions, a sensitivity study was conducted for ${ }^{99} \mathrm{Tc}$ in which this length was varied from $1,000 \mathrm{~m}$ (the simulations above) to a maximum value of $5,000 \mathrm{~m}$. As expected, the transport times increase considerably for the longer path in the reducing zone (Figure 2.5-6). This effect is completely due to sorption because precipitation 
influences all of the breakthrough curves similarly, by lowering the concentrations downstream of the reducing zone.

Sensitivity to the length of the reducing zone highlights an important conclusion: the influence of precipitation relies solely on the presence of a reducing zone through which radionuclides pass, rather than on the size of that zone. Specifically, the existence of the reducing zone is critical because it induces precipitation, but its extent is only important in so far as its impact on increased sorption. As long as the kinetics of precipitation are rapid, precipitation will lower downstream concentration (if the upstream values are greater than the solubility limit). . Thus, downstream radionuclide concentrations will be primarily sensitive to the presence of the reducing zone and only secondarily sensitive to its extent. Increased sorption in the reducing zone impacts transport times, but in a manner that depends on the size of the reducing zone, the magnitude of the sorption coefficient, and, for the fractured volcanic tuffs, the diffusion parameters in the dual porosity system (diffusion coefficient, aperture, and fracture spacing). In general, a more extensive reducing zone will reduce radionuclide concentrations, but this effect is secondary to the presence of the zone, which precipitates radionuclides and significantly reduces their concentrations.

The relative importance of the solubility limit and enhanced sorption in a reducing zone along the flowpath in the SZ depends on the radionuclide concentration entering the reducing zone. If the concentration is below the solubility limit under reducing conditions, then precipitation would not occur and the solubility limit would have no impact on migration of the radionuclide. Enhanced sorption, however, would still retard the transport of the radionuclide to the accessible environment under these conditions. If the concentration is above the solubility limit under reducing conditions, then both processes are operative. The concentration reduction factor (reduction in radionuclide release rate downstream) is equal to the ratio of the incoming concentration to the solubility limit. It should be noted that radionuclide mass precipitated in the reducing zone would be remobilized for transport when input concentrations fall below the solubility limit. If the incoming radionuclide concentration greatly exceeds the solubility limit by a large amount, then precipitation would be the dominant process attenuating radionuclide releases in the reducing zone. If the incoming radionuclide concentration is near or below the solubility limit under reducing conditions, then enhanced sorption would be the dominant retardation process.

\subsection{ANALYSIS OF SENSITIVITY TO SORPTION}

An effective $K_{d}$ approach is used to examine the general sensitivity of enhanced sorption in the $\mathrm{SZ}$ due to locally reducing conditions. This simplified approach relates the effective sorption along the entire flow path in the SZ to the fraction of the flow path with reducing conditions and corresponding enhanced sorption. This analysis yields an approximate evaluation of the impact on radionuclide transport due to the presence of a localized reducing zone.

Explicit simulation of radionuclide transport with a zone of reducing conditions and enhanced sorption was conducted using the three-dimensional site-scale SZ transport model (BSC 2004 [DIRS 170036]). Simulations were performed to study the sensitivity of breakthrough curves (at the boundary to the accessible environment) to the sorption coefficients of neptunium and technetium expected to occur under reducing conditions. The transport model parameter 
expected to be most sensitive to redox conditions is the sorption coefficient $\left(K_{d}\right)$. As discussed in Section 2.3, compared to oxidizing conditions, the sorption coefficient for neptunium and technetium can increase by many orders of magnitude under reducing conditions. The base-case site-scale SZ transport model (BSC 2004 [DIRS 170036]) uses $K_{d}$ values for various radionuclides assuming that redox conditions are oxidizing along the entire flow path. This assumption was modified by assigning higher $K_{d}$ values appropriate for reducing conditions to a portion of the transport flow path. Note that sorption in the volcanic units in this model is only in the rock matrix, sorption onto fracture surfaces is neglected.

\subsubsection{Effective Sorption Coefficient}

This section examines the general sensitivity of SZ transport to the presence of an enhanced sorption zone along the flow path from the repository to the accessible environment. General relationships between the fraction of the flow path subject to enhanced sorption, the contrasting values of the sorption coefficient, and a representative effective sorption coefficient for the entire flow path are developed.

To evaluate the impacts of enhanced sorption in zones with reducing conditions, consider a simplified, one-dimensional flow path where flow and radionuclide transport occur in a porous medium and that the flow path consists of two zones, one with reducing conditions and the other with oxidizing conditions. Furthermore, it is assumed that groundwater flow velocity, porosity, and bulk density are constant along the flow path. The configuration of this one-dimensional flow path and parameters of the system are shown in the schematic diagram in Figure 2.6-1.

The total transport time for a nonsorbing solute is the sum of the transport times through the reducing zone and the oxidizing zone:

$$
t_{\text {total }}^{c}=t_{r}^{c}+t_{o}^{c}
$$

where

$$
\begin{array}{ll}
t_{\text {total }}^{c} & =\text { total transport time with no sorption, } \\
t_{r}^{c} & =\text { transport time through reducing zone with no sorption, } \\
t_{o}^{c} & =\text { transport time through oxidizing zone with no sorption. }
\end{array}
$$

For a sorbing solute, Equation 2.6-1 can be modified using the retardation factors for the reducing zone and the oxidizing zone and a value of the effective retardation factor for the entire flow path can also be used to modify the total transport time.

$$
R_{f}^{e f f} t_{\text {total }}^{c}=R_{f}^{r} t_{r}^{c}+R_{f}^{o} t_{o}^{c}
$$

where

$$
R_{f}^{r}=\text { retardation factor in the reducing zone, }
$$


$R_{f}^{o}=$ retardation factor in the oxidizing zone,
$R_{f}^{e f f}=$ effective retardation factor for the entire flow path.

Equation 2.6-2 can be rewritten using the relationships between transport time for a nonsorbing solute, length, and groundwater velocity:

$$
R_{f}^{e f f}\left(\frac{L}{v}\right)=R_{f}^{r}\left(\frac{L\left(x_{r}\right)}{v}\right)+R_{f}^{o}\left(\frac{L\left(1-x_{r}\right)}{v}\right)
$$

where

$$
v \quad=\text { groundwater velocity. }
$$

Equation 2.6-3 can be simplified to yield the effective retardation factor for the entire flow path as a linear combination of the retardation factors in the reducing zone and the oxidizing zone, and proportional to the fraction of flow path under each condition.

$$
R_{f}^{e f f}=x_{r} R_{f}^{r}+\left(1-x_{r}\right) R_{f}^{o}
$$

Using the standard definition of the retardation factor for linear sorption, Equation 2.6-4 can be rewritten as

$$
1+\frac{\rho_{b} K_{d}^{\text {eff }}}{\phi}=x_{r}\left(1+\frac{\rho_{b} K_{d}^{r}}{\phi}\right)+\left(1-x_{r}\right)\left(1+\frac{\rho_{b} K_{d}^{o}}{\phi}\right)
$$

where

$$
\begin{array}{ll}
R_{f} & =\text { retardation factor } \\
\rho_{b} & =\text { bulk density } \\
\phi \quad & =\text { porosity } \\
K_{d}^{e f f} & =\text { effective sorption coefficient for the flow path }
\end{array}
$$

The effective sorption coefficient for the flow path is a linear combination of the sorption coefficients in the reducing and oxidizing zones, and proportional to the fraction of flow path under each condition:

$$
K_{d}^{e f f}=x_{r} K_{d}^{r}+\left(1-x_{r}\right) K_{d}^{o},
$$

Equation 2.6-6 can be plotted as a series of type curves for each sorption coefficient in the reducing zone as shown in Figure 2.6-2. Each type curve shows the effective sorption coefficient for the entire flow path as a function of the fraction of the flow path with reducing conditions for technetium with $K_{d}$ ranging from 1 to $1,000 \mathrm{~mL} / \mathrm{g}$. Figure 2.6-3 and Figure 2.6-4 
show type curves of effective sorption coefficient for neptunium under oxidizing conditions equal to those expected in the volcanic units and in the alluvium, respectively.

The results shown in Figures 2.6-2 through 2.6-4 show that even for a small fraction of the flow path through reducing geochemical conditions, the effective sorption coefficient for the entire flow path is significantly higher. The steep rise in the effective sorption coefficient with increasing fraction of the flow path length at small values of the fraction is illustrated. For example, Figure 2.6-2 indicates that if the sorption coefficient for technetium is $1,000 \mathrm{~mL} / \mathrm{g}$ under reducing conditions and 5 percent of the flow path is reducing, that this is equivalent to an effective sorption coefficient of $50 \mathrm{~mL} / \mathrm{g}$ for the entire flow path.

\subsubsection{Saturated Zone Site-Scale Transport Model Setup}

As discussed in Section 2.1, redox measurements show that SZ groundwaters in the volcanic zones directly to the east and south of the repository footprint at the Yucca Mountain are in reducing states. A continuous zone is defined and incorporated into the site-scale SZ transport model as a curtain of reducing redox conditions. The eastern boundary of the curtain is taken just to the east of the well WT-12, the southern boundary is taken just to the south of the well WT-12, western boundary is taken just to the east of the well H-3 but to the west of the south-east corner of the repository footprint, and the northern boundary of the curtain is taken between the wells b\#1 and H-4. The curtain is shown by dashed red line in Figure 2.6-5 and coordinates of the region are given in Table 2.6-1. This curtain has a north-south extent of $9,047 \mathrm{~m}$ and an east-west width of $2,286 \mathrm{~m}$. For the sake of sensitivity analysis, another curtain was also considered with the same boundaries to the north, south and west, but with the eastern boundary adjusted to yield a width of $1,000 \mathrm{~m}$.

The base-case sorption coefficient for technetium was taken to be 0 (BSC 2004 [DIRS 170036], Table C-14). The base-case sorption coefficient for neptunium was taken to be $1.3 \mathrm{~mL} / \mathrm{g}$ in the volcanics and $6.3 \mathrm{~mL} / \mathrm{g}$ in the alluvium (BSC 2004 [DIRS 170036], Section 6.8 .2 and Table C-14). As discussed in Section 3.3, the sorption coefficient for both technetium and neptunium under fully reducing conditions is on the order of $1,000 \mathrm{~mL} / \mathrm{g}$ (base case). Also, lower values of $50 \mathrm{~mL} / \mathrm{g}$ for technetium and $200 \mathrm{~mL} / \mathrm{g}$ for neptunium were used for sensitivity analyses. These lower values correspond to the more conservative estimates of $K_{d}$ under reducing conditions used in performance assessment analyses by Vieno and Nordman (1999 [DIRS 172783], Table 11-9).

These simulations were performed using the three-dimensional base-case site-scale SZ transport model (BSC 2004 [DIRS 170036]; DTN: LA0306SK831231.001 [DIRS 164362]). It should be noted that this model is for expected groundwater flow under present-day climatic conditions. The file 02_calib_basecase.dat was modified to define the redox curtain zone. To assess the sensitivity of the breakthrough curves to the geometry of the redox curtain, two suites were run: one with a curtain width of $2,286 \mathrm{~m}$ and another with a curtain width of $1,000 \mathrm{~m}$. The file sptr 100 basecase.macro was modified to include appropriate values of the sorption coefficient in the redox curtain for each case. The porosity of the curtain zones was chosen to lead to a 50 percent breakthrough time of approximately 705 years for the base case without sorption. Note that the base-case simulation for technetium was done with $K_{d}=0$, everywhere, while the base-case simulation for neptunium was done with a sorption coefficient of $1.3 \mathrm{~mL} / \mathrm{g}$ in the 
volcanic matrix and $6.3 \mathrm{~mL} / \mathrm{g}$ in the alluvium. These runs, along with 50 percent breakthrough times, are summarized in Table 2.6-2.

\subsubsection{Transport Simulation Results with Sorption}

The 50 percent breakthrough times for all the simulations are summarized in Table 2.6-2. Figure 2.6-6 shows the breakthrough curves for technetium for the case of the wide reducing zone curtain. The base case with $K_{d}=0$ is shown for comparison along with the cases of $K_{d}=50$ and $1,000 \mathrm{~mL} / \mathrm{g}$. Note that in the volcanics, sorption is only in the rock matrix; sorption onto the fracture surfaces is neglected in this model. Figure 2.6-6 shows a dramatic influence on retardation due to radionuclide sorption in the volcanic matrix under reducing conditions for a wide redox curtain. Even for a moderate value of $K_{d}=50 \mathrm{~mL} / \mathrm{g}$, the 50 percent breakthrough time increases by more than a factor of 30 from a value of 700 years to 22,750 years. For a $K_{d}$ value of $1,000 \mathrm{~mL} / \mathrm{g}$, the value likely to be encountered in a fully reducing zone, the 50 percent breakthrough time increases even more dramatically to 404,300 years.

A comparison of the breakthrough curves for technetium with a wide redox curtain and $K_{d}=1,000 \mathrm{~mL} / \mathrm{g}$ for two different values of the matrix diffusion coefficient, $5 \times 10^{-12} \mathrm{~m}^{2} / \mathrm{s}$ (base case) and $5 \times 10^{-13} \mathrm{~m}^{2} / \mathrm{s}$, is shown in Figure 2.6-7. The sorption in the volcanics in this transport model is in the rock matrix only; sorption onto the fracture surfaces is neglected. Thus the breakthrough curves are expected to be sensitive to the parameters affecting the matrix diffusion, such as the matrix diffusion coefficient, matrix porosity, fracture aperture, and fracture porosity. As demonstrated in Figure 2.6-7, the 50 percent breakthrough time for the lower matrix diffusion is approximately an order of magnitude faster than that for the base case.

The results for technetium with a narrower redox zone (a width of $1,000 \mathrm{~m}$ ) are shown in Figure 2.6-8, for $K_{d}=0,50$, and $1,000 \mathrm{~mL} / \mathrm{g}$. Similar to the wide curtain, results for a narrower curtain also show a significant increase in the 50 percent breakthrough times, with a value in excess of 100,000 years for a $K_{d}=1,000 \mathrm{~mL} / \mathrm{g}$. Note that the width of the curtain has a significant impact on the breakthrough delay: an increase in the width by a factor of 2.3 leads to an increase in the delay time by a factor of 3 to 4 .

Results for neptunium with wide redox curtain are shown in Figure 2.6-9 for the cases of $K_{d}=200 \mathrm{~mL} / \mathrm{g}$ and $K_{d}=1,000 \mathrm{~mL} / \mathrm{g}$ for comparison, along with the base case with $K_{d}=1.3 \mathrm{~mL} / \mathrm{g}$ (volcanics) and $K_{d}=6.3 \mathrm{~mL} / \mathrm{g}$ (alluvium). Similar plots for neptunium with a narrow redox curtain are shown in Figure 2.6-10. Results comparable to those for technetium are exhibited: wider redox zones demonstrate increased breakthrough time. 


\section{CONCLUSIONS}

Delay in radionuclide release is affected by factors such as groundwater flow rates, the flow pathways, matrix diffusion in fractured volcanic rocks, sorption, and colloid filtration. Current SZ transport simulations incorporate these processes (BSC 2004 [DIRS 170036]; BSC 2005 [DIRS 174012]), but do not consider limits to radionuclide solubility or the potential impacts of variability in geochemical conditions on solubility and sorption. This study assessed the potential impacts of precipitation and enhanced sorption due to variations in redox conditions on radionuclide transport in the SZ. This work examined the distribution of redox conditions at Yucca Mountain, the relationships between sorption and redox conditions, developed the conceptualization of relevant processes, and analyzed model sensitivity to several input parameters. The potential implications of this study to performance assessment and recommendations for future work are presented.

Sensitivity analyses are conducted for enhanced sorption using the three-dimensional site-scale SZ transport model. Additional sensitivity analyses of radionuclide transport are conducted with a one-dimensional model that incorporate the processes of solubility limits and enhanced sorption. It should be noted that the schedule and resources allocated for this effort preclude an in-depth assessment that would be required for this work to be included in the TSPA model.

\subsection{Redox Conditions in the Saturated Zone}

Redox conditions in the SZ were examined through analysis of site-specific redox data. As Figure 2.1-2 demonstrates, the Yucca Mountain site is dominated, by oxidizing groundwaters. Reducing conditions are found directly east of Yucca Mountain and the available data suggest the existence of a north-south zone of reducing groundwaters in the volcanic units. This reducing zone cuts across the transport pathways from the repository predicted by the flow model. Measurements of redox conditions in alluvium along potential flow paths from the repository indicate that these are primarily oxidizing conditions. Core from selected boreholes has shown that the Tram Tuff contains primary pyrite and the amount of pyrite is sufficient to cause reducing conditions. Comparison of the average sulfate concentrations in the oxidizing wells to the reducing wells indicates that the average sulfate concentration in the reducing wells is higher by approximately the amount expected from reaction with pyrite in the system. This redox barrier in the lower Tram Tuff may retard the transport of redox-sensitive radionuclides to the deeper saturated zone. The redox barrier east of the repository footprint may retard the transport of redox-sensitive radionuclides eastward and possibly southward from the repository footprint.

\subsubsection{Solubility as a Function of Redox Conditions}

The solubility of technetium is redox sensitive and has dramatically different solubilities under oxidizing and reducing conditions. Solubility limits for technetium are needed to examine the impact of redox conditions on radionuclide transport in the SZ by explicitly simulating solubility limits and enhanced sorption using a one-dimensional streamtube model as discussed in Sections 2.5.2 and 2.5.3. 
The chemical equilibrium and speciation code EQ3 (BSC 2003 [DIRS 162228]) was used to determine solubility under specified conditions. The aqueous concentrations in equilibrium with a solid phase known to be controlling under reducing and oxidizing conditions, were individually simulated to derive the corresponding low-Eh solubility. Calculations were also done to evaluate transitions in solubility using the chemical reaction path code EQ6 (BSC 2003 [DIRS 162228]) for neptunium and technetium in solid and aqueous phases within the Eh interval of interest $(-800$ to $+800 \mathrm{mV})$.

The results of technetium solubility calculations are summarized in Table 2.2-2. Technetium solubility is not constrained when Eh is greater than $150 \mathrm{mV}$ to $360 \mathrm{mV}$. Technetium solubility rapidly decreases when Eh drops below this level and reaches its lower limit when Eh drops below -100 to $0.0 \mathrm{mV}$ (depending on $\mathrm{pH}$ ). The lower technetium solubility is $4 \times 10^{-13} \mathrm{M}$ with $\mathrm{TcO}_{2}$ as a controlling solid or $4 \times 10^{-9} \mathrm{M}$ with $\mathrm{TcO}_{2} \cdot 1.6 \mathrm{H}_{2} \mathrm{O}$ as a controlling solid. The lower solubility limits are independent of water composition and $\mathrm{pH}$. Comparison of these results with other studies in the literature regarding the range of estimated technetium solubility and critical Eh values indicate that the most likely controlling solid is $\mathrm{TcO}_{2} \cdot 1.6 \mathrm{H}_{2}$. Consequently, a value for technetium solubility of $4 \times 10^{-9} \mathrm{M}$ will be used within the reducing zone as input to the one-dimensional streamtube model to assess the impact of redox conditions on radionuclide transport in the SZ. Note, that the no solubility limits (infinite solubility) were applied to technetium in TSPA-LA calculations.

\subsubsection{Sorption as a Function of Redox Conditions}

Sorption coefficient distributions have been developed by BSC (2004 [DIRS 170036]) assuming redox conditions are oxidizing along potential flow paths to the accessible environment. However, redox field data discussed in Section 2.1 indicate that reducing conditions exist in some parts of the SZ flow field. Sorption coefficients for reducing conditions were developed for use in SZ transport simulations to assess the impact of reducing conditions on the transport of redox sensitive radionuclides. Sorption coefficients for reducing conditions were based on data reported by Lieser and Muhlenweg (1988 [DIRS 106684]) for neptunium, and Lieser and Bauscher (1987 [DIRS 172722]) for technetium. Surface complexation modeling was also performed to support the determination of sorption coefficients for neptunium under reducing conditions.

As discussed in Section 2.3, the sorption coefficients for neptunium and technetium can increase by many orders of magnitude under reducing conditions when compared to oxidizing conditions. Under reducing conditions, the neptunium sorption coefficient reported by Lieser and Muhlenweg (1988 [DIRS 106684]) is approximately $1,000 \mathrm{~mL} / \mathrm{g}$ and compares favorably to the surface complexation modeling results for neptunium of approximately $1,000 \mathrm{~mL} / \mathrm{g}$.

The average values of the technetium and neptunium sorption coefficients under reducing conditions are similar. The main differences based on the studies from Lieser and Muhlenweg (1988 [DIRS 106684]) and Lieser and Bauscher (1987 [DIRS 172722]) are that the average sorption coefficient under oxidizing conditions is lower for technetium $(0.1 \mathrm{~mL} / \mathrm{g})$ than for neptunium $(1 \mathrm{~mL} / \mathrm{g}$ to $4 \mathrm{~mL} / \mathrm{g})$ and the $\mathrm{Eh}$ value at which there is a step in the sorption coefficient distribution is lower for technetium (approximately $150 \mathrm{mV}$ ) than neptunium (approximately $200 \mathrm{mV}$ ) at neutral $\mathrm{pH}$. On the basis of the sorption coefficient data presented by 
Lieser and Bauscher (1987 [DIRS 172722]) and the general similarity in rock and water compositions used in these experiments to Yucca Mountain rock and water compositions, it is recommended that a sorption coefficient of $1,000 \mathrm{~mL} / \mathrm{g}(<150 \mathrm{mV}$ at $\mathrm{pH}=7.0)$ be used to model technetium sorption under reducing conditions. For comparison purposes, note that the sorption coefficient used for technetium for the TSPA-LA calculations was 0 and the expected sorption coefficient values used for neptunium in the alluvium was approximately $6.3 \mathrm{~mL} / \mathrm{g}$ and $1.4 \mathrm{~mL} / \mathrm{g}$ in the volcanic units.

\subsection{Conceptual Model of Redox Conditions, Solubility, and Sorption}

A conceptual model of the features and processes in the SZ that could affect the transport of redox-sensitive radioelements was developed to form the basis for the sensitivity analyses performed in Sections 2.5 and 2.6.

Assessment of redox measurements in groundwater samples indicates that there are reducing conditions in the fractured volcanic aquifer to the east and south of Yucca Mountain. The most likely reductant responsible for these conditions is pyrite in the volcanic units, particularly the Tram Tuff. The conceptual model of redox conditions in the SZ includes a "curtain" of reducing conditions to the east and south of Yucca Mountain extending from the water table into the older volcanic units. This curtain is located such that it would be encountered by all or most of the flow pathways from beneath the repository in the SZ see Figure 2.6-5.

Where reducing conditions exist in the SZ, the transport of redox-sensitive species would be subject to precipitation due to lower solubility and enhanced sorption due to higher sorption coefficients. Enhanced sorption would occur in the rock matrix of volcanic units in the SZ. This conceptual model includes diffusion of radionuclides into the rock matrix where sorption may take place.

Potentially significant uncertainties in this conceptual model include: a greater spatial heterogeneity in redox conditions than is represented in the sensitivity analyses; uncertainties in the interpretations of chemical data and limited resolution of observations in wells; potential areas of oxidizing conditions within the reducing curtain and isolated zones of reducing conditions within the generally oxidizing zones of the aquifer; and precipitation as or onto colloids is a possible process that potentially could allow further migration of radionuclides after precipitation from the aqueous phase. These conceptual uncertainties should be addressed through additional analyses of existing data and more complex modeling.

\subsubsection{Summary of Solubility Limits Sensitivity Analysis}

A simplified approach was presented to assess the relation between radionuclide mass input, the volumetric groundwater flow rate in the $\mathrm{SZ}$, and solubility limits. This approach provides a method to determine whether the radionuclide precipitation will occur under specific volumetric groundwater flow rates and radionuclide release rates. Relationships were developed between the peak simulated radionuclide releases to the SZ (Table 2.5-1), volumetric groundwater flow rate in the SZ (Figure 2.5-1), and solubility limits (Figure 2.5-1). This simplified approach provides a first-order assessment of the potential relevance of solubility limits to radionuclide transport in the SZ. 
Based on this approach and using the mean value of the peak simulated release rates of ${ }^{99} \mathrm{Tc}$ calculated in the TSPA-LA nominal early failure modeling case, technetium precipitation could occur if the volumetric groundwater flow rate is less than 1 acre- $\mathrm{ft} / \mathrm{yr}\left(1,233 \mathrm{~m}^{3} / \mathrm{yr}\right)$. Assuming the mean peak UZ release rates for ${ }^{99} \mathrm{Tc}$ from the TSPA-LA igneous intrusion modeling case and seismic mechanical damage modeling case, and the TSPA-SR nominal scenario correspond to volumetric flow rates of about $7\left(8,634 \mathrm{~m}^{3} / \mathrm{yr}\right), 50\left(61,674 \mathrm{~m}^{3} / \mathrm{yr}\right)$, and $120 \mathrm{acre}-\mathrm{ft} / \mathrm{year}$ $\left(148,019 \mathrm{~m}^{3} / \mathrm{yr}\right)$, respectively, the range of expected volumetric flow rates in the $\mathrm{SZ}$ is from 1 acre-ft/year to 100 acre- $\mathrm{ft} /$ year. Consequently, precipitation of ${ }^{99} \mathrm{Tc}$ in reducing zones in the $\mathrm{SZ}$ could be a significant process in the disruptive scenarios in TSPA-LA or at longer times as represented in the TSPA-SR nominal scenario.

A one-dimensional reactive transport model for the $\mathrm{SZ}$ was developed to explicitly simulate the coupled processes of radionuclide precipitation, matrix diffusion, and sorption. Two cases were examined for ${ }^{99} \mathrm{Tc}$, a simulation with sorption and solubility-limited reaction in the reducing zone and a simulation with sorption in the reducing zone with no solubility-limited reaction. The technetium results showed that the case of no solubility limit had somewhat longer transport times than the case with solubility-limited precipitation. The reason for this behavior is that the time required for ${ }^{99} \mathrm{Tc}$ concentration to reach the solubility limit is short because the solubility is more than two orders of magnitude lower than the inlet concentration. In contrast, breakthrough at the compliance boundary for the case of no solubility limit occurs over the entire 10,000-year simulation period, due to the impact of matrix diffusion and dispersion. This implies that differences between normalized curves are due to different technetium concentrations at the upstream boundary of the reducing zone, rather than to any differences in the transport behavior through the rest of the streamtube.

The one-dimensional reactive transport model for the $\mathrm{SZ}$ also examined the influence of transient radionuclide releases. Results show that the process of precipitation is not an irreversible retardation mechanism because the radionuclides present in the system can re-dissolve when the radionuclide source is exhausted. Despite the fact that precipitation could be reversible under certain circumstances, solubility-limited behavior is potentially important to performance because the dose contribution of a radionuclide is directly proportional to the concentration at the compliance boundary.

A sensitivity study was conducted for ${ }^{99} \mathrm{Tc}$ subject to varied path lengths in the reducing zone. As expected, transport times increase considerably for longer paths in the reducing zone. This effect is completely due to sorption because precipitation influences all portions of the breakthrough curves equally - by lowering concentrations downstream of the reducing zone. This sensitivity analysis found that the influence of precipitation relies solely on the presence of a reducing zone through which radionuclides pass, rather than on the size of that zone.

\subsubsection{Summary of Sorption Sensitivity Analysis}

An effective sorption coefficient approach was developed to examine the general sensitivity of enhanced sorption in the SZ due to locally reducing conditions. This simplified approach as shown in Figures 2.6-2 through 2.6-4, relates the effective sorption along the entire flow path in the SZ to the fraction of the flow path with reducing conditions and associated enhanced sorption. These figures show that even for a small fraction of the flow path through reducing 
geochemical conditions, the effective sorption coefficient for the entire flow path can be significantly higher. The steepest rise in the effective sorption coefficient with increasing fraction of the flow path length is at the smallest flow path fractions.

In addition, explicit transport simulations were performed using the three-dimensional base-case site-scale SZ transport model (BSC 2004 [DIRS 170046] to study the sensitivity of breakthrough curves to the sorption coefficients of neptunium and technetium expected to occur under reducing conditions. These simulations included a continuous zone of reducing conditions as shown in Figure 2.6-5. The results of these simulations are summarized in Table 2.6-2. Transport simulations for technetium and neptunium were conducted and compared to base-case simulations for various conditions including, a narrow redox zone of $1,000 \mathrm{~m}$ in width; a wide redox zone of $2,286 \mathrm{~m}$ in width; maximum sorption coefficient of $1,000 \mathrm{~mL} / \mathrm{g}$ for neptunium and technetium; technetium sorption coefficient of $50 \mathrm{~mL} / \mathrm{g}$; and neptunium sorption coefficient of $200 \mathrm{~mL} / \mathrm{g}$. The technetium transport simulations indicate that even for a moderate value of $K_{d}=50 \mathrm{~mL} / \mathrm{g}$, and the narrow redox zone, the 50 percent breakthrough time increases by more than an order of magnitude from a transport time of 723 years for the base case to 9,110 years. For $K_{d}=1,000 \mathrm{~mL} / \mathrm{g}$, the value likely to be encountered in a fully reducing zone, the 50 percent breakthrough time increases even more dramatically to 126,500 years. Similar results for technetium using a wider curtain show a more significant increase from the base-case 50 percent breakthrough times, with a value in excess of 400,000 years for $K_{d}=1,000 \mathrm{~mL} / \mathrm{g}$.

For the neptunium transport simulations with a narrow redox curtain and sorption coefficient of $200 \mathrm{~mL} / \mathrm{g}$, the 50 percent breakthrough time increased by a factor of approximately 2.5 , from the base value of 25,820 years to 64,900 years. Similar results for neptunium using a wider curtain show a more significant increase in the 50 percent breakthrough times, with a value in excess of 400,000 years for $K_{d}=1,000 \mathrm{~mL} / \mathrm{g}$. Note that the thickness of the curtain has a significant impact on the breakthrough delay: an increase in the width by a factor of 2.3 leads to an increase in the delay time by a factor of 3 to 4 .

\subsection{Implications for Performance Assessment}

The information presented in this report is intended to aid in the assessment of conservatism in the SZ transport model with respect to the effect of enhanced sorption due to reducing conditions and solubility limits in the TSPA. Overall, this analysis indicates that the impacts of solubility limits in reducing zones in the SZ could have an impact on the simulations of ${ }^{99} \mathrm{Tc}$ and ${ }^{237} \mathrm{~Np}$ transport in TSPA calculations. As discussed in Section 2.2, there are not enough data to discard $\mathrm{TcO}_{2}$ as a solubility-controlling solid in the determination of technetium solubility. The use of this controlling solid results in four orders of magnitude lower solubility limit than what was used in the one-dimensional reactive transport model sensitivity calculations. Consequently, the implications for TSPA could be even greater than estimated in this study. Sensitivity studies of enhanced sorption using the three-dimensional base-case site-scale SZ transport model (BSC 2004 [DIRS 170046] demonstrated significant increases in transport times. The results of the three-dimensional sensitivity analysis showed that the transport times for ${ }^{99} \mathrm{Tc}$ and ${ }^{237} \mathrm{~Np}$ ranged from one to three orders of magnitude longer than the base-case results, depending upon the width of the reducing zone and the value of the sorption coefficient. The one-dimensional reactive transport model, which included solubility limits and enhanced sorption, showed that for ${ }^{99} \mathrm{Tc}$, the case of no solubility limit results in somewhat longer transport times than for the case 
with solubility-limited precipitation. The results also indicate the relative importance of the solubility limit and that enhanced sorption in a reducing zone along the flowpath depends on the radionuclide concentration entering the reducing zone.

There are uncertainties that would have to be considered associated with implementing this approach in the TSPA calculation including uncertainties associated with the conceptual model, redox measurement uncertainties, and parameter uncertainties. There is spatial variability in redox conditions in groundwater flow systems over a wide range of scales, from centimeters to kilometers. The extent of redox measurements at the Yucca Mountain site is limited, for example the WT wells were not measured for dissolved oxygen. Accurate assessment of the extent of the reducing zone is limited by the data available. There is also uncertainty associated with the sorption coefficient parameters. Details of other uncertainties are discussed throughout this study.

In summary, the results of this study demonstrate significant increases to transport times that could impact TSPA calculations. Including enhanced sorption in a reducing zone yields a greater increase to transport times than incorporation of solubility limits. It is possible that the impacts to the TSPA calculations could be even more important at time scales beyond 10,000 years if changes in the regulation require such calculations.

\subsection{Recommendations}

The results from this study suggest that the conceptualization of enhanced sorption and inclusion of solubility limits should be considered for incorporation in TSPA calculations. Data at the Yucca Mountain site indicate the existence of a redox barrier east of the repository footprint that may retard the transport of redox-sensitive radionuclides.

A full assessment of uncertainties discussed in this work would need to be conducted to incorporate the conceptual model of enhanced sorption and solubility limits in the TSPA calculation. Additionally, including solubility limits in the TSPA calculation would require extensive model development to implement solubility limits in the TSPA calculations.

To test potential retardation of technetium in the alluvium, an analogue for the pertechnetate ion could be injected at a test site at Yucca Mountain, such as the Alluvial Testing Complex. The (non-radioactive) perrhenate ion is recommended as an analogue for the pertechnetate ion. This could reduce uncertainties related to technetium sorption coefficients in the alluvium.

It is also recommended that redox measurements be made at wells where redox data do not currently exist. It is important to delineate the extent of the reducing zone in the lateral and vertical directions delineation of the reducing zone may be possible if the processes that lead to the formation of this zone are well understood and supported by field data and modeling. 


\section{INTENTIONALLY LEFT BLANK}




\section{REFERENCES}

\subsection{DOCUMENTS CITED}

162982 Allard, B.; Olofsson, U.; Torstenfelt, B.; and Kipatsi, H. 1983. Sorption Behaviour of Well-Defined Oxidation States. SKB TR-83-61. Stockholm, Sweden: Svensk Kärnbränsleförsörjning A.B. TIC: 206122.

172848 Amme, M. 2002. "Geochemical Modeling as a Tool for Actinide Speciation During Anoxic Leaching Processes of Nuclear Fuel.” Aquatic Geochemistry, vol. 8, pp. 177-198.

169425 BSC (Bechtel SAIC Company) 2004. Dissolved Concentration Limits of Radioactive Elements. ANL-WIS-MD-000010 REV 03. Las Vegas, Nevada: Bechtel SAIC Company. ACC: DOC.20041109.0006.

170037 BSC 2004. Saturated Zone Site-Scale Flow Model. MDL-NBS-HS-000011 REV 02. Las Vegas, Nevada: Bechtel SAIC Company. ACC: DOC.20041122.0001.

170036 BSC 2004. Site-Scale Saturated Zone Transport. MDL-NBS-HS-000010 REV 02. Las Vegas, Nevada: Bechtel SAIC Company. ACC: DOC.20041103.0004.

174012 BSC 2005. Saturated Zone Flow and Transport Model Abstraction. MDL-NBS-HS000021 REV 03. Las Vegas, Nevada: Bechtel SAIC Company.

173859 BSC 2005. Technical Work Plan for Saturated Zone Flow and Transport Modeling. TWP-NBS-MD-000006 REV 01. Las Vegas, Nevada: Bechtel SAIC Company. ACC: DOC.20050525.0002.

173951 BSC 2005. Technical Work Plan for Unsaturated Zone Flow, Drift Seepage and Unsaturated Zone Transport Modeling. TWP-MGR-HS-000004 REV 01. Las Vegas, Nevada: Bechtel SAIC Company. ACC: DOC.20050523.0003.

174227 BSC 2005. Total System Performance Assessment Model/Analysis for the License Application. MDL-WIS-PA-000004 REV 01. Las Vegas, Nevada: Bechtel SAIC Company.

174566 BSC 2005. Dissolved Concentration Limits of Radioactive Elements. ANL-WIS-MD000010 REV 05. Las Vegas, Nevada: Bechtel SAIC Company. ACC:

DOC.20050713.0006.

101322 Caporuscio, F.; Vaniman, D.; Bish, D.; Broxton, D.; Arney, B.; Heiken, G.; Byers, F.; Gooley, R.; and Semarge, E. 1982. Petrologic Studies of Drill Cores USW-G2 and UE25b-1H, Yucca Mountain, Nevada. LA-9255-MS. Los Alamos, New Mexico: Los Alamos National Laboratory. ACC: NNA.19870519.0041.

101522 Carr, W.J.; Byers, F.M., Jr.; and Orkild, P.P. 1984. Stratigraphic and VolcanoTectonic Relations of Crater Flat Tuff and Some Older Volcanic Units, Nye County, 
Nevada. Open-File Report 84-114. Denver, Colorado: U.S. Geological Survey. ACC: NNA.19870518.0075.

102495 Castor, S.B.; Tingley, J.V.; and Bonham, H.F., Jr. 1994. "Pyritic Ash-Flow Tuff, Yucca Mountain, Nevada." Economic Geology, 89, 401-407. E1 Paso, Texas: Economic Geology Publishing. TIC: 234278.

172748 Choppin, G.R. 1999. "Utility of Oxidation State Analogs in the Study of Plutonium Behavior." Radiochimica Acta, 85, pp. 89-95. Munich, Germany: Oldenbourg Wissenschaftsverlag. TIC: 256662.

153246 CRWMS M\&O 2000. Total System Performance Assessment for the Site Recommendation. TDR-WIS-PA-000001 REV 00 ICN 01. Las Vegas, Nevada: CRWMS M\&O. ACC: MOL.20001220.0045.

172740 Edmunds, W.M.; Cook, J.M.; Darline, W.G.; Kinniburgh, D.G.; Miles, D.L.;Bath, A. 1987. "Baseline Geochemical Conditions in the Chalk Aquifer, Berkshire, U.K.: A Basis for Groundwater Quality Management." Applied Geochemistry, 2. New York, New York: Pergamon Journals. TIC: 256856.

172728 Edmunds, W.M.; Guendouz, A.H.; Mamou, A.; Moulla, A.; Shand, P.; Zouari, K. 2003. "Groundwater Evolution in the Continental Intercalaire Aquifer of Southern Algeria and Tunisia: Trace Element and Isotopic Indicators." Applied Geochemistry, 18. Oxford, England: Pergamon. TIC: 256857.

172726 Ginn, T.R. 2001. "Stochastic-Convective Transport with Nonlinear Reactions and Mixing : Finite Streamtube Ensemble Formulation for Multicomponent Reaction Systems with Intra-Streamtube Dispersion." Journal of Contaminant Hydrology, 47. Amsterdam, Netherlands: Elsevier Science. TIC: 256851.

158074 Guilbert, J.M. and Park, C.F., Jr. 1999. The Geology of Ore Deposits. New York, New York: W.H. Freeman and Company. TIC: 252103.

105905 Hakanen, M. and Lindberg, A. 1991. "Sorption of Neptunium Under Oxidizing and Reducing Groundwater Conditions." Radiochimica Acta, 52/53, 147-151. Munchen, Germany: R. Oldenbourg Verlag. TIC: 237041.

172847 Hu, Q.H., and Smith, D.K., 2004, "Field-Scale Migration of Tc-99 and I-129 at the Nevada Test Site," 28th Symposium on the Scientific Basis for Nuclear Waste Management, Symposium held April 13-16, 2004, San Francisco, California, vol. 824, pp. 399-404. Warrendale, Pennsylvania: Materials Research Society.

161904 Hummel, W.; Berner, U.; Curti, E.; Pearson, F.J.; and Thoenen, T. 2002. Nagra/PSI Chemical Thermodynamic Data Base 01/01. Parkland, Florida: Universal Publishers. TIC: 253421.

172727 Iwatsuki, T. and Yoshida, H. 1999. "Groundwater Chemistry and Fracture Mineralogy in the Basement Granitic Rock in the Tono Uranium Mine Area, Gifu Prefecture, 
Japan - Groundwater Composition, Eh Evolution Analysis by Fracture Filling Minerals." Geochemical Journal, 33, (1). Tokyo, Japan: Terra Scientific Publishing Co. TIC: 256858.

172771 Jankowski, J., 2001, "Mobilisation and Precipitation of Ferrous Iron on the SO42- / S2- Redox Boundary in a Fractured Bedrock Aquifer," in New Approaches Characterizing Groundwater Flow, Vols. 1 and 2, pp. 965-969, Rotterdam, Netherlands: A.A. Balkema.

122379 Kaszuba J.P. and Runde W.H. 1999. "The Aqueous Geochemistry of Neptunium: Dynamic Control of Soluble Concentrations with Applications to Nuclear Waste Disposal.” Environmental Science \& Technology, 33, (24), 4427-4433. Washington, D.C.: American Chemical Society. TIC: 246667.

100051 Langmuir, D. 1997. Aqueous Environmental Geochemistry. Upper Saddle River, New Jersey: Prentice Hall. TIC: 237107.

147532 Lieser, K.H. and Hill, R. 1992. "Chemistry of Thorium in the Hydrosphere and in the Geosphere.” Radiochimica Acta, 56, 141-151. Munchen, Germany: R. Oldenbourg Verlag. TIC: 237124.

106684 Lieser, K.H. and Muhlenweg, U. 1988. "Neptunium in the Hydrosphere and in the Geosphere, I. Chemistry of Neptunium in the Hydrosphere and Sorption of Neptunium from Groundwaters on Sediments Under Aerobic and Anaerobic Conditions." Radiochimica Acta, 43, 27-35. Munchen, Germany: R. Oldenbourg Verlag. TIC: 236783.

172723 Lieser, K.H.; Bauscher, C.; and Nakashima, T. 1987. "Dissolution of $\mathrm{TcO}_{2}$ in Aqueous Solutions under Various Conditions.” Radiochimica Acta, 42, (4). Munich, Germany: Munich, Germany. TIC: 256860.

172722 Lieser, K.H. and Bauscher, C. 1987. "Technetium in the Hydrosphere and in the Geosphere: I. Chemistry of Technetium and Iron in Natural Waters and Influence of the Redox Potential on the Sorption of Technetium." Radiochemica Acta, 42, (4). Munich, Germany: R. Oldenbourg Verlag. TIC: 256859.

106685 Lindberg, R.D. and Runnells, D.D. 1984. “Ground Water Redox Reactions: An Analysis of Equilibrium State Applied to Eh Measurements and Geochemical Modeling." Science, 225, 925-927. Washington, D.C.: American Association for the Advancement of Science. TIC: 224111.

101051 Meijer, A. 1998. Eh-pH Measurements in the Saturated Zone in Wells USW-WT\#3, and USW-WT\#17 at Yucca Mountain. BA0000000-01717-5700-00010. Los Alamos, New Mexico: Los Alamos National Laboratory. ACC: MOL.19981022.0152.

172733 Meyer, R.E.; Arnold, W.D.; Case, F.I.; O'Kelley, G.D. 1991. "Solubilities of Technetium(IV) Oxides." Radiochimica Acta, 55, . Munich, Germany: R. Oldenbourg 
Verlag. TIC: 256861.

173265 Mitchell, J.T., Jr. 2005. "Contract No. DE-AC28-01RW12101 - Response to Contracting Officer Authorization Letter No. 05-001, Improvements and Refinements in the Technical Bases that Support the Safety Analysis Report (SAR)." Letter from J. Mitchell, Jr. (BSC) to B. Hamilton-Ray (DOE/ORD), December 3, 2004, 1203044102, with enclosures. ACC: MOL.20050110.0076.

100783 Ogard, A.E. and Kerrisk, J.F. 1984. Groundwater Chemistry Along Flow Paths Between a Proposed Repository Site and the Accessible Environment. LA-10188-MS. Los Alamos, New Mexico: Los Alamos National Laboratory.

ACC: HQS.19880517.2031.

172732 Ortega-Guerrero, A. 2003. "Origin and Geochemical Evolution of Groundwater in a Closed-Basin Clayey Aquitard, Northern Mexico." Journal of Hydrology, 284. New York, New York: Elsevier. TIC: 256862.

172603 Pabalan, R.T.; Turner, D.R.; and Miklas, M.P., Jr. 2000. "Technetium-99 Chemistry in Reducing Groundwaters: Implications for the Performance of a Proposed High-Level Nuclear Waste Repository at Yucca Mountain, Nevada." Scientific Basis for Nuclear Waste Management XXIII, Symposium held November 29-December 2, 1999, Boston, Massachusetts. Smith, R.W. and Shoesmith, D.W., eds. 608, 231-236. Warrendale, Pennsylvania: Materials Research Society. TIC: 249052.

172724 Robinson, B.A.; Viswanathan, H.S. 2003. "Application of the Theory of Micromixing to Groundwater Reactive Transport Models." Water Resources Research, 39, (11), . Washington, DC: American Geophysical Union. TIC: 256853.

172744 Ryu, J-H.; Dahlgren, R.A.; Gao, S.; and Tanji, K.K. 2004. "Characterization of Redox Processes in Shallow Groundwater of Owens Dry Lake, California." Environmental Science and Technology, 38, (22), 5950-5957. Washington, D.C.: American Chemical Society. TIC: 256863.

172604 Salter, P.F. and Jacobs, G.K. 1982. "Evaluation of Radionuclide Transport: Effect of Radionuclide Sorption and Solubility." Scientific Basis for Nuclear Waste Management V, Proceedings of the Materials Research Society Fifth International Symposium held June 7-10, 1982, Berlin, Germany. Lutze, W., ed. 11, 801-810. New York, New York: North-Holland. TIC: 204398.

172731 Schurch, M.; Edmunds, W. M.; and Buckley, D. 2004. "Three-Dimensional Flow and Trace Metal Mobility in Shallow Chalk Groundwater, Dorset, United Kingdom." Journal of Hydrology, 292, . New York, NY: Elsevier. TIC: 256864.

172719 Simmons, C.S., Ginn, T.R., Wood, B.D. 1995. "Stochastic-Convective Transport with Nonlinear Reaction - Mathematical Framework." Water Resources Research, 31, (11). Washington, D.C.: American Geophysical Union. TIC: 252318. 
100829 Stumm, W. and Morgan, J.J. 1981. Aquatic Chemistry, An Introduction Emphasizing Chemical Equilibria in Natural Waters. 2nd Edition. New York, New York: John Wiley \& Sons. TIC: 208448.

162989 Turner, D.R.; Pabalan, R.T.; and Bertetti, F.P. 1998. "Neptunium(V) Sorption on Montmorillonite: An Experimental and Surface Complexation Modeling Study." Clays and Clay Minerals, 46, (3), 256-269. Boulder, Colorado: Clay Minerals Society. TIC: 254532.

172783 Vieno, T. and Nordman, H. 1999. Safety Assessment of Spent Fuel Disposal in Hastholmen, Kivetty, Olkiluoto, and Romuvaara TILA-99. POSIVA 99-07, Helsinki, Finland: POSIVA OY.

172725 Viswanathan, H.S.; Valocchi, A.J. 2004. "Comparison of Streamtube and ThreeDimensional Models of Reactive Transport in Heterogeneous Media." Journal of Hydraulic Research, 42, (Extra Issue). Madrid, Spain: International Association of Hydraulic Engineering and Research. TIC: 256852.

100191 Wilson, M.L.; Gauthier, J.H.; Barnard, R.W.; Barr, G.E.; Dockery, H.A.; Dunn, E.; Eaton, R.R.; Guerin, D.C.; Lu, N.; Martinez, M.J.; Nilson, R.; Rautman, C.A.; Robey, T.H.; Ross, B.; Ryder, E.E.; Schenker, A.R.; Shannon, S.A.; Skinner, L.H.; Halsey, W.G.; Gansemer, J.D.; Lewis, L.C.; Lamont, A.D.; Triay, I.R.; Meijer, A.; and Morris, D.E. 1994. Total-System Performance Assessment for Yucca Mountain SNL Second Iteration (TSPA-1993). SAND93-2675. Executive Summary and two volumes. Albuquerque, New Mexico: Sandia National Laboratories.

ACC: NNA.19940112.0123.

\subsection{SOFTWARE}

155343 BSC (Bechtel SAIC Company) 2001. Software Code: PHREEQC. V2.3. PC, LINUX, Windows 95/98/NT, Redhat 6.2. 10068-2.3-00.

162228 BSC (Bechtel SAIC Company) 2003. Software Code: EQ3/6. V8.0. PC w/ Windows 95/98/2000/NT 4.0. 10813-8.0-00.

161725 LANL (Los Alamos National Laboratory) 2003. Software Code: FEHM. V2.20. SUN, PC. 10086-2.20-00.

\subsection{CODES, STANDARDS, REGULATIONS, AND PROCEDURES}

15660510 CFR 63. Energy: Disposal of High-Level Radioactive Wastes in a Geologic Repository at Yucca Mountain, Nevada. Readily available.

\subsection{DATA, LISTED BY DATA TRACKING NUMBER}

152561 GS940308314211.010. Table of Contacts in Borehole USW UZ-N11. Submittal date: $03 / 10 / 1994$. 
164362 LA0306SK831231.001. SZ Site-Scale Transport Model, FEHM Files for Base Case. Submittal date: 06/25/2003.

149522 LAAM831311AQ98.010. Static Measurements for UE-25 WT\#17, 01 Jul 98. Submittal date: 09/14/1998.

161756 MO0302SPATHDYN.000. Thermodynamic Data Input Files - Data0.YMP.R2. Submittal date: 02/05/2003.

170929 SN0407T0504404.002. Distributed Recharge and Lateral Boundary Conditions for the Saturated Zone (SZ) Site-Scale Flow and Transport Model. Submittal date: 07/15/2004. 
INTENTIONALLY LEFT BLANK 


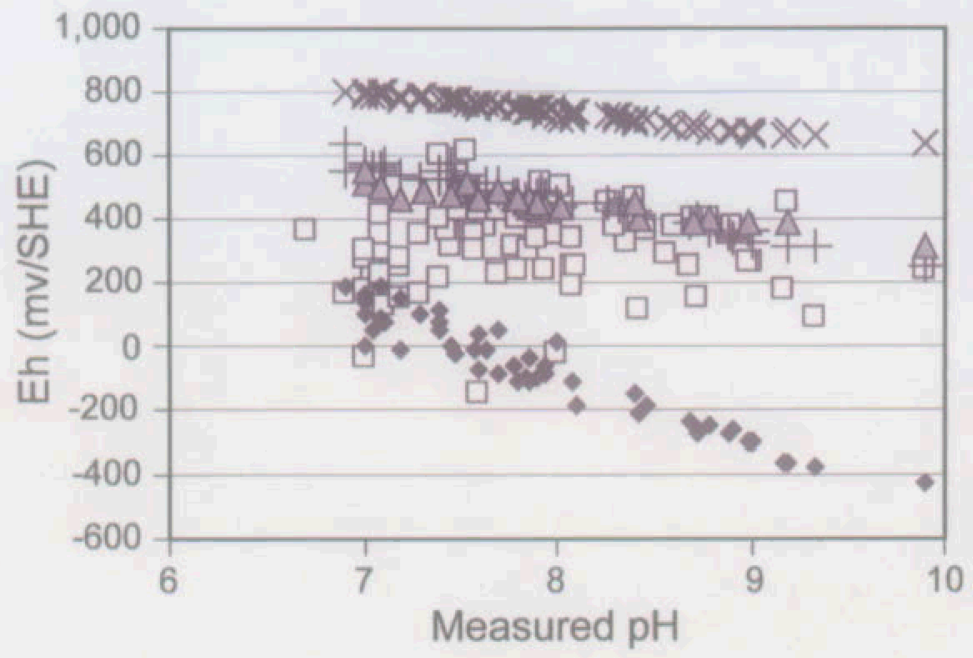

$\square$ Measured

$\times \mathrm{H}_{2} \mathrm{O} / \mathrm{DO}$

$+\mathrm{Mn}_{2}{ }^{+} / \mathrm{MnO}_{2}$

$\triangle \mathrm{NO}_{2}{ }^{-} / \mathrm{NO}_{3}{ }^{-}$

- $\mathrm{Fe} / \mathrm{Fe}(\mathrm{OH})_{3}$

Figure 2.1-1. Eh Versus $\mathrm{pH}$ for Oxidizing (i.e., DO>1.0 mg/L) Groundwaters from the Yucca Mountain Area 


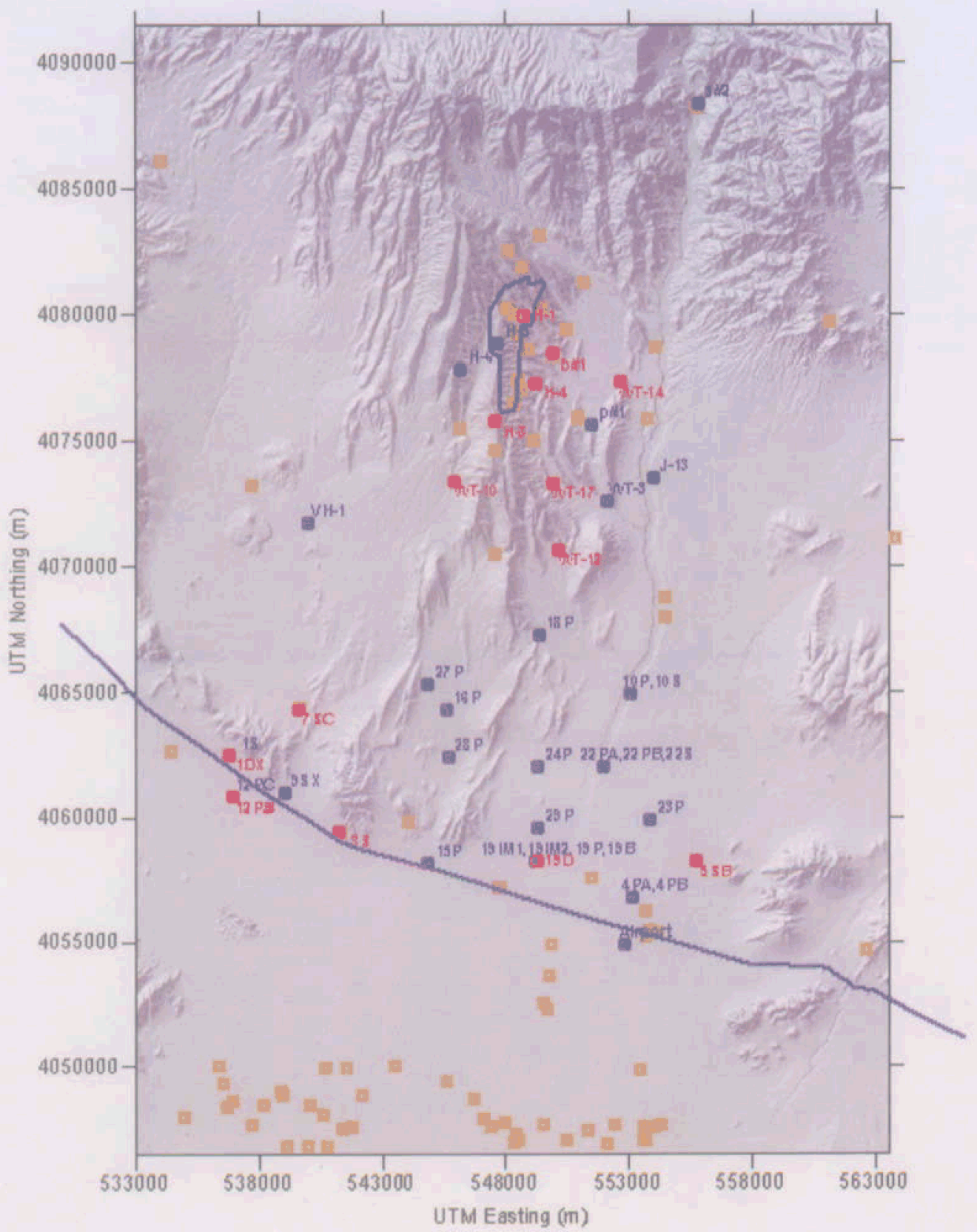

NOTE: Wells with oxidizing groundwater are shown with blue filled circles, wells with reducing groundwater are shown with red filled circles, and wells in which redox conditions have not been measured are shown with filled brown squares. Wells with both oxidizing and reducing conditions ( $\mathrm{H}-1$ and $19-\mathrm{D})$ are shown with open red circles. The repository is outlined in blue in the north-central part of the map and Highway 95 is shown as blue line in southern part of map.

Figure 2.1-2. Map Showing Locations of Wells with Oxidizing and Reducing Groundwaters 


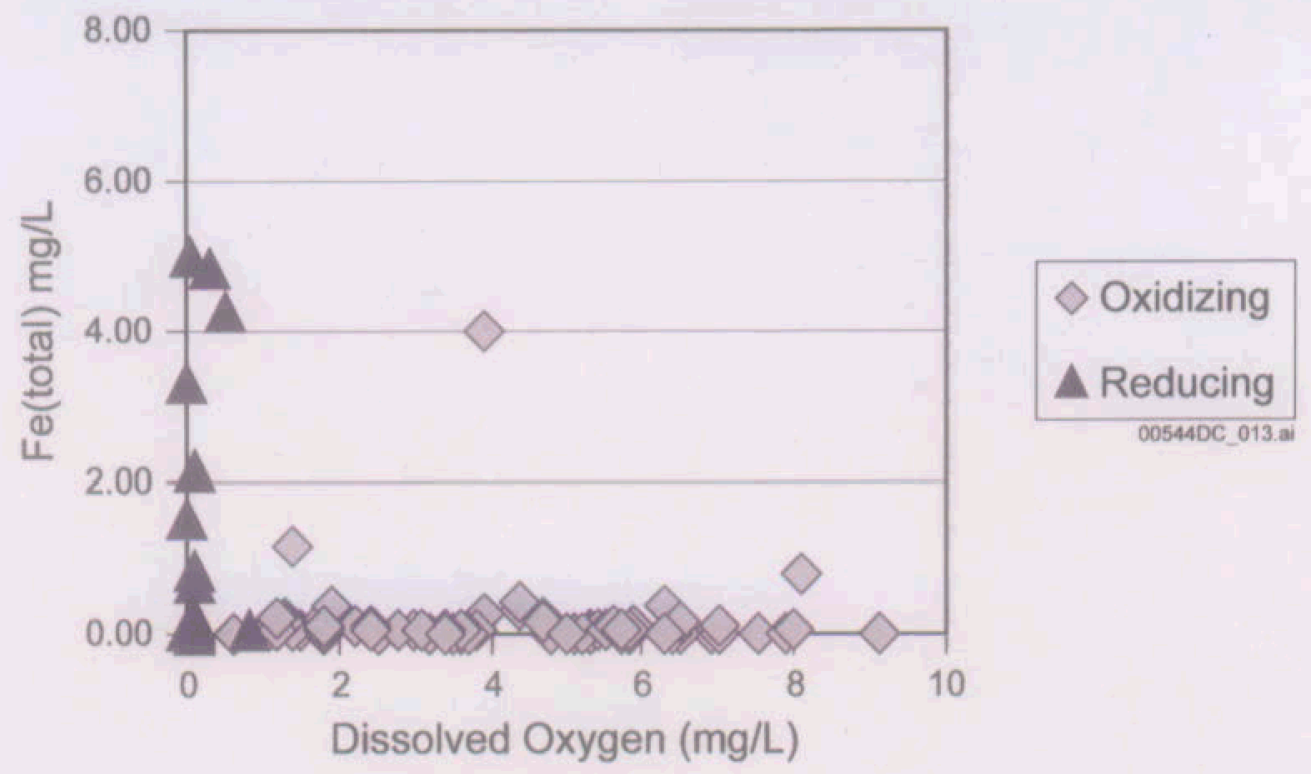

Figure 2.1-3. Measured Dissolved Oxygen Versus Measured Total Iron in Oxidizing (DO>1.0 mg/L) and Reducing (DO<1.0 mg/L) Groundwaters.

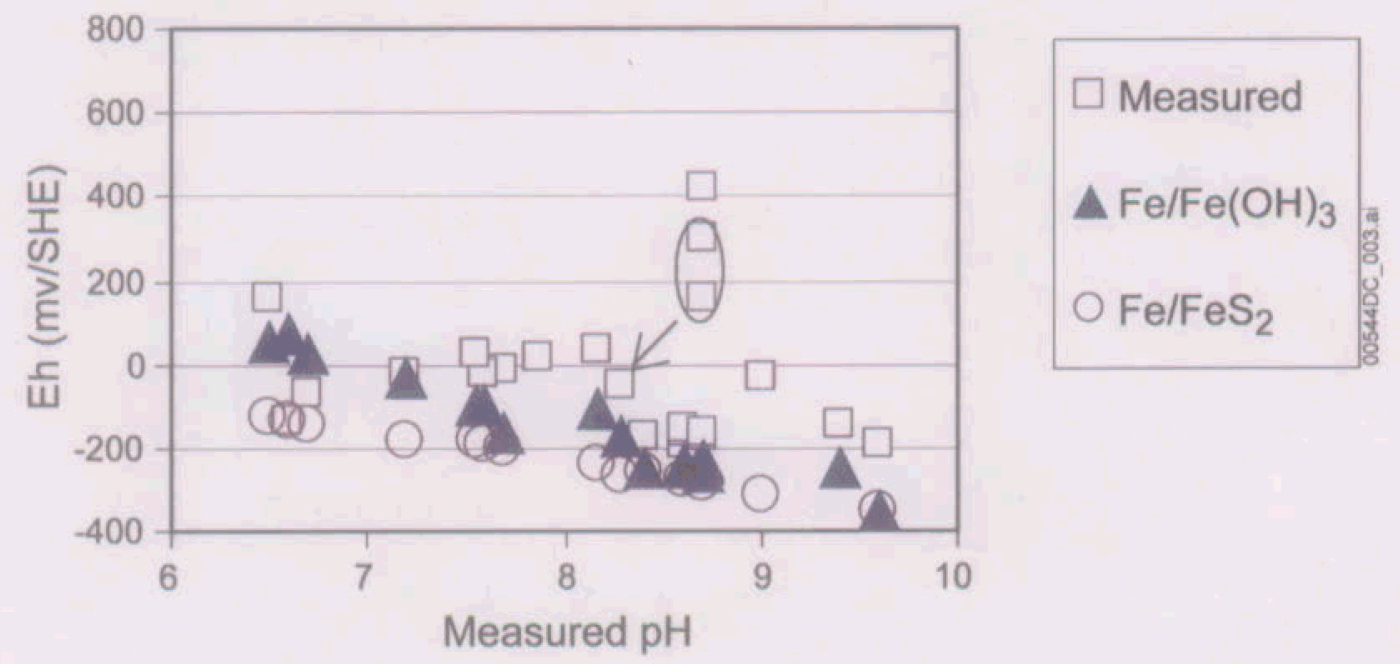

NOTE: The oval represents early measurements on a single well. The arrowhead points to a measurement made a year after the early measurements

Figure 2.1-4. Measured $\mathrm{pH}$ Values Versus Measured and Calculated Eh Values 


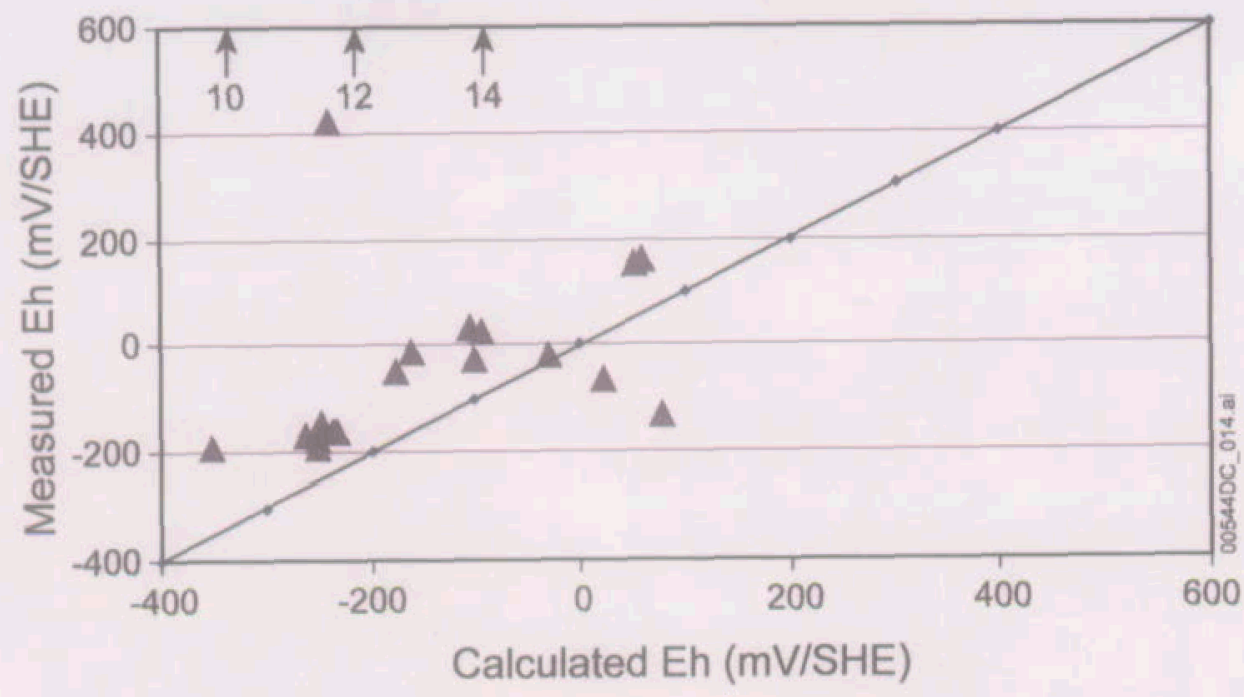

NOTE: Calculated Eh values for groundwaters from boreholes WT-10, WT-12, and WT14 are also shown.

Figure 2.1-5. Measured Eh Values (Platinum Electrode) Versus Eh Values Calculated From Total Iron Concentrations 


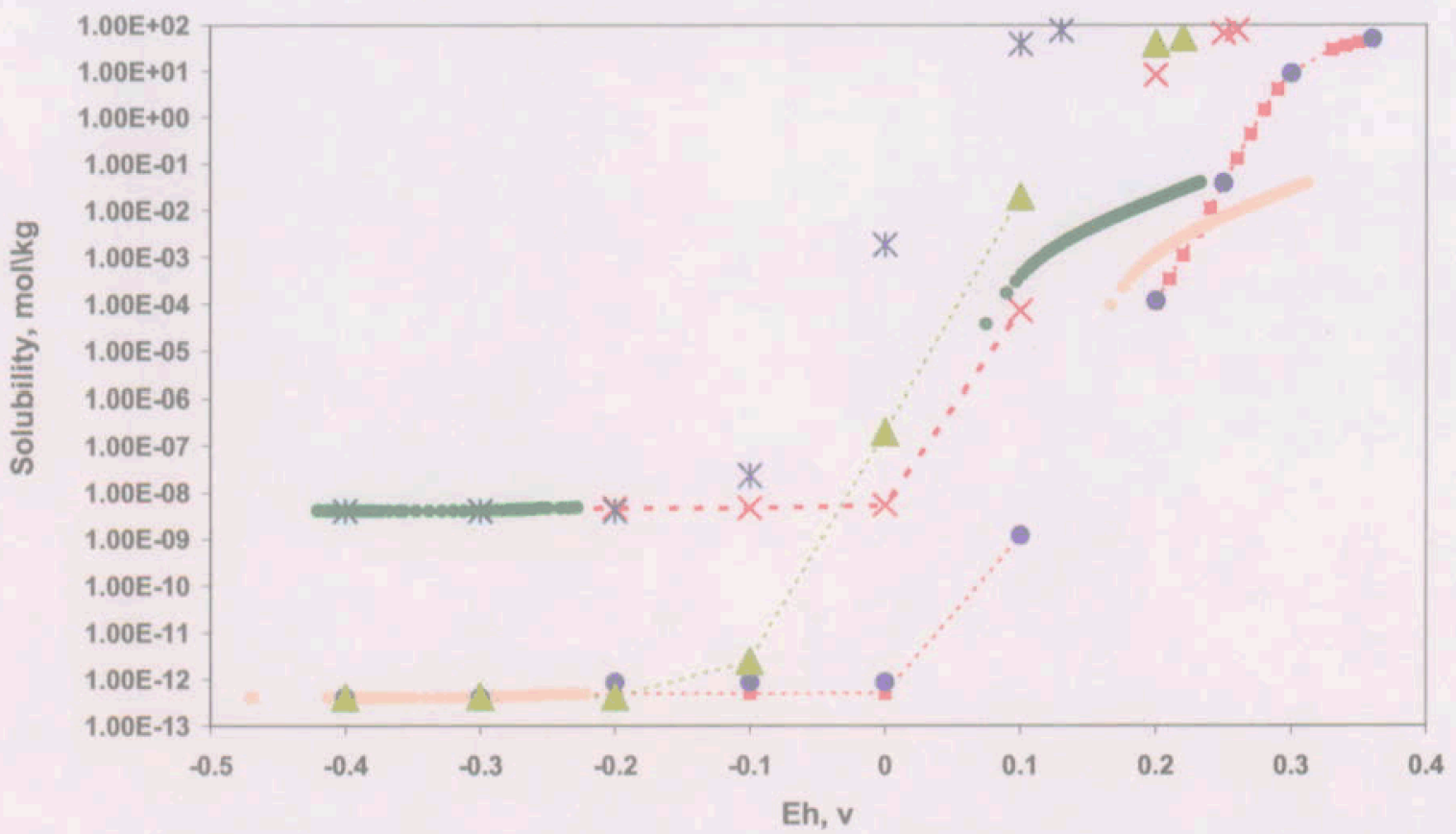

\begin{tabular}{|c|c|c|c|}
\hline$=$ & $\mathrm{J}-13 \mathrm{pH}=6.9$ & - $\mathrm{J}-13 \mathrm{pH}=8.5$ & $-\not \times-J-13 \mathrm{pH}=6.9 \mathrm{TcO}^{*} 1.6 \mathrm{H} 2 \mathrm{O}$ \\
\hline * & $\mathrm{J}-13 \mathrm{pH}=8.5 \mathrm{TcO} 2^{*} 1.6 \mathrm{H} 20$ & * J-13 EQ6 & - J-13 EQ6 TcO2*1.6H2O \\
\hline - & $\mathrm{p} \# 1 \mathrm{pH}=6.7$ & p\#1 $\mathrm{pH}=8.5$ & \\
\hline
\end{tabular}

NOTE: In EQ6 simulations, $\mathrm{pH}$ changes as the reaction progresses.

Figure 2.2-1. Technetium Solubility in $\mathrm{J}-13$ and $\mathrm{p \# 1}$ Water from EQ3 and EQ6 Calculations (J-13) 


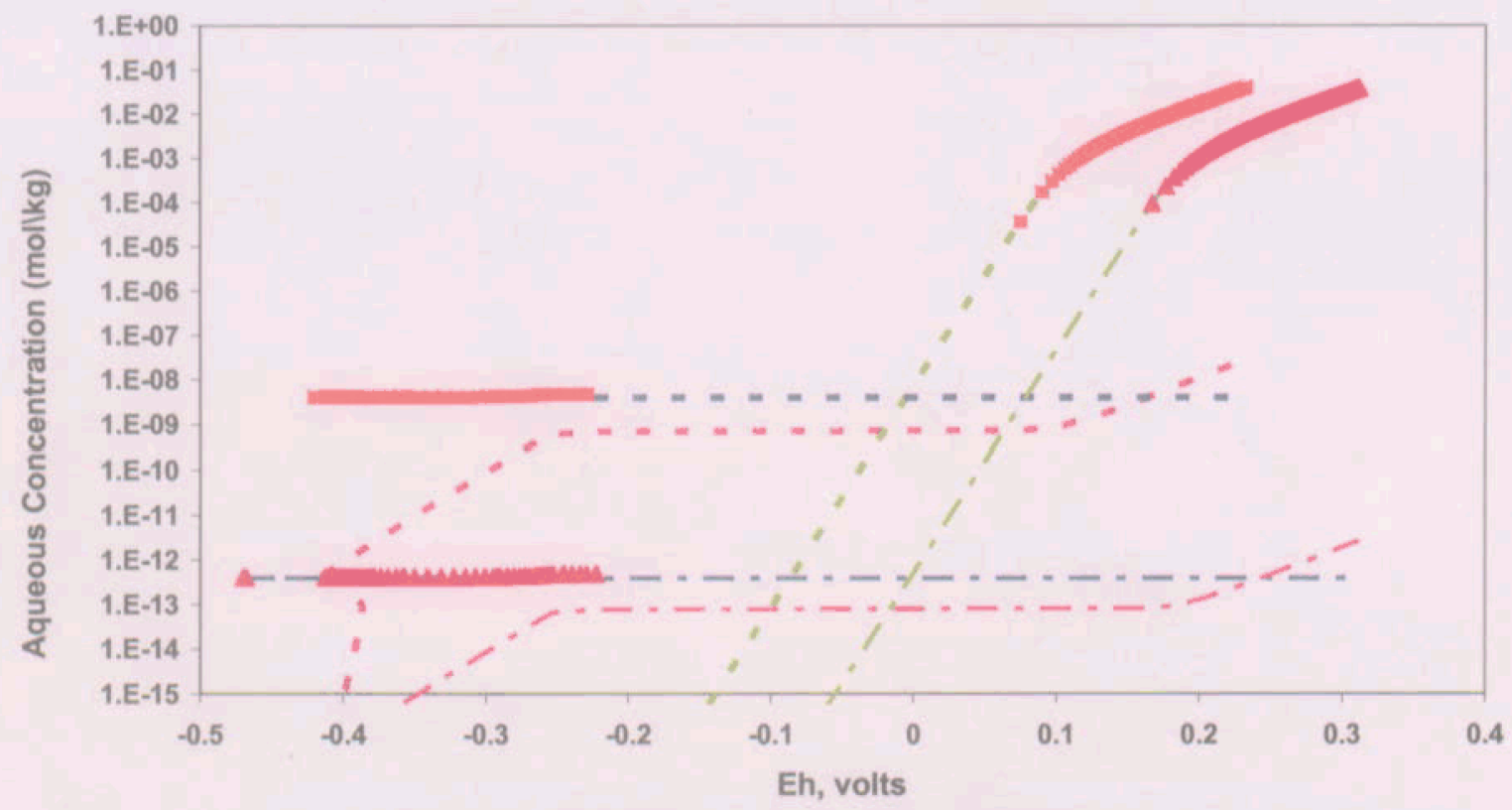

\begin{tabular}{|c|c|c|c|}
\hline in & Total Dissolved Tc $\left(\mathrm{TcO}^{*} 1.6 \mathrm{H} 2 \mathrm{O}\right)$ & $=-$ & $\mathrm{TcCO} 3(\mathrm{OH}) 2$ aq $\left(\mathrm{TcO}^{*} 1.6 \mathrm{H} 2\right)$ \\
\hline "' & $\mathrm{TcO} 4-\left(\mathrm{TcO}_{2} * 1.6 \mathrm{H} 2\right)$ & -- & $\mathrm{TcO}(\mathrm{OH}) 2 \mathrm{aq}\left(\mathrm{TcO}^{*} 1.6 \mathrm{H} 2 \mathrm{O}\right)$ \\
\hline A & Total Dissolve Tc (TcO2) & & TcO4- (TcO2) \\
\hline - - & $\mathrm{TcO}(\mathrm{OH}) 2 \mathrm{aq}(\mathrm{TcO} 2)$ & & $\mathrm{TcCO} 3(\mathrm{OH}) 2$ aq $(\mathrm{TcO} 2)$ \\
\hline
\end{tabular}

Figure 2.2-2. Major Aqueous Technetium Species and Total Dissolved Technetium as a Function of Eh 


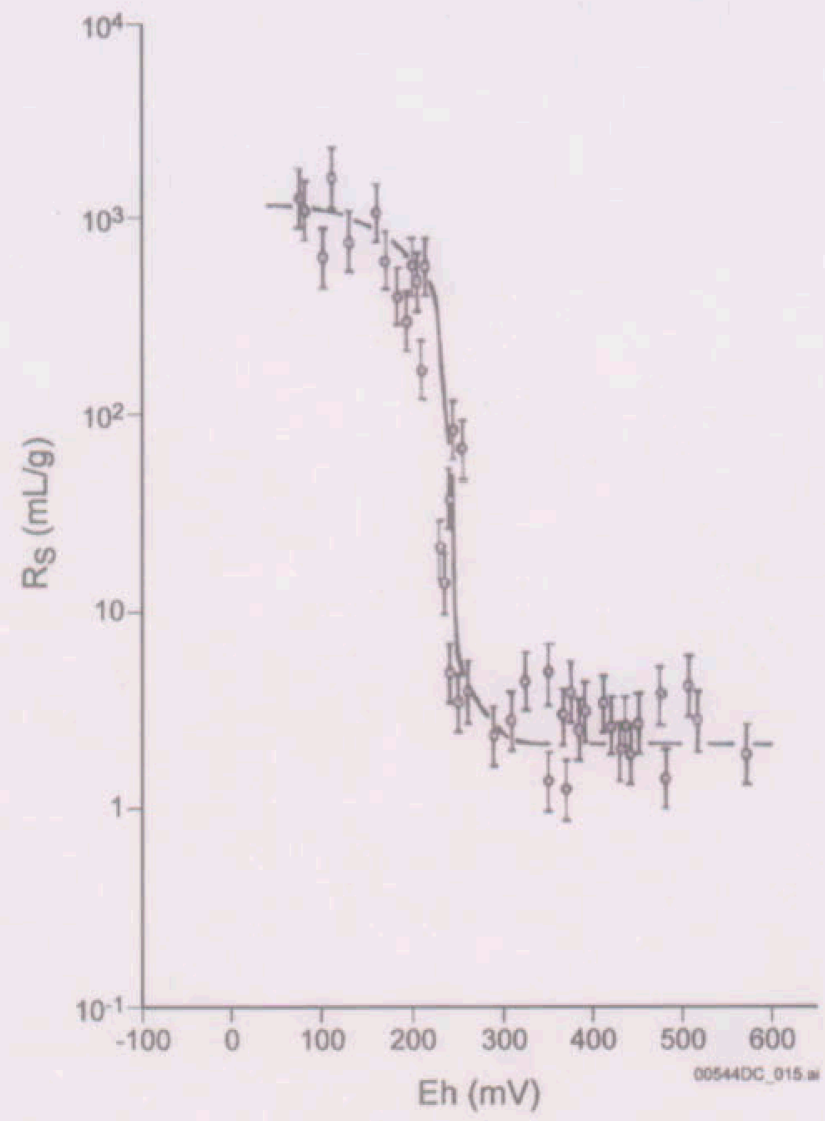

Source: Lieser and Muhlenweg 1988 [DIRS 106684]

Figure 2.3-1. Neptunium Sorption Coefficients versus Eh on Sediments and Groundwaters from the Gorleben Site in Germany

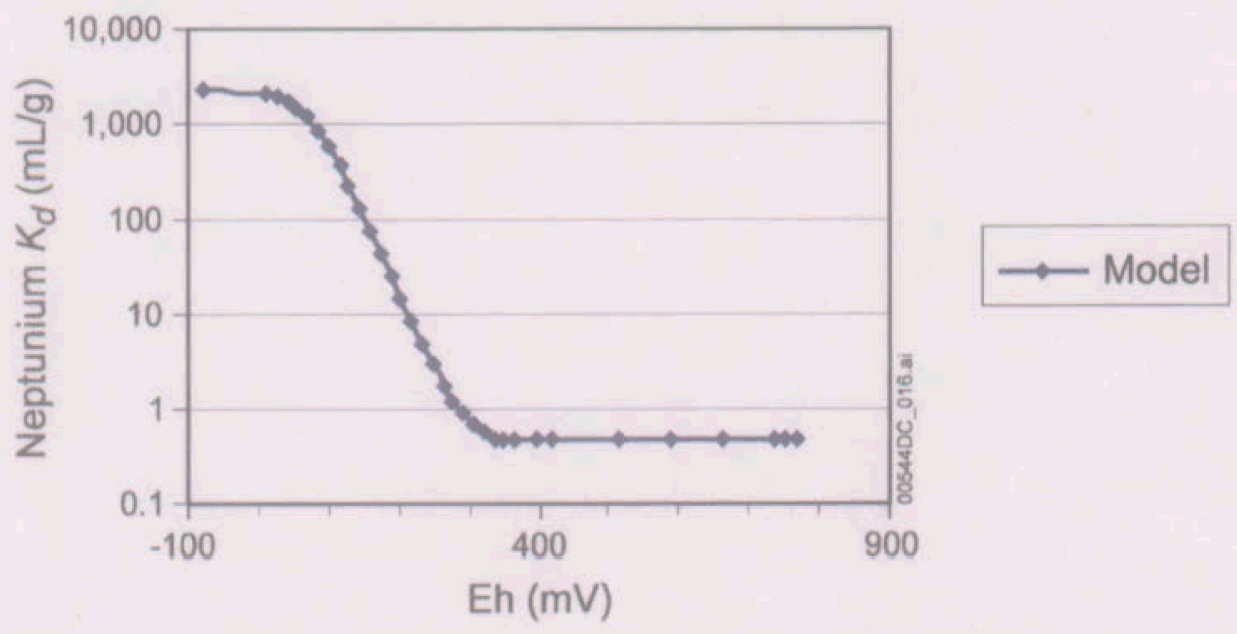

Figure 2.3-2. Surface Complexation Modeling Results for Neptunium Sorption on Quartz in Dilute Groundwater as a Function of Eh 


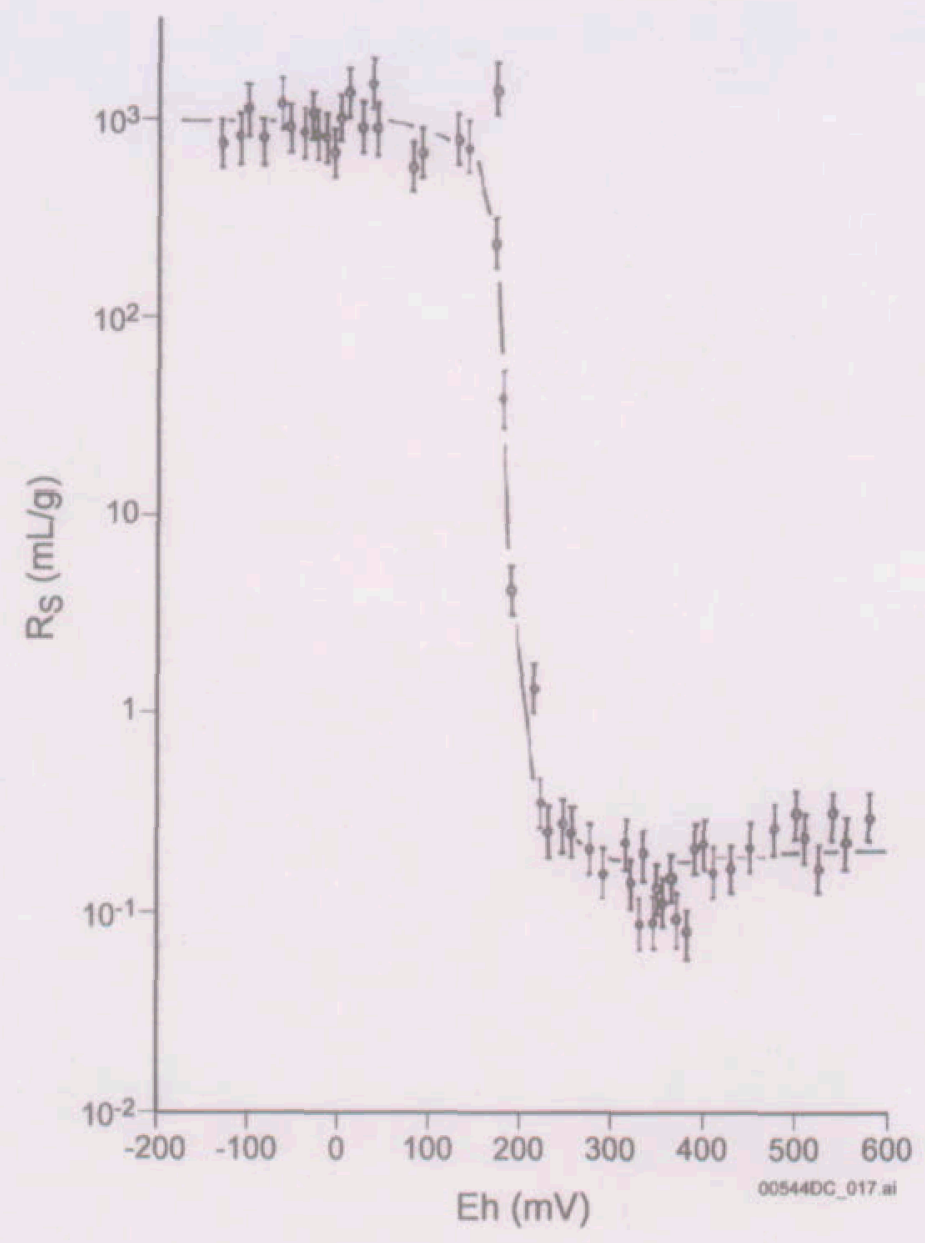

Source: Lieser and Bauscher 1987 [DIRS 172723]

Figure 2.3-3. Technetium Sorption Coefficients versus Eh on Sediments and Groundwaters from the Gorleben Site in Germany 


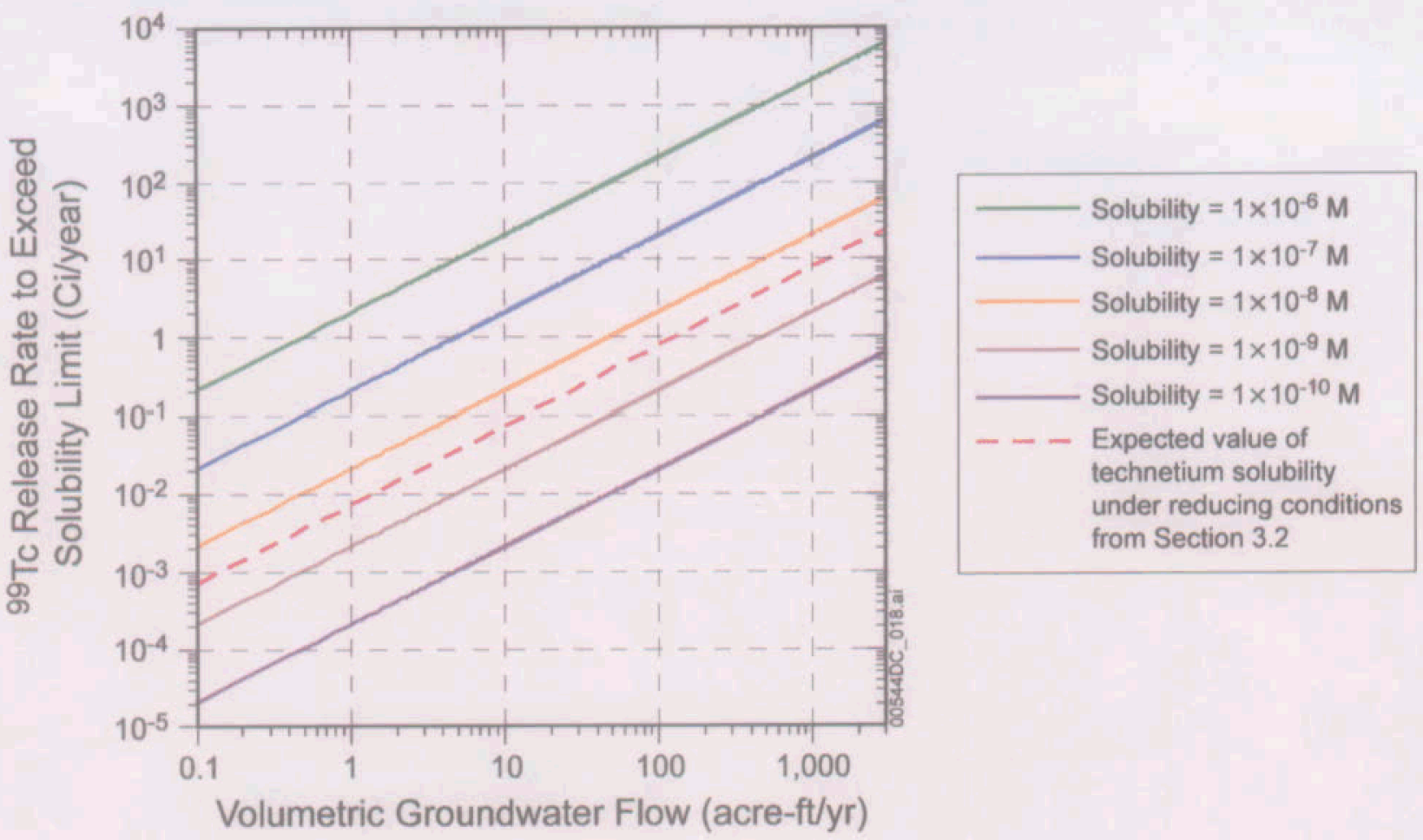

NOTE: Red dashed line indicates the expected value of technetium solubility under reducing conditions from Section 2.2 .

Figure 2.5-1, ${ }^{99}$ Tc Release Rate Required to Exceed the Solubility Limit as a Function of Volumetric Groundwater Flow Rate for a Range of Solubility Limits 


\section{Tc Concentration vs Time}

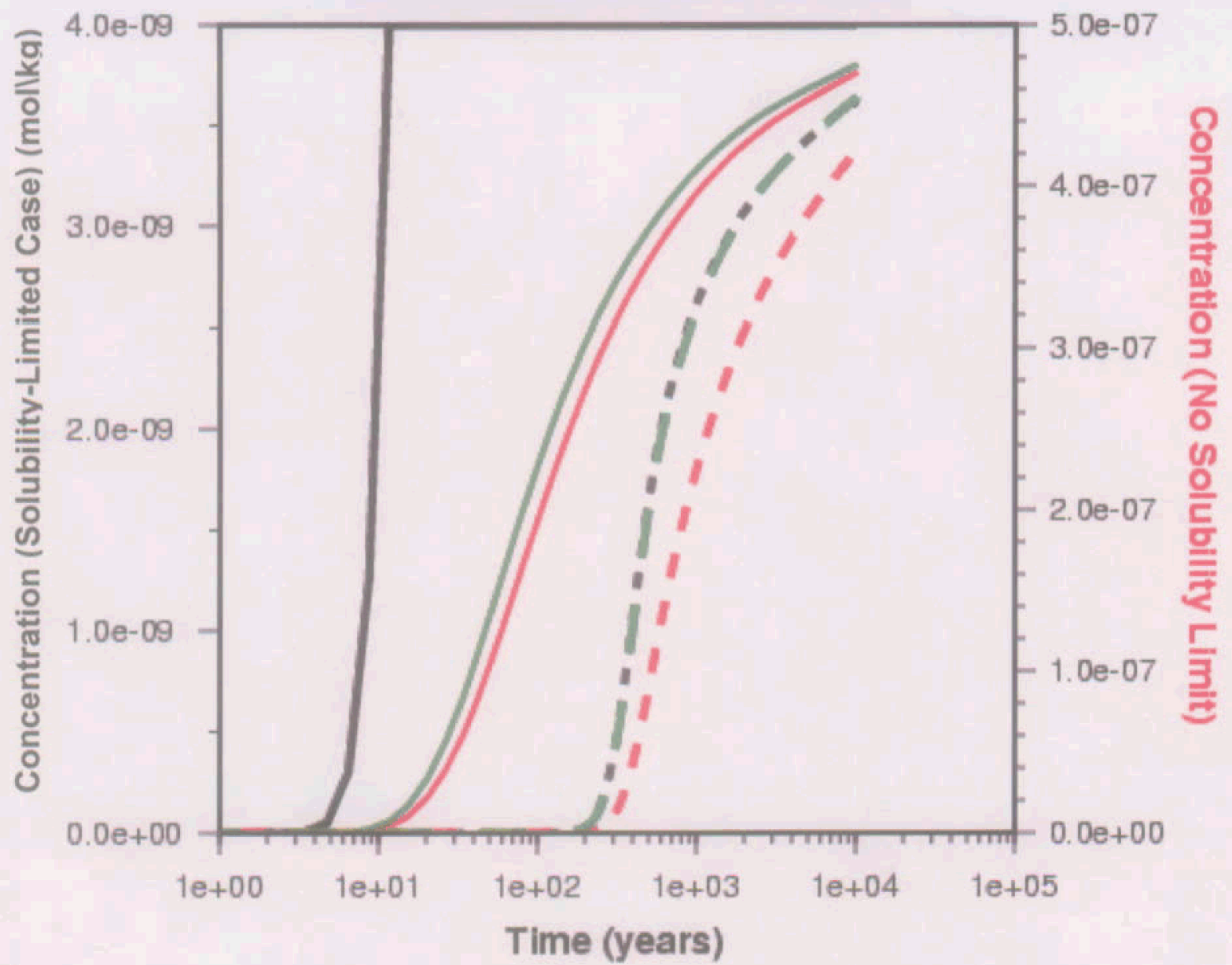

\section{Sorption with Solubility-limited Reaction (left axis) \\ - - - Compliance Boundary \\ Entrance of Redox Zone}

Sorption and No Solubility Limit (right axis)

- Entrance of Redox Zone

No Sorption and No Solubility Limit (right axis)

- Compliance Boundary

- Entrance of Redox Zone

NOTE: $\quad$ Cases include combined sorption and solubility-limited reaction (red curves); sorption only (black curves); and conservative transport (green curves). The sorption coefficient for Tc in reducing zone is $50 \mathrm{~mL} / \mathrm{g}$. Input concentration of $\mathrm{Tc}$ is $5 \times 10^{-7} \mathrm{M}$.

Figure 2.5-2. ${ }^{99} \mathrm{Tc}$ Breakthrough Curves at the Compliance Boundary and at the Entrance of the Reducing Zone for the One-Dimensional Streamtube Model 


\section{Tc Concentration vs Time Concentrations at Compliance Boundary}

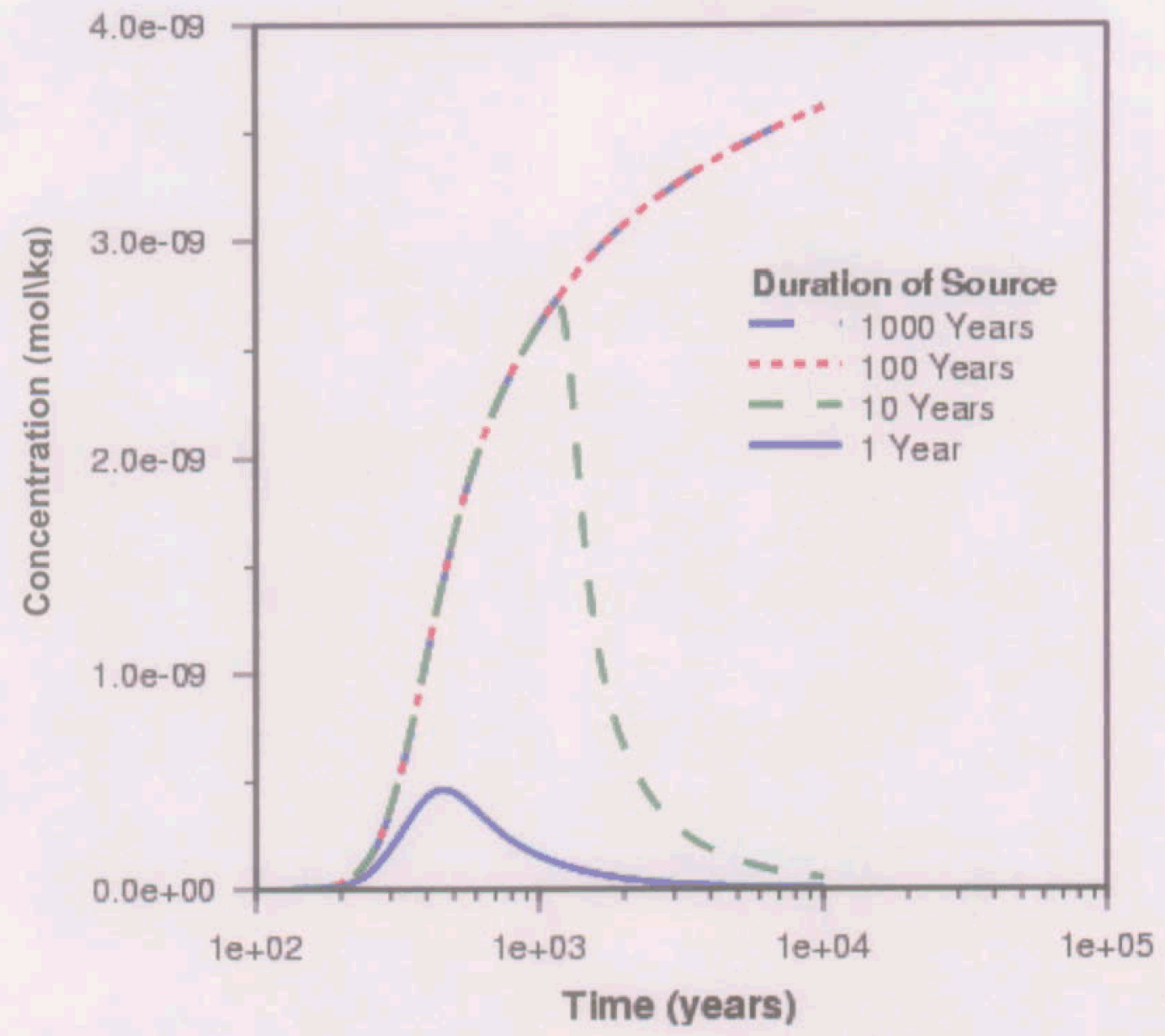

NOTE: Cases include combined sorption and solubility-limited reaction. Sorption coefficient for Tc in the reducing zone is $50 \mathrm{~mL} / \mathrm{g}$. The input concentration of Tc is $5 \times 10^{-7} \mathrm{M}$.

Figure 2.5-3. $\quad{ }^{99} \mathrm{Tc}$ Breakthrough Curves at the Compliance Boundary for the One-Dimensional Streamtube Model for Different Durations of the Input Concentration 


\section{Tc Concentration vs Time Concentrations at Entrance of Redox Zone}

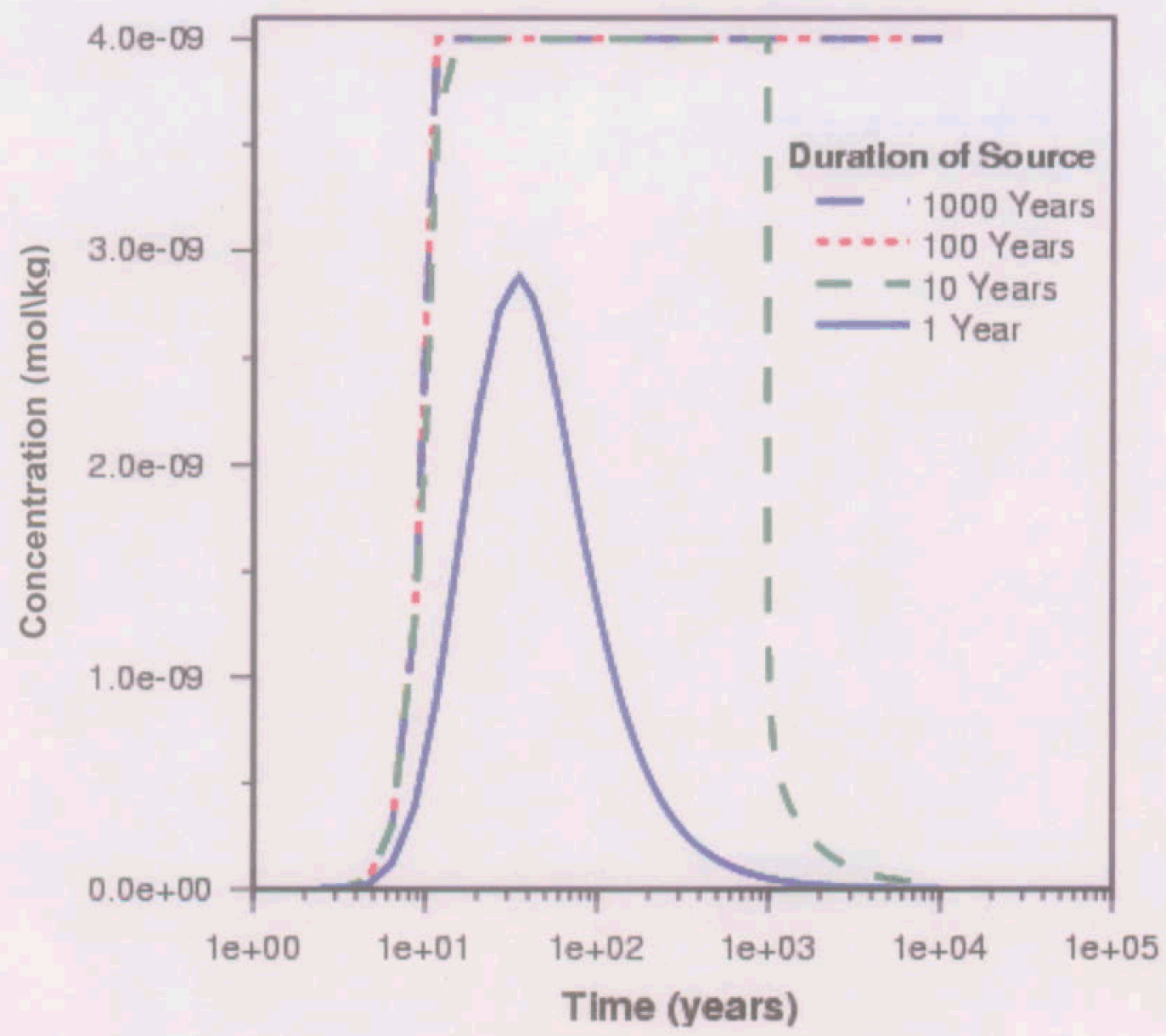

NOTE: Input concentration of Tc specified as $5 \times 10^{-7} \mathrm{M}$.

Figure 2.5-4. ${ }^{99} \mathrm{Tc}$ Concentrations at the Entrance to the Reducing Zone for the One-Dimensional Streamtube Model for Different Durations of the Input Concentration 

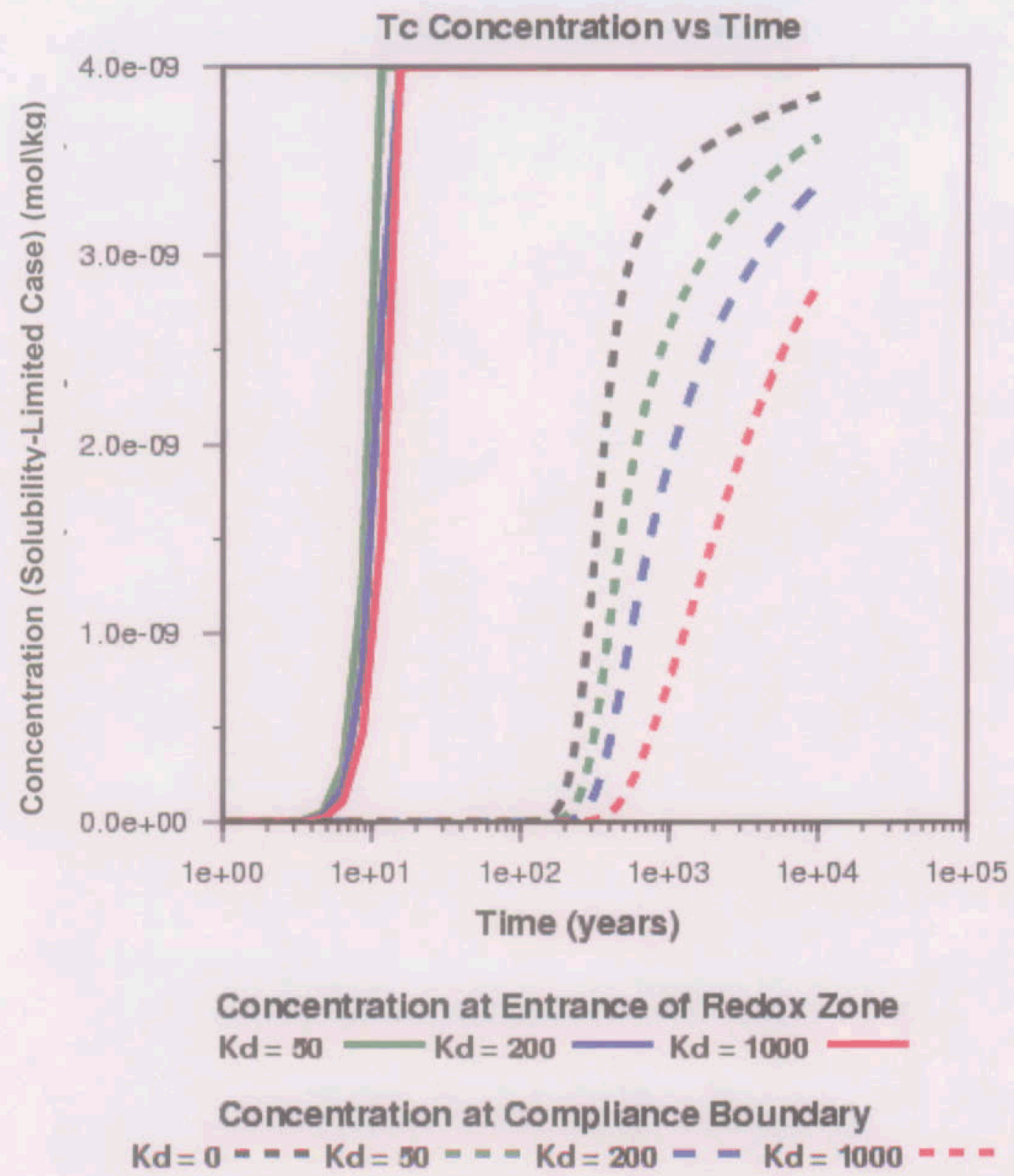

NOTE: Cases include combined sorption and solubility-limited reaction. The input concentration of Tc is $5 \times 10^{-7} \mathrm{M}$.

NOTE: Cases include combined sorption and solubility-limited reaction. The sorption coefficient for Tc in reducing zone is $50 \mathrm{~mL} / \mathrm{g}$. The input concentration of Tc is $5 \times 10^{-7} \mathrm{M}$.

Figure 2.5-5. $\quad{ }^{90} \mathrm{Tc}$ Breakthrough Curves at the Compliance Boundary and at the Entrance of the Reducing Zone for the One-Dimensional Streamtube Model for Different Values of the Sorption Coefficient $\left(K_{d}\right)$ in the Reducing Zone 


\section{Tc Concentration vs Time}

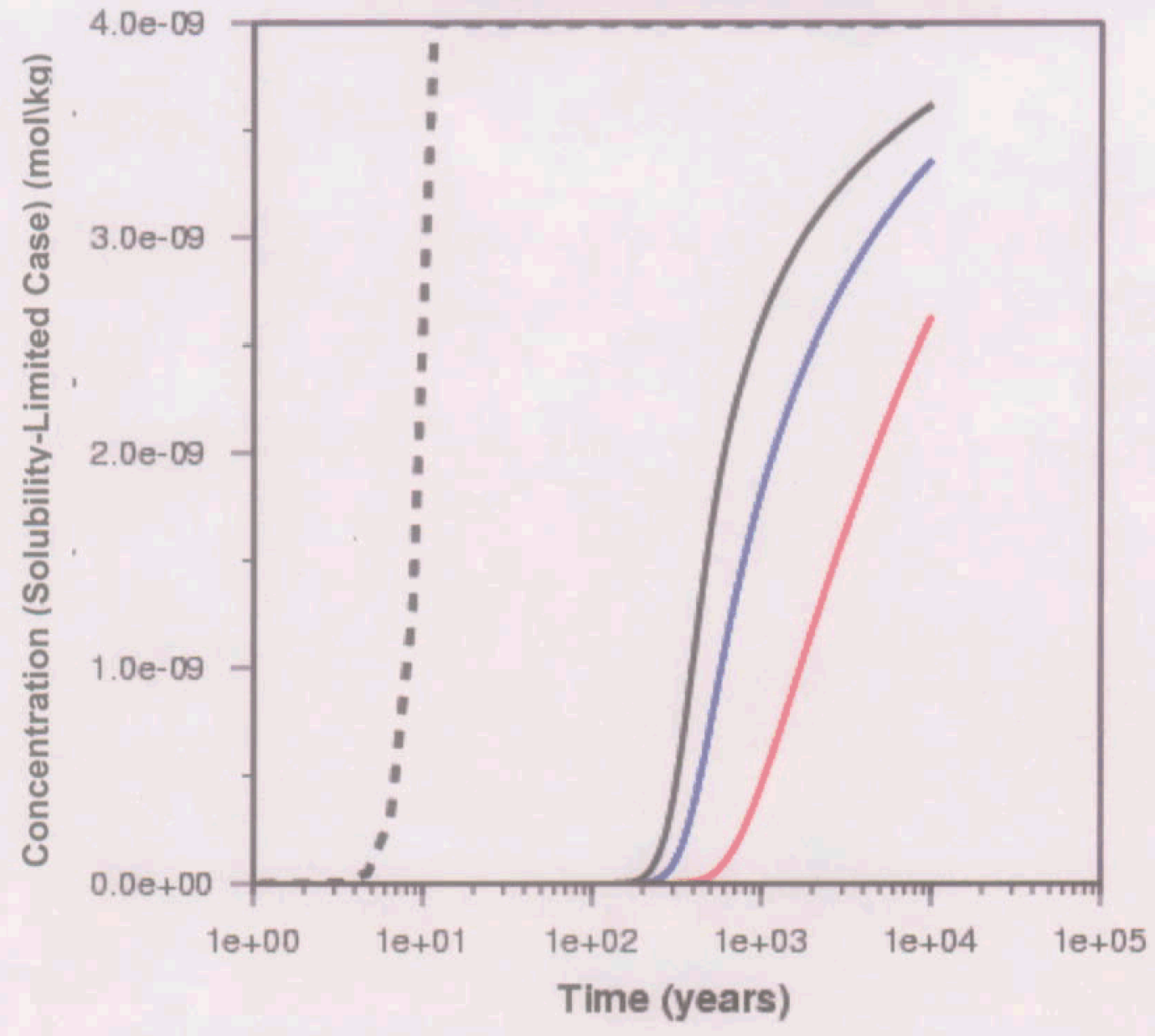

Tc Concentrations at Compliance Boundary

Reducing Zone $=5000$ meters
Reducing Zone $=2000$ meters
- Reducing Zone $=1000$ meters
- All cases, $C$ at Entrance of Reducing Zone

Figure 2.5-6. ${ }^{99} \mathrm{Tc}$ Breakthrough Curves at the Compliance Boundary and at the Entrance of the Reducing Zone for the One-Dimensional Streamtube Model for Different Values Lengths of the Pathway Within the Reducing Zone 
$L$

$\longrightarrow$\begin{tabular}{c:c|}
\hline$K_{d}^{r}$ & $K_{d}^{o}$ \\
\hline$x_{r}$ & $1-x_{r}$
\end{tabular}

where: $\quad x_{r} \quad=$ fraction of flow path with reducing conditions

$K_{d}^{r} \quad=$ sorption coefficient under reducing conditions

$K_{d}^{o} \quad=$ sorption coefficient under oxidizing conditions

$L \quad=$ total length of the flow path $\quad$ 005410 _ 000 .ai

Figure 2.6-1. Schematic Diagram of One-Dimensional Flow Path with Two Zones of Contrasting Values in Sorption Coefficient

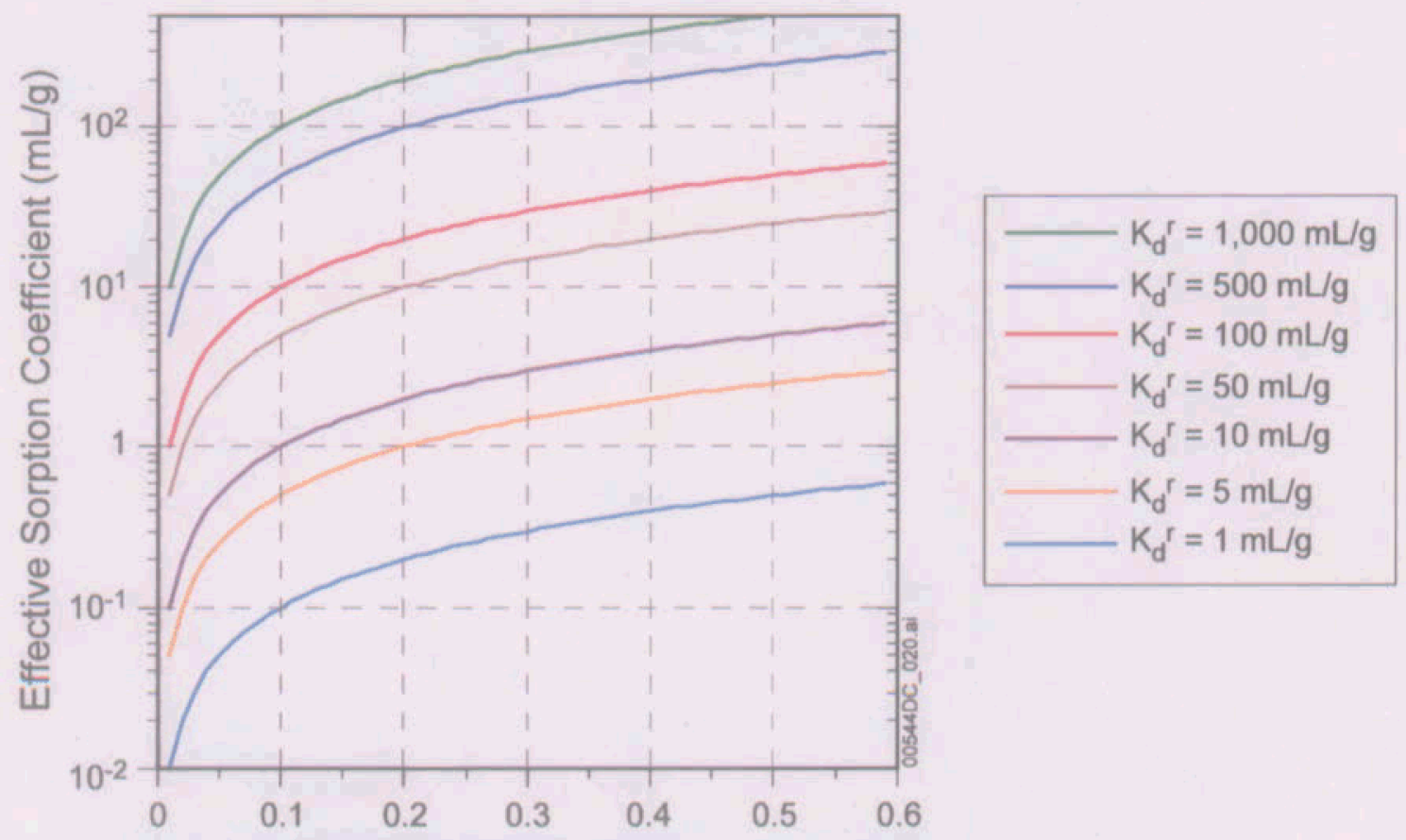

Fraction of Flow Path with Reducing Conditions

NOTE: Plots are given for various values of the sorption coefficient under reducing conditions. The sorption coefficient under oxidizing conditions is zero.

Figure 2.6-2. Effective Sorption Coefficients as Functions of Fraction of the Flow Path with Reducing Conditions for Technetium 


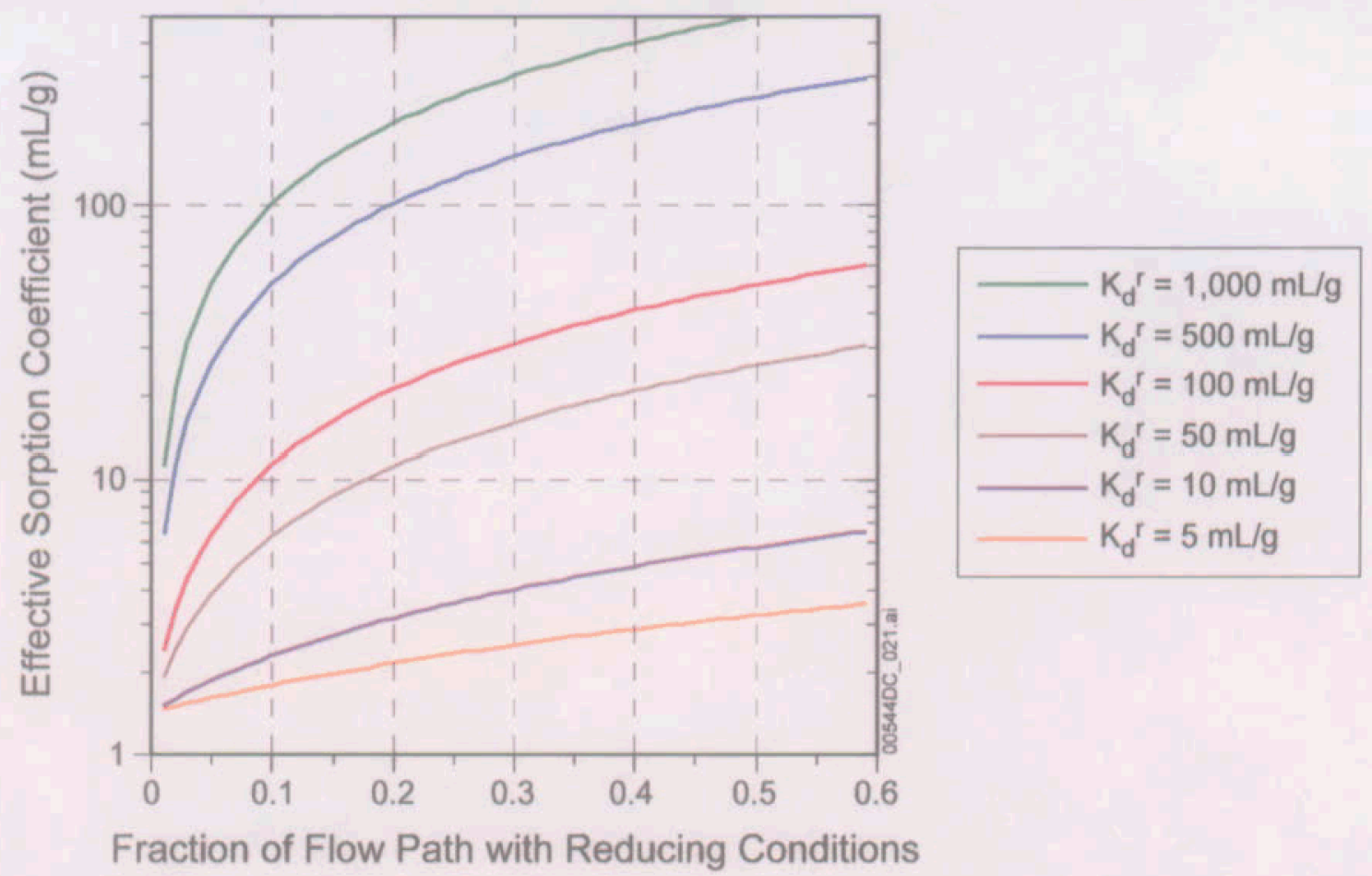

NOTE: Plots are given for various values of the sorption coefficient under reducing conditions. The sorption coefficient under oxidizing conditions is $1.43 \mathrm{~mL} / \mathrm{g}$.

Figure 2.6-3. Effective Sorption Coefficient as a Function of Fraction of the Flow Path with Reducing Conditions for Neptunium in Volcanic Units 


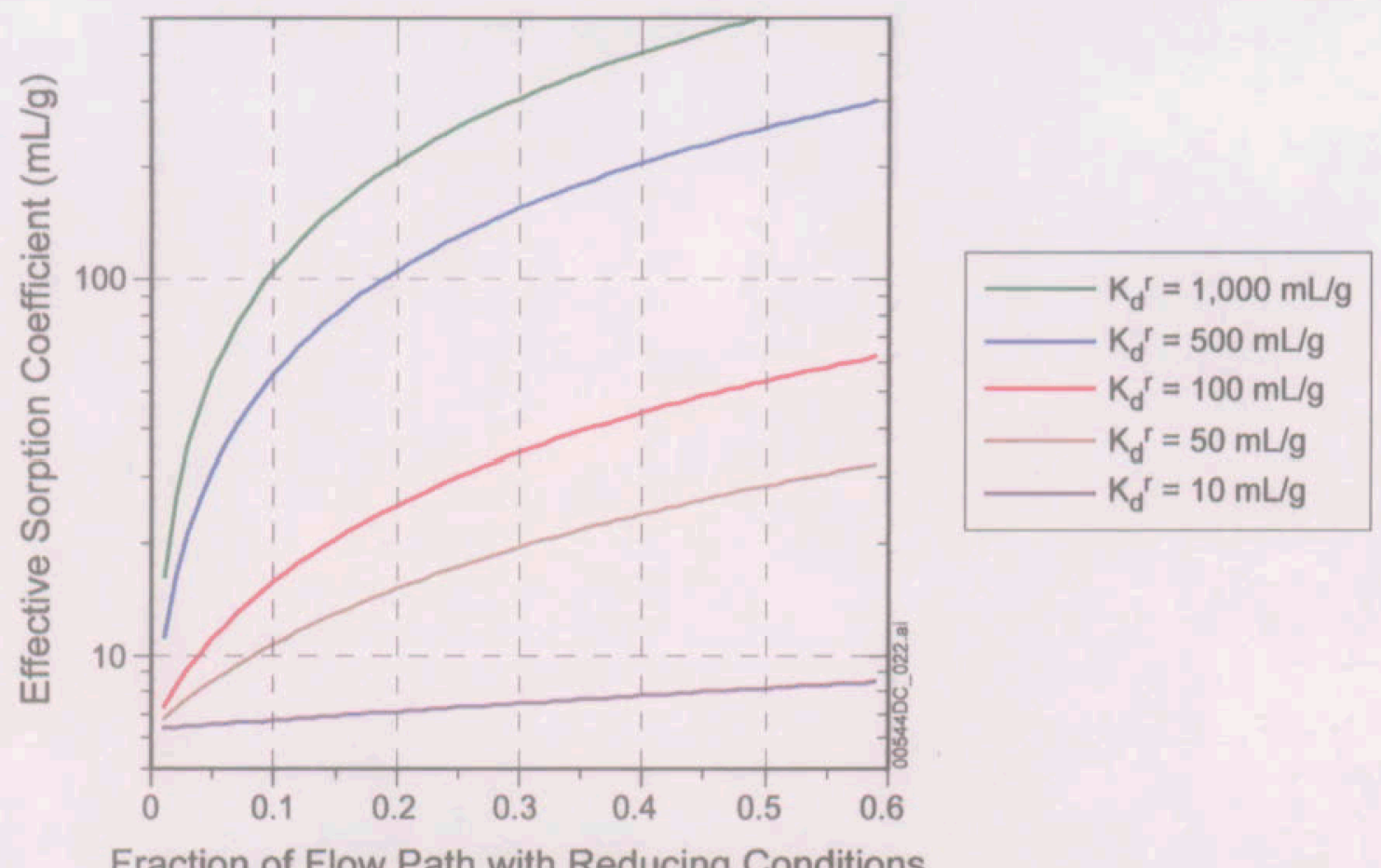

NOTE: Plots are given for various values of the sorption coefficient under reducing conditions. The sorption coefficient under oxidizing conditions is $6.35 \mathrm{~mL} / \mathrm{g}$.

Figure 2.6-4. Effective Sorption Coefficient as a Function of Fraction of the Flow Path with Reducing Conditions for Neptunium in Alluvium 


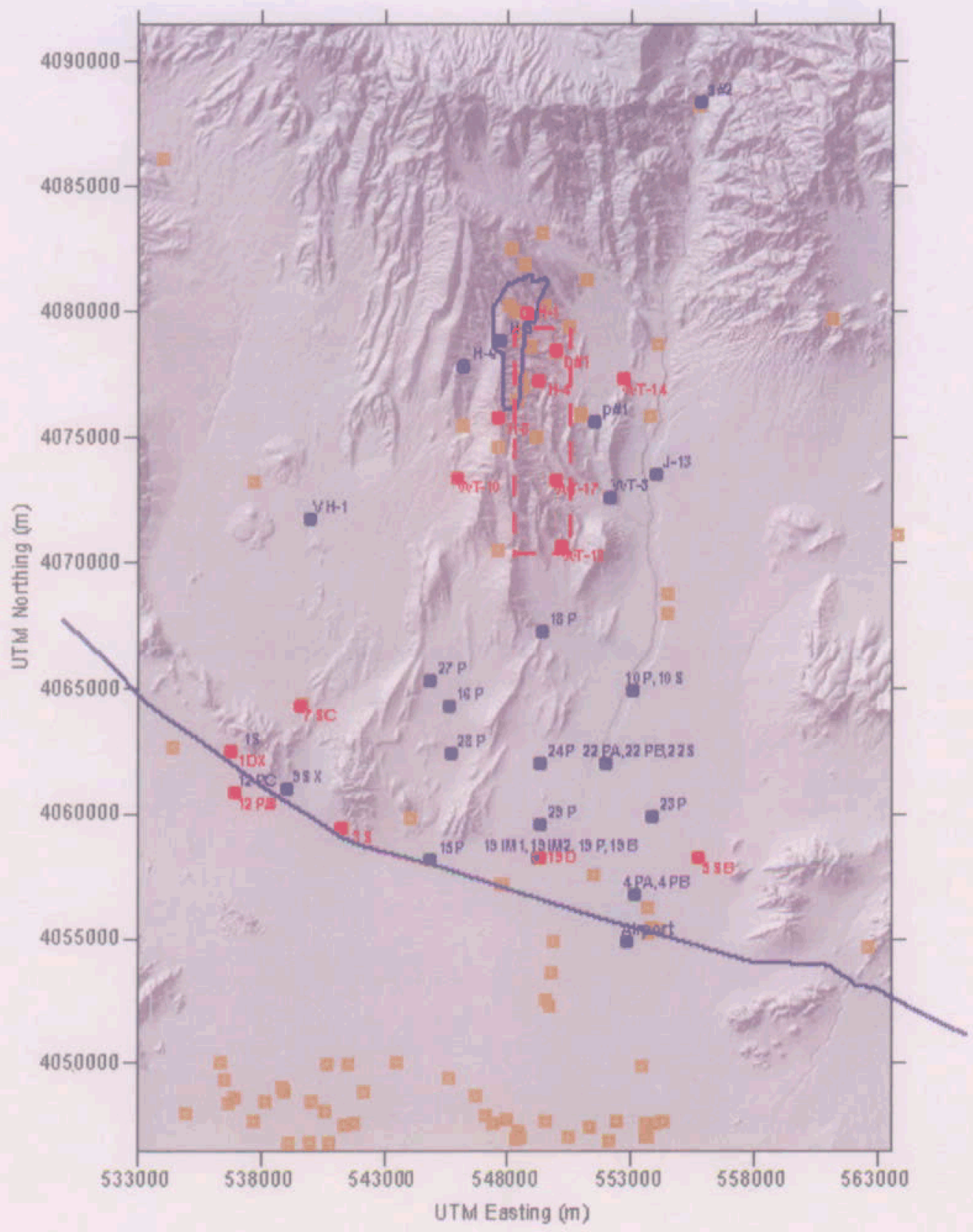

Figure 2.6-5. Footprint of the Redox Curtain and Footprint of the Repository at Yucca Mountain 


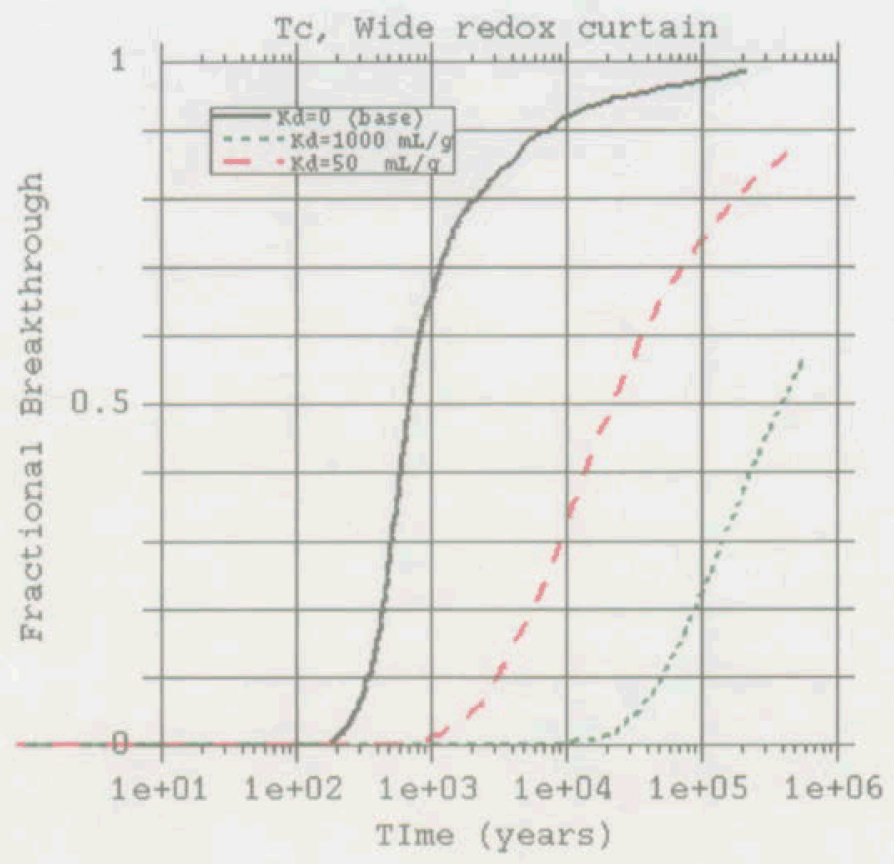

Figure 2.6-6. Breakthrough Curves for Technetium with Wide Redox Curtain for $K_{d}=0$ (base case), $K_{d}=50 \mathrm{~mL} / \mathrm{g}$, and $K_{d}=1000 \mathrm{~mL} / \mathrm{g}$
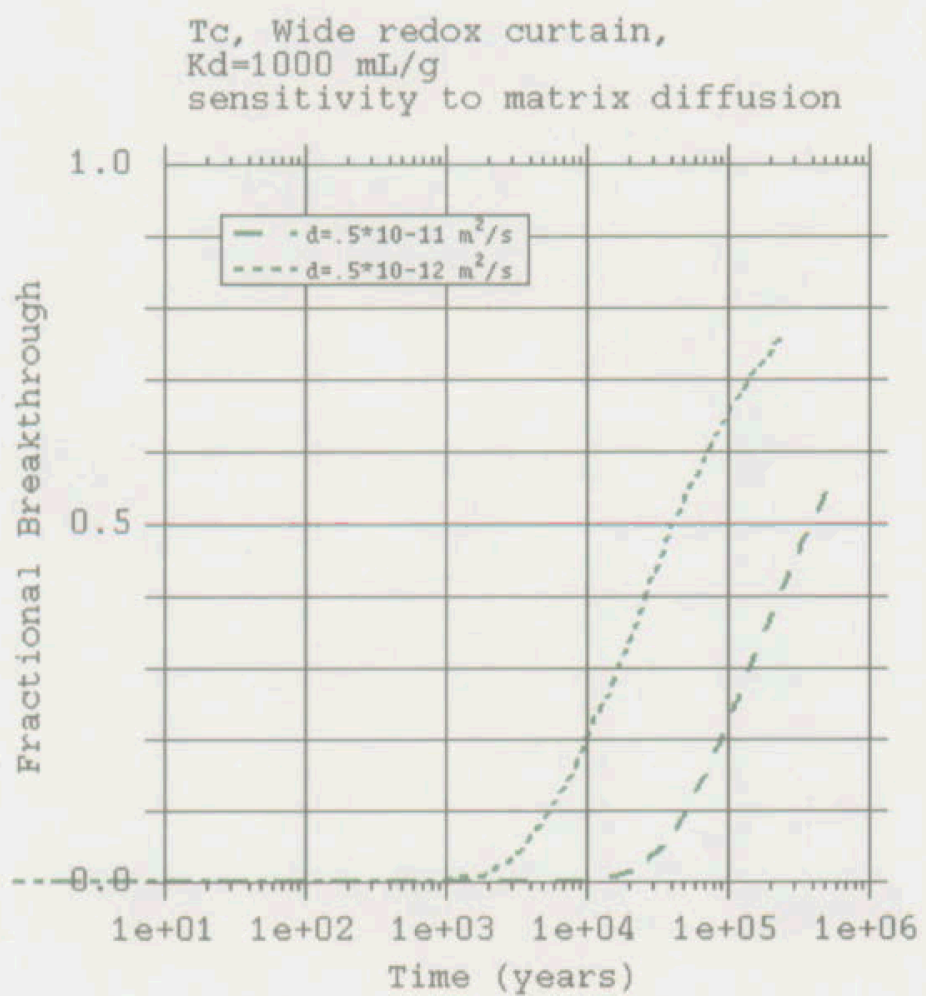

Figure 2.6-7. Comparison of Breakthrough Curves for Different Matrix Diffusion Coefficients for Technetium with Wide Redox Curtain and $K_{d}=1000 \mathrm{~mL} / \mathrm{g}$ 


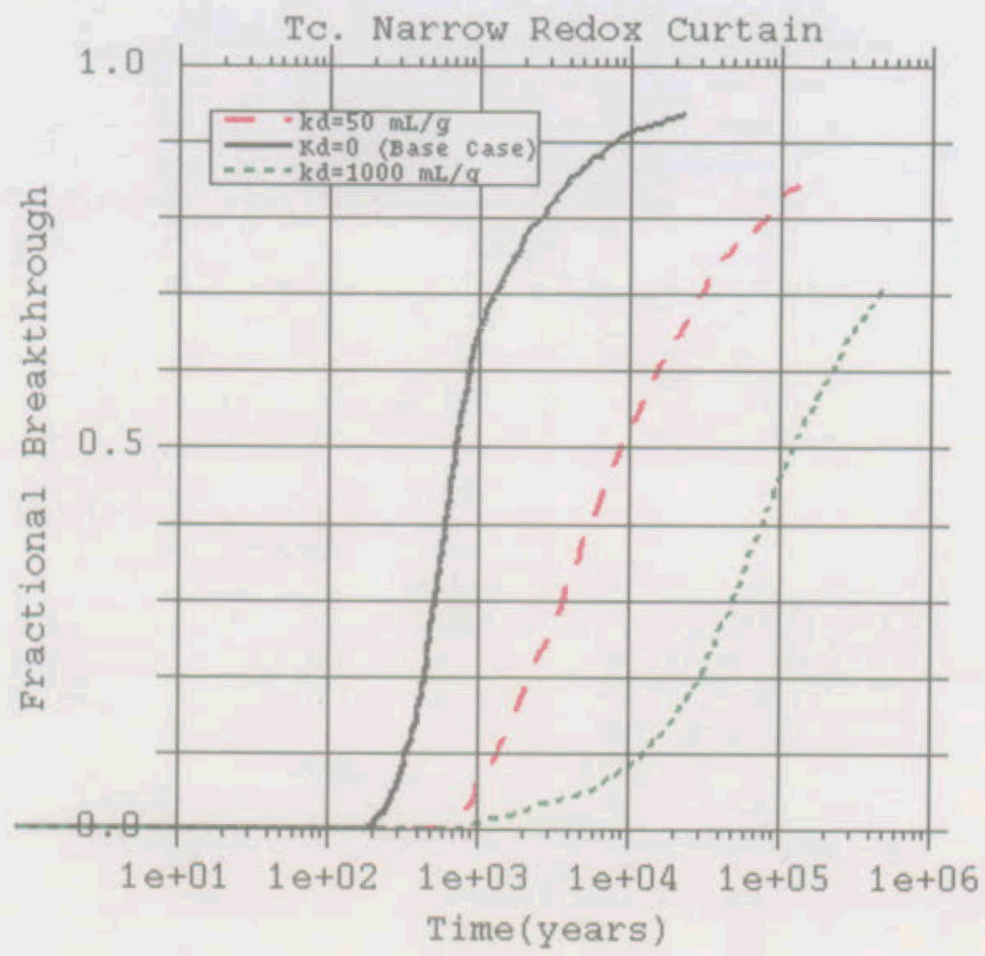

Figure 2.6-8. Breakthrough Curves for Technetium with Narrow Redox Curtain and $K_{d}=0$ (base case), $K_{d}=50$, and $K_{d}=1000 \mathrm{~mL} / \mathrm{g}$

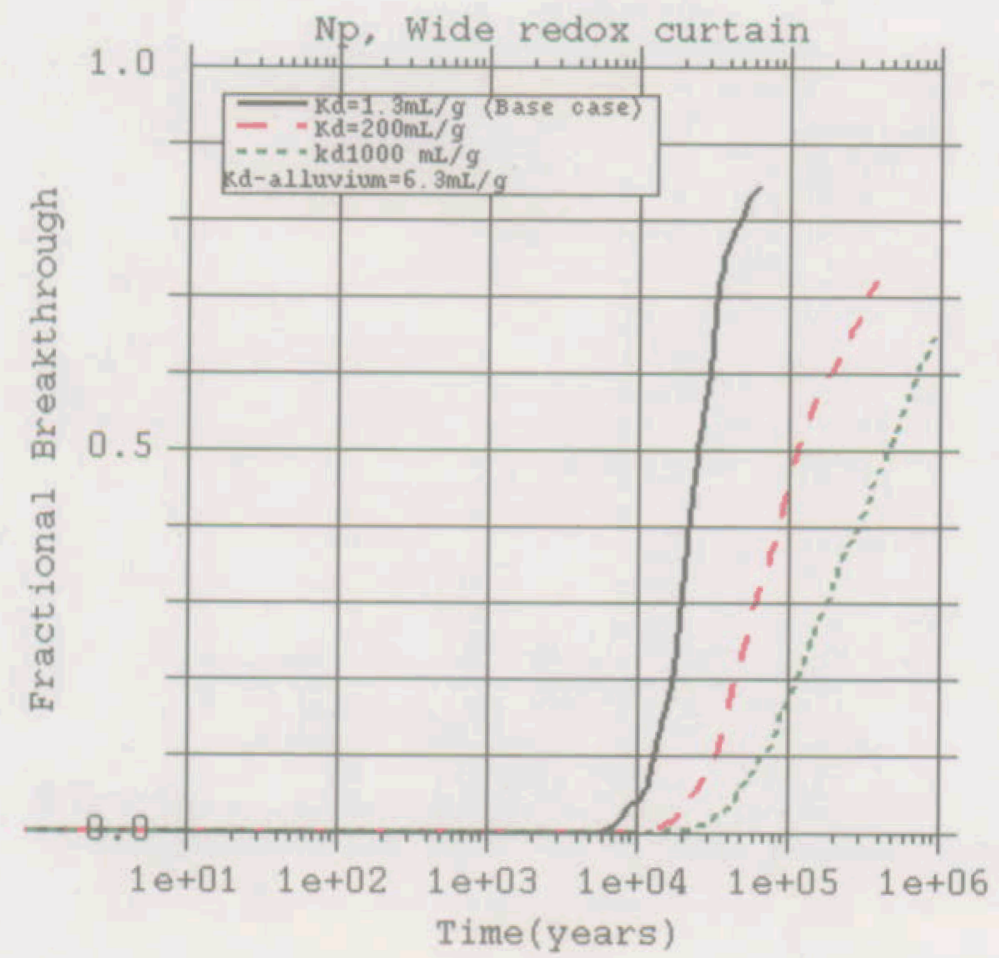

Figure 2.6-9. Breakthrough Curves for Neptunium with Wide Redox Curtain and $K_{d}=1.3$ (base case), $K_{d}=200$, and $K_{d}=1000 \mathrm{~mL} / \mathrm{g}$ 


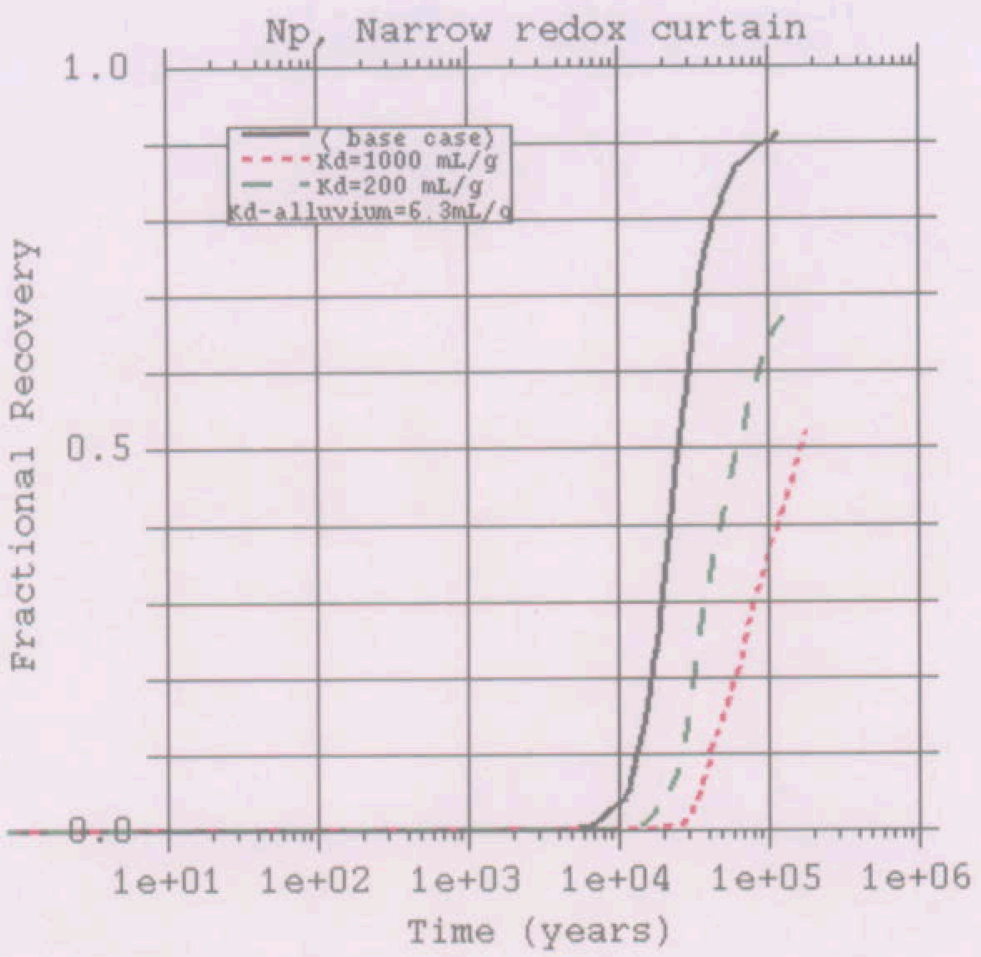

Figure 2.6-10. Breakthrough Curves for Neptunium with Narrow Redox Curtain and $K_{d}=1.3$ (base case), $K_{d}=200$, and $K_{d}=1000 \mathrm{~mL} / \mathrm{g}$ 


\section{INTENTIONALLY LEFT BLANK}


Table 2.2-1. Ground Water Composition in Wells $\mathrm{J}-13$ and $\mathrm{p \# 1.}$

\begin{tabular}{|c|c|c|}
\hline $\begin{array}{c}\text { Chemical } \\
\text { Constituents }\end{array}$ & $\begin{array}{c}\text { J-13 Water } \\
\text { (mg/L) }\end{array}$ & $\begin{array}{c}\text { p\#1 Carbonate Aquifer } \\
\text { water (mg/L) }\end{array}$ \\
\hline $\mathrm{Ca}^{2+}$ & 11.5 & 87.8 \\
\hline $\mathrm{Mg}^{2+}$ & 1.76 & 31.9 \\
\hline $\mathrm{Na}^{+}$ & 45 & 171 \\
\hline $\mathrm{K}^{+}$ & 5.3 & 13.4 \\
\hline $\mathrm{SiO}_{2}$ & 64.2 & 64.2 \\
\hline $\mathrm{Cl}^{-}$ & 6.2 & 37 \\
\hline $\mathrm{F}^{-}$ & 2.1 & 3.5 \\
\hline $\mathrm{SO}_{4}{ }^{2-}$ & 18.1 & 129 \\
\hline $\mathrm{CO}_{3}{ }^{2-}$ & 128 & 666 \\
\hline $\mathrm{pH}^{*}$ & 6.9 & 6.7 \\
\hline
\end{tabular}

Source: BSC 2004 \{DIRS 170036], Table A-2a.

NOTE: $\mathrm{pH}$ is in $\mathrm{pH}$ units

Table 2.2-2. Summary of Technetium Solubility Calculations

\begin{tabular}{|c|c|c|c|c|}
\hline \multirow{2}{*}{$\begin{array}{c}\text { Redox } \\
\text { Conditions }\end{array}$} & \multirow{2}{*}{$\begin{array}{c}\text { Controlling } \\
\text { Solid }\end{array}$} & \multicolumn{2}{|c|}{ Tc Solubility } & \multirow[b]{2}{*}{ Eh (V) } \\
\hline & & $\mathrm{mol} / \mathrm{kg}$ & $\mathrm{mg} / \mathrm{L}$ & \\
\hline \multirow[t]{2}{*}{ Oxidizing } & $\mathrm{TcO}_{2} \times 1.6 \mathrm{H}_{2} \mathrm{O}$ & Infinite & Infinite & $>0.15$ to 0.26 \\
\hline & $\mathrm{TcO}_{2}$ & Infinite & Infinite & 0.22 to 0.36 \\
\hline \multirow[t]{2}{*}{ Transitional $^{*}$} & $\mathrm{TcO}_{2} \times 1.6 \mathrm{H}_{2} \mathrm{O}$ & $1 \times 10^{-2}$ & 100 & -0.1 to 0.0 to 0.15 to 0.26 \\
\hline & $\mathrm{TcO}_{2}$ & $1 \times 10^{-4}$ & 1 & 0.22 to 0.36 \\
\hline \multirow[t]{2}{*}{ Reducing } & $\mathrm{TcO}_{2} \times 1.6 \mathrm{H}_{2} \mathrm{O}$ & $4 \times 10^{-9}$ & $4 \times 10^{-5}$ & $<-0.1$ to 0.0 \\
\hline & $\mathrm{TcO}_{2}$ & $4 \times 10^{-13}$ & $4 \times 10^{-8}$ & $<-0.1$ to 0.0 \\
\hline
\end{tabular}

NOTE: *Solubility value is calculated at the midpoint of the corresponding Eh interval.

The range of Eh values shown for each specific redox conditions and specific controlling solid is the result of the differences in water composition and $\mathrm{pH}$ considered. 
Table 2.5-1. Peak Simulated Releases from the UZ

\begin{tabular}{|c|c|c|c|c|c|c|c|}
\hline & & $\begin{array}{l}\text { Mean } \\
\text { (g/yr) }\end{array}$ & $\begin{array}{l}\text { Mean } \\
(\mathrm{Ci} / \mathrm{yr})\end{array}$ & $\begin{array}{c}\text { Time } \\
\text { (years) }\end{array}$ & $\begin{array}{c}95 \% \text { tile } \\
\text { (g/yr) }\end{array}$ & $\begin{array}{l}\text { 95\%tile } \\
\text { (Ci/yr) }\end{array}$ & $\begin{array}{c}\text { Time } \\
\text { (years) }\end{array}$ \\
\hline \multirow{2}{*}{$\begin{array}{l}\text { Nominal Early Failure } \\
\text { Modeling Case }\end{array}$} & ${ }^{99} \mathrm{Tc}$ & $6 \times 10^{-2}$ & $1 \times 10^{-3}$ & 600 & $5 \times 10^{-1}$ & $8 \times 10^{-3}$ & 600 \\
\hline & ${ }^{237} \mathrm{~Np}$ & $4 \times 10^{-3}$ & $3 \times 10^{-6}$ & 2,000 & $1 \times 10^{-2}$ & $8 \times 10^{-6}$ & 2,100 \\
\hline \multirow{2}{*}{$\begin{array}{l}\text { Igneous Intrusion Modeling } \\
\text { Case }^{2}\end{array}$} & ${ }^{99} \mathrm{Tc}$ & 3 & $5 \times 10^{-2}$ & 9,800 & - & - & - \\
\hline & ${ }^{237} \mathrm{~Np}$ & $2 \times 10^{-1}$ & $1 \times 10^{-4}$ & 20,000 & - & - & - \\
\hline \multirow{2}{*}{$\begin{array}{l}\text { Seismic Mechanical Damage } \\
\text { Modeling Case }^{3}\end{array}$} & ${ }^{99} \mathrm{Tc}$ & $2 \times 10^{-1}$ & $3 \times 10^{-1}$ & 20,000 & - & - & - \\
\hline & ${ }^{237} \mathrm{~Np}$ & $3 \times 10^{-1}$ & $2 \times 10^{-4}$ & 20,000 & - & - & - \\
\hline \multirow{2}{*}{ Nominal Scenario ${ }^{4}$} & ${ }^{99} \mathrm{Tc}$ & - & 1 & 100,000 & - & - & - \\
\hline & ${ }^{237} \mathrm{~Np}$ & - & $3 \times 10^{-2}$ & 100,000 & - & - & - \\
\hline
\end{tabular}

Notes: ${ }^{1}$ TSPA-LA (BSC 2004 [DIRS 168504], Figure 8.3.1-15).

2 TSPA-LA (BSC 2004 [DIRS 168504], Figure 8.3.1-16).

3 TSPA-LA (BSC 2004 [DIRS 168504], Figure 8.3.3-15).

4 TSPA-SR (CRWMS M\&O 2000 [DIRS 153246], Figure 4.1-11).

Table 2.6-1. Coordinates of the Footprint of the Redox Curtain

\begin{tabular}{|l|c|c|}
\hline & UTM Easting (m) & UTM Northing (m) \\
\hline $\begin{array}{l}\text { West-North } \\
\text { Corner }\end{array}$ & 548240 & 4079338 \\
\hline $\begin{array}{l}\text { East-North } \\
\text { Corner }\end{array}$ & 550526 & 4079338 \\
\hline $\begin{array}{l}\text { East-South } \\
\text { Corner }\end{array}$ & 550526 & 4070291 \\
\hline $\begin{array}{l}\text { West-South } \\
\text { Corner }\end{array}$ & 548240 & 4070291 \\
\hline
\end{tabular}


Table 2.6-2. Simulations for Sensitivity Analysis and 50\% Breakthrough Times for Technetium and Neptunium

\begin{tabular}{|l|l|l|l|}
\hline & & \multicolumn{1}{|c|}{$\boldsymbol{K}_{\boldsymbol{d}}(\mathbf{m L} \mathbf{g})$} & $\mathbf{5 0} \%$ Breakthrough Time (years) \\
\hline \multirow{4}{*}{ Tc } & 0 (base case) & 700 \\
\cline { 3 - 4 } & \multirow{4}{*}{ Wide Curtain } & 50 & 22,700 \\
\cline { 3 - 4 } & & 1,000 & 404,300 \\
\hline \multirow{4}{*}{ Narrow Curtain } & 0 & 723 \\
\cline { 3 - 4 } & 50 & 9,110 \\
\cline { 3 - 4 } & 1,000 & 126,500 \\
\hline \multirow{4}{*}{ Wide Curtain } & $\begin{array}{l}\text { Volcanics: } 1.3 \\
\text { Alluvium: } 6.3 \\
\text { (base case) }\end{array}$ & 25790 \\
\cline { 3 - 4 } & 200 & 11,8840 \\
\cline { 3 - 4 } & 1,000 & 465,500 \\
\cline { 3 - 4 } & \multirow{4}{*}{ Narrow Curtain } & $\begin{array}{l}\text { Volcanics: } 1.3 \\
\text { Alluvium: } 6.3\end{array}$ & 25,820 \\
\cline { 3 - 4 } & 200 & 64,900 \\
\cline { 3 - 4 } & 1,000 & 181,270 \\
\hline
\end{tabular}


INTENTIONALLY LEFT BLANK 